Emrouznejad, A. and M. Marra (2014) Ordered Weighted Averaging Operators 1988-2014: A Citation-Based Literature Survey, International Journal of Intelligent Systems, 29 (11): 994-1014. DOI 10.1002/int.21673. (Download)

\title{
Ordered Weighted Averaging Operators 1988-2014: A Citation-Based Literature Survey
}

Ali Emrouznejad and Marianna Marra

Aston Business School
Aston University
Birmingham,
UK

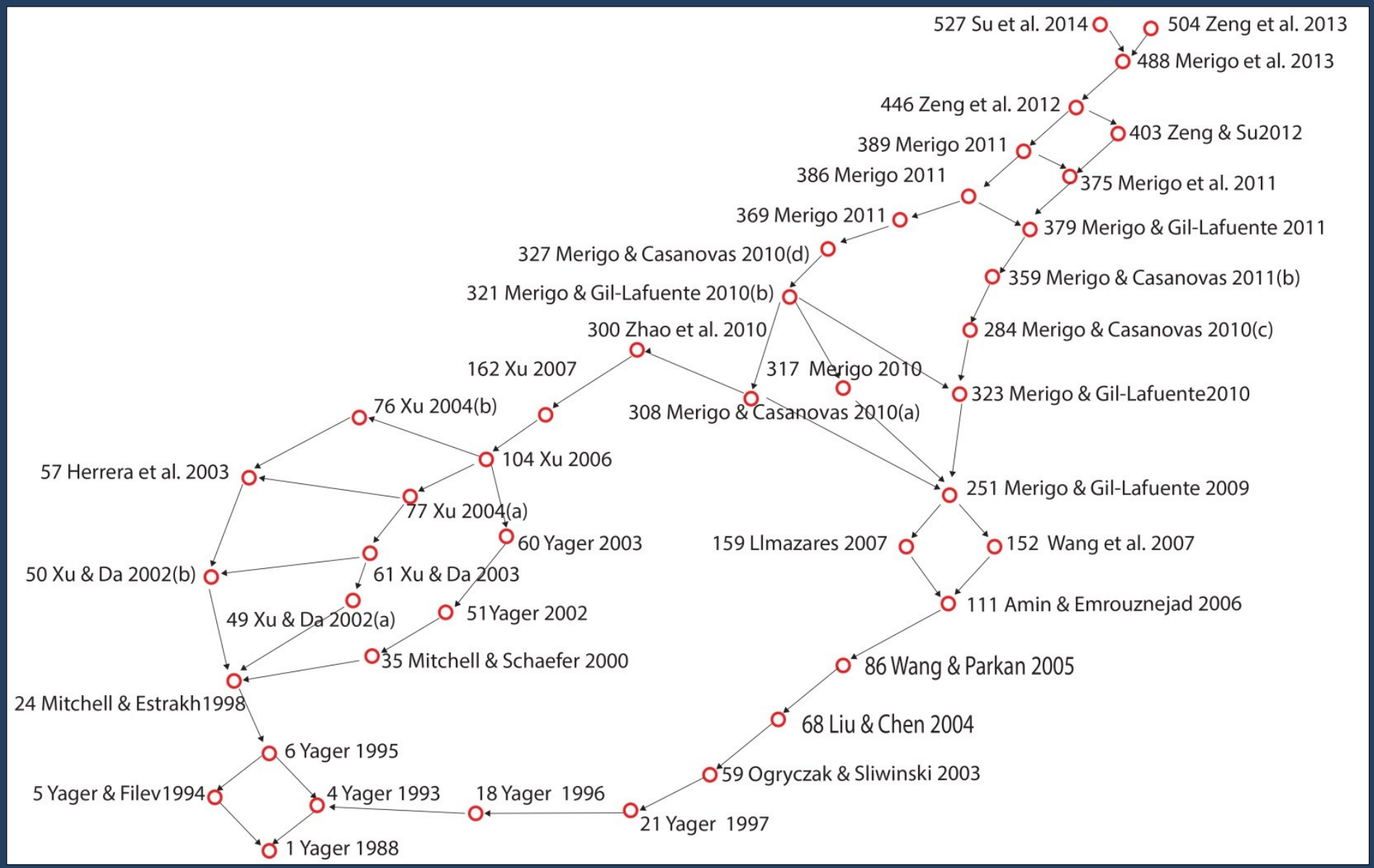

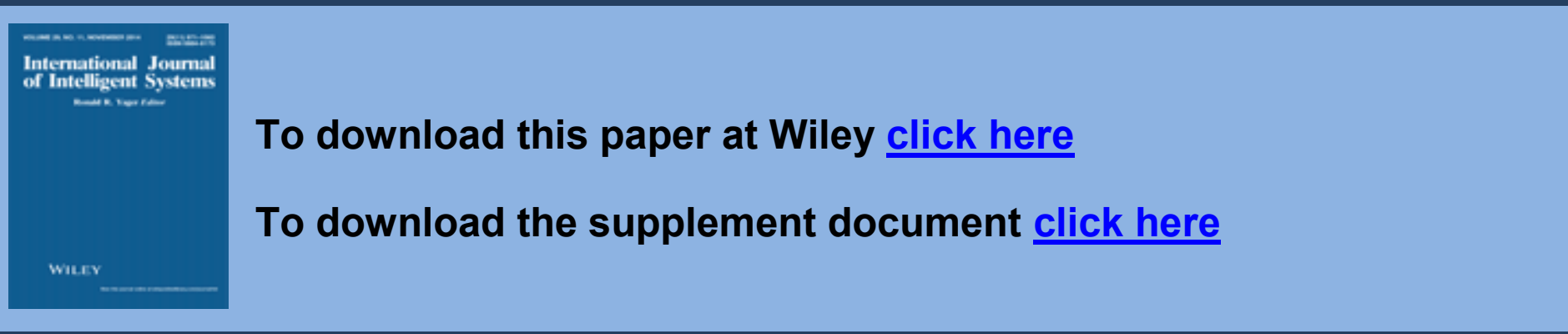


Emrouznejad, A. and M. Marra (2014) Ordered Weighted Averaging Operators 1988-2014: A Citation-Based Literature Survey, International Journal of Intelligent Systems, 29 (11): 994-1014. DOI 10.1002/int.21673. (Download)

\title{
Ordered Weighted Averaging Operators 1988-2014: A citation-based literature survey
}

\author{
Ali Emrouznejad* and Marianna Marra \\ Aston Business School, Aston University, Birmingham, UK
}

\begin{abstract}
This study surveys the Ordered Weighted Averaging (OWA) operator literature using a citation network analysis. The main goals are the historical reconstruction of scientific development of the OWA field, the identification of the dominant direction of knowledge accumulation that emerged since the publication of the first OWA paper and to discover the most active lines of research. The results suggest, as expected, that Yager (1988) [Yager, Ronald R. On ordered weighted averaging aggregation operators in multicriteria decision making. IEEE Transactions on Systems, Man, and Cybernetics, 18(1), 183-190.] is the most influential paper and the starting point of all other research using OWA. Starting from his contribution other lines of research developed and we describe them.
\end{abstract}

Keywords: Ordered weighted averaging (OWA); Aggregation operator; OWA Survey; OWA development

\section{Introduction}

The family of OWA operators was first introduced by Yager (1988) as a tool to deal with the problem of aggregating multicriteria to form an overall decision function. He described it as cumulative operators for membership aggregation. Following this conceptualization, the role of OWA weighting vector has been highlighted as a means for introducing the decision maker's attitude (Yager, 1995a) and the OWA operator has

\footnotetext{
* Corresponding author Email: A.Emrouznejad@aston.ac.uk
} 
received great attention and has been applied in different disciplinary contexts, for example, decision making under uncertainty (Yager and Kreinovich, 1999), fuzzy system and Information Retrieval System (IRS) (Kacprzyk and Zadrożny, 2001; Herrera-Viedma et al., 2003), data mining (Torra, 2004). It is widely recognised that the OWA operators have been applied to different research fields, but the present study is the first work depicting the OWA development scenario and describing its development path. This paper is the first systematic review of the growing literature on the OWA operator, it aims to trace the development of OWA research using Social Network Analysis (SNA) and presents a survey on the diffusion of the OWA in the literature over the last 26 years. Our main goals are:

- To identify the major publications/citations in the OWA field;

- To identify and illustrate the intellectual structure of this research domain;

- To describe the sub-area in which the OWA have been most applied.

To conduct this review we employ the data of ISI Web of Knowledge and elaborated them first with the HistCite software (Garfield et al., 1964; Garfield, 2009) to obtain the corresponding historiograph, secondly we analysed the data applying an algorithm widely used in the analysis of citation network, the Critical Path Method (CPM) (Kejžar et al., 2010). The historiograph displays how each paper has influenced other papers included in the panel provided by ISI (Garfield, 2003) and allows the chance to understand the role of key events (papers), people (authors) and journals in a field. This historiograph analysis is focused on the most influential contributions to the body of research on the OWA operators. Differently the CPM aims to trace the dominant direction of knowledge 
accumulation. To identify the papers dealing with the OWA we first used the keyword “ordered weighted averaging" and obtained $537^{1}$ results that include published academic paper (394) and proceedings (143).

\section{The OWA operators: Background}

The formulation of OWA, as proposed originally by Yager (1988), refers to the issue of aggregating criteria functions to form an overall decision function.

Definition: A mapping F from

$$
\mathrm{I}^{\mathrm{n}} \rightarrow \mathrm{I}(\text { where } \mathrm{I}=[0,1])
$$

is called an OWA operator of dimension $\mathrm{n}$ if associate with $\mathrm{F}$, is a weighting vector $\mathrm{W}$,

$$
\mathrm{W}=\left[\begin{array}{l}
\mathrm{W}_{1} \\
\mathrm{~W}_{2} \\
\mathrm{~W}_{\mathrm{n}}
\end{array}\right]
$$

such that

$$
\begin{aligned}
& \mathrm{W}_{1} \in(0,1) \\
& \sum_{\mathrm{i}} \mathrm{W}_{\mathrm{i}}=1
\end{aligned}
$$

$F\left(a_{1}, a_{2}, \ldots, a_{n}\right)=W_{1} b_{1}+W_{2} b_{2}+\cdots+W_{n} b_{n}$,

where $b_{1}$ is the largest element in the collection $a_{1}, a_{2}, \ldots, a_{n}$. And an $n$ vector $B$ can be the ordered argument vector if each element $b_{i} \in[0,1]$ and $b_{i} \geq b_{j}$ if $j>i$. Given and OWA operator $F$ with weight vector $W$ and an argument tuple $\left(a_{1}, a_{2}, \ldots, a_{n}.\right)$ we can associate with this tuple an ordered input vector B is the vector consisting of the argument of $F$ put in descending order. Using this notation then

$$
F\left(a_{1}, a_{2}, \ldots, a_{n}\right)=W^{\prime} B
$$

\footnotetext{
${ }^{1}$ The full list of papers cen be found in a supplementary document provided on line.
} 
the inner product of $W^{\prime}$ and $B$. It is also possible to denote $F\left(a_{1}, a_{2}, \ldots, a_{n}\right.$. $)$ as $F(B)$ where $B$ is the highest associated ordered argument vector.

Furthermore, Yager (1988) points to the fact that the weights, the $\mathrm{W}^{\prime} \mathrm{s}$, are associated with particular ordered position rather than a particular element, that is, $W_{i}$ is the weight associated with the i-th largest vector B and any OWA operator F with weighting vector W that $0 \leq \mathrm{F}(\mathrm{B}) \leq 1$.

\section{Methodology}

The study of papers citation network by means of SNA has become very popular in the last few years as it allows to understand different dynamics such as collaboration among researchers (De Stefano et al., 2011; Lee et al., 2014); knowledge patterns and (Calero-Medina and Noyons, 2008) and emerging knowledge trends within disciplines (Ding et al., 2013; Liu et al., 2013). Two major contributions characterised this growing methodological approach, the pioneering study by Garfield et al. (1964) and the development of three algorithms proposed by Hummon and Doreian (Hummon and Doreian, 1989). The former seeks to shed light on the chronological representation of the development of a discipline focusing on the most cited authors and works to infer about their impact on the discipline's progress; while the latter shifts the attention from nodes to links allowing the so-called connectivity analysis. More specifically, Hummon and Doreian (1989) algorithms, Search Path Link Count (SPLC), Search Path Node Pairs (SPNP) and Node Projection Pairs Count (NPPC), capture the level of connectivity of each citation (a link between two nodes) and are based on sequences of links and nodes called "search path". Recently, Batagelj (2003) elaborated the Search Path Count (SPC) algorithm, which is considered the best development of Hummon and Doreain algorithms and overcome some limitations. In this works citations are considered proxies for knowledge flows, thus if the author ' $\mathrm{A}$ ' cites author's ' $\mathrm{B}$ ' we assume there is a knowledge flows between them, more precisely, 'A' work relies to some extent on 'B' contribution (Figure 1). 


\section{$\mathrm{A} \longleftarrow \mathrm{B}$}

\section{Figure 1. Example of citation network}

In this study we combine the two citations-based methodologies, to investigate the OWA literature. As outputs we provide first the historiograph (Garfield et al., 1964) of the related discipline to study the chronological development of the discipline, then we apply the Critical Path Method (CPM) which is based on the SPC that calculates traversal weights on arcs, and finally we analyse co-citation network of most cited publications to highlight similarities between these works. Traversal weights measure the importance of path linking entry vertices in a network to exit ones. Entry vertices are those not cited within the dataset, while exit vertices do not cite others within the dataset. The CPM algorithm determines the path from entry vertices to exit vertices with the largest total sum of weights on the arcs and provides a visual display of a broader longitudinal connectivity then the SPC output. We apply it to map the knowledge underlying the evolution of the main direction the field. We consider this as the backbone of the discipline.

The analysis of the historiography was first introduced by Garfield et al. (1964), which described the historiography as a chronological map allowing the historical reconstruction of scientific development of a field and its chronological representation. Typically it shows only a portion of the most cited works within the field. Thus, it is a genealogical approach to the study of a discipline, showing when it starts and what its descendants are. We choose to provide the historiograph of the OWA field (Figure 3) as output as this paper is the first review of the scientific development of this discipline.

CPM captures the dominant direction of knowledge accumulation that emerged over the whole time period covered by this analysis, namely the backbone of the field of interest. By 
computing the total number of paths linking the oldest vertices in a citation network to the most recent ones, the algorithm maps all possible streams of cumulative growth of knowledge, and selects the most important one. CPM determines the source-sink path(s) with the largest total sum of weights and identifies the path from entry vertices to exit vertices with the largest total sum of weights on the arcs. We conduct the CPM to highlight the intellectual structure underpinning the scientific development of the field of interest and complement this analysis with insights from a co-citation perspective. In fact the analysis of references of published articles allows to highlight if any two references are commonly co-cited, that is referenced together. Is a set of references is commonly co-cited, it can be argued that they constitute the intellectual structure of the field (Leydesdorff and Vaughan, 2006). Data have been analysed with two major software: HistCite and Pajek².

\section{Data and basic statistics}

We adopt ISI Web of Science (WoS) as the data source of this study. OWA papers have been searched and retrieved through the use of the keyword "ordered weighted averaging". We first obtained 540 results, 3 of these were not imported as they do not belong to the 'Core Collection within ISI Web Science3, thus the procedure ended up with 537 results, 674 authors and 249 journals. A main issue to handle when searching for OWA papers is the right 'search key', we opt to use "ordered weighted averaging" instead of the abbreviation OWA to avoid potential misunderstanding. As first goal we identify the major publications and authors in the OWA field. The growing attention received by this topic is shown in Figure 2, which depicts the trend of publications since Yager's first OWA paper in 1988.

\footnotetext{
${ }^{2}$ These two software are available free: $\underline{h t t p} / / /$ interest.science.thomsonreuters.com/forms/HistCite/; http://pajek.imfm.si/doku.php?id=download.

${ }^{3}$ The data to be analysed with HistCite software should belong to the Web of Science Core Collection. The 3 results not included are papers published in the Journal of Environmental Systems by Smith, P. N.
} 


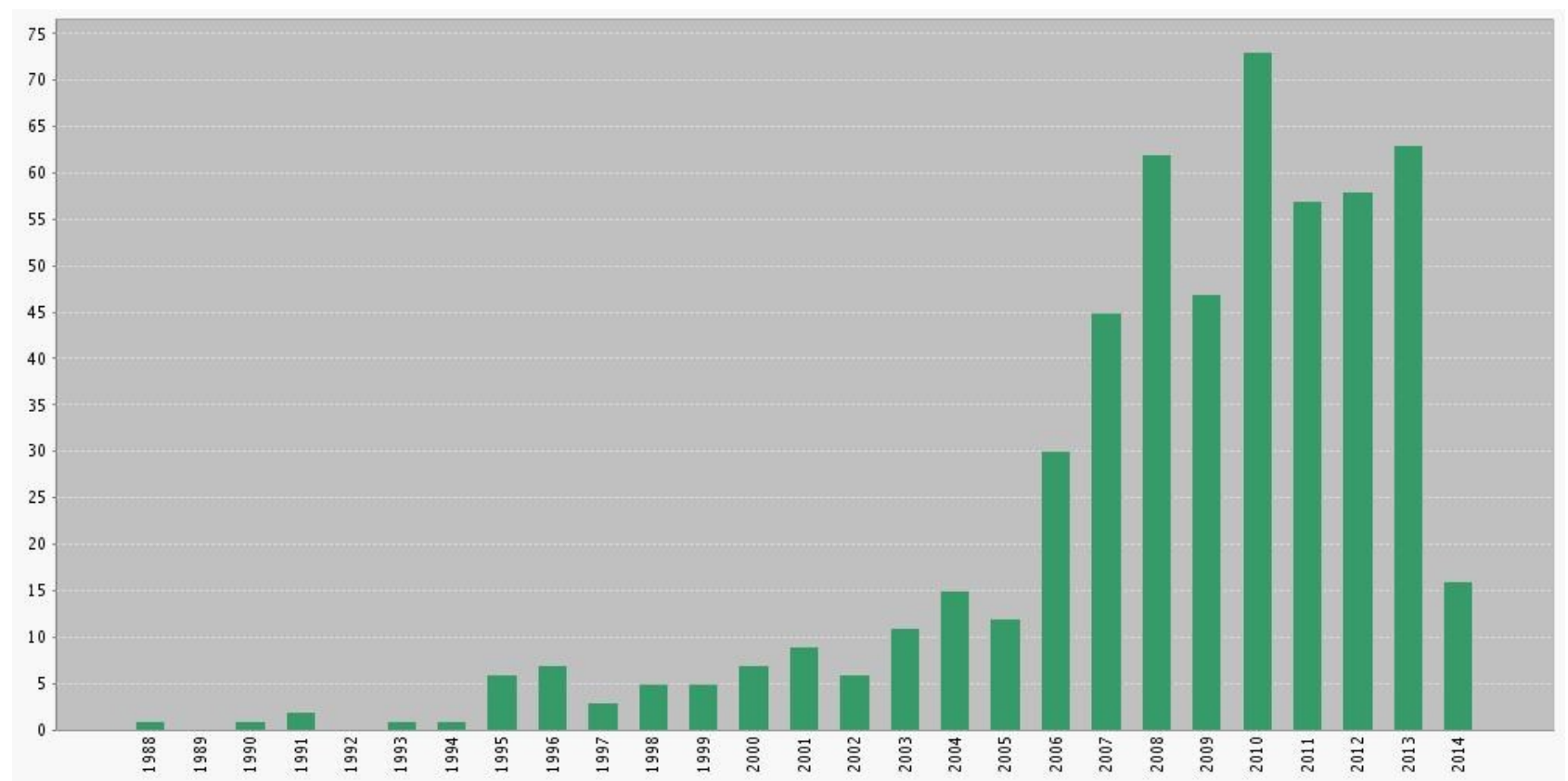

Figure 2. Published items in each year. Source Web of Science

We ranked authors and journals using the Total Local Score (TLC), which refers to how many times the author's papers included in this collection have been cited by other papers also in the collection and the Total Global Citation Score (TGCS), which refers to how many times the author's papers included in this collection have been cited. This score is calculated from the Times Cited score retrieved from the Web of Science. Thus, considering TGCS means accounting also for the influence that authors' publication has outside the discipline's borders. However it is based only on the materials included in the ISI WoS database, which constitute the main limitation of this kind of study.

The first visual representation of our analysis is the historiograph depicted in Figure 3 that provides a citation-based graphical representation of how core papers have influenced one another. The figure depicts only the top 30 most cited papers as shown in Table 1 . The decision to set a threshold of 30 papers is arbitrary, however is usually suggested as reasonable to get first information about most influential works. A key indicator of influence is relative circle size, which reflects the extent of an article's influence over the development of the core body of knowledge concerning the OWA research domain. As expected the Yager 
(1988) paper shows the biggest shape as it is recognised as the starting and most influential contribution.

Table 1. First 30 most cited papers ranked according to Global Citation Score (GCS)

\begin{tabular}{|c|c|c|c|}
\hline ID & Authors & LCS & GCS \\
\hline 1 & Yager RR, 1988, IEEE Transactions on Systems & 451 & 2029 \\
\hline 4 & Yager RR, 1993, Fuzzy Sets and Systems & 171 & 485 \\
\hline 5 & Yager RR, 1994, International Journal of General Systems & 40 & 85 \\
\hline 7 & Fodor J, 1995, IEEE Transactions on Fuzzy Systems & 41 & 108 \\
\hline 8 & Filev D, 1995, Information Sciences & 50 & 92 \\
\hline 9 & Herrera F, 1995, Information Sciences & 36 & 213 \\
\hline 17 & Herrera F, 1996, Fuzzy Sets and Systems & 43 & 264 \\
\hline 20 & $\begin{array}{l}\text { Mitchell HB, 1997, International Journal of Uncertainty Fuzziness and Knowledge- } \\
\text { based Systems }\end{array}$ & 24 & 40 \\
\hline 30 & Yager RR, 1999, IEEE Transactions on Systems & 130 & 284 \\
\hline 46 & Fuller R, 2001, Fuzzy Sets and Systems & 78 & 127 \\
\hline 49 & Xu ZS, 2002, International Journal of Intelligent Systems & 55 & 144 \\
\hline 50 & Xu ZS, 2002, International Journal of Intelligent Systems & 33 & 95 \\
\hline 45 & Fuller R, 2003, Fuzzy Sets and Systems & 65 & 106 \\
\hline 60 & Yager RR, 2003, Fuzzy Sets and Systems & 56 & 117 \\
\hline 61 & Xu ZS, 2003, International Journal of Intelligent Systems & 99 & 268 \\
\hline 69 & Chiclana F, 2004, International Journal of Intelligent Systems & 26 & 69 \\
\hline 86 & Wang YM, 2005, Information Sciences & 48 & 73 \\
\hline 110 & Xu ZS, 2006, Information Fusion & 28 & 112 \\
\hline 156 & Chiclana F, 2007, European Journal of Operational Research & 38 & 92 \\
\hline 162 & Xu ZS, 2007, IEEE Transactions on Fuzzy Systems & 34 & 219 \\
\hline 251 & Merigó JM, 2009, Information Sciences & 75 & 144 \\
\hline 254 & Wu J, 2009, Computers \& Industrial Engineering & 26 & 49 \\
\hline 259 & Merigó JM, 2009, International Journal of Intelligent Systems & 44 & 75 \\
\hline 285 & Merigó JM, 2010, Cybernetics and Systems & 27 & 47 \\
\hline 301 & Zhao H, 2010, International Journal of Intelligent Systems & 39 & 104 \\
\hline 309 & Merigó JM, 2010, International Journal of Fuzzy Systems & 34 & 60 \\
\hline 317 & Merigó JM, 2010, Computers \& Industrial Engineering & 41 & 69 \\
\hline 321 & $\begin{array}{l}\text { Merigó JM, 2010, International Journal of Uncertainty Fuzziness and Knowledge- } \\
\text { based Systems }\end{array}$ & 25 & 52 \\
\hline 324 & Merigó JM, 2010, Information Sciences & 50 & 87 \\
\hline 360 & Merigó JM, 2011, Computers \& Industrial Engineering & 28 & 53 \\
\hline
\end{tabular}




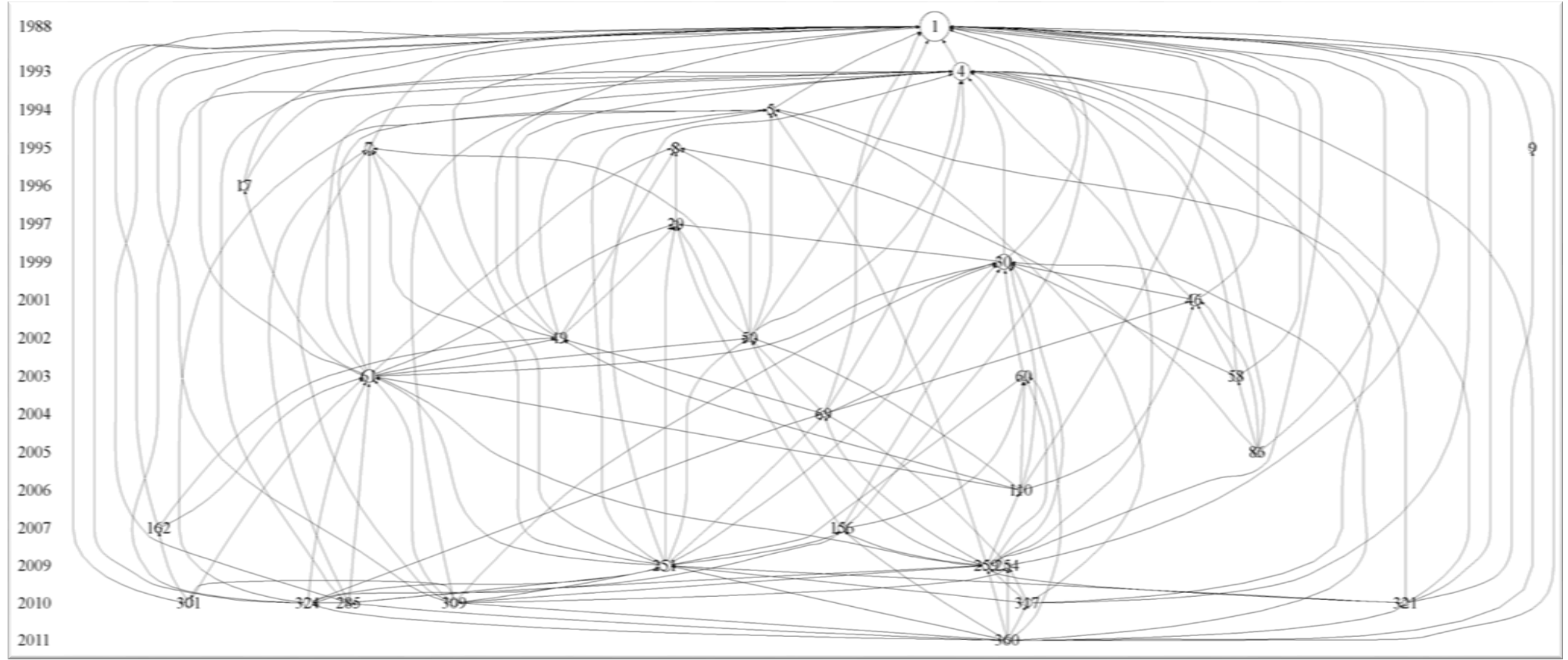

Figure 3. The historiograph showing the top 30 most cited OWA papers 


\section{$\underline{\text { Researcher statistics }}$}

The 20 most cited authors have been ranked in Table 2 according to the number of total citation score excluding self-citations, which are less indicative of influence on others. As expected Yager is the most cited author, followed by $\mathrm{Xu}$, Merigó and Filev in the top 5 positions.

Table 2. Most cited authors ranked by TLCSx (Total citations score excluding self-citation).

\begin{tabular}{llllllll} 
& & $\begin{array}{l}\text { Number } \\
\text { of record }\end{array}$ & TLCS & TLCS/t & TLCSx & TGCS & TGCS/t \\
\hline 1 & Authors & 40 & 1078 & 57.21 & $\mathbf{9 9 5}$ & 3669 & 185.11 \\
\hline 2 & Xu ZS & 27 & 431 & 48.85 & $\mathbf{3 6 4}$ & 1572 & 180.39 \\
\hline 3 & Merigó JM & 62 & 524 & 112.27 & $\mathbf{1 9 1}$ & 958 & 206.92 \\
\hline 4 & Filev DP & 3 & 193 & 11.24 & $\mathbf{1 8 0}$ & 412 & 24.06 \\
\hline 5 & Herrera F & 10 & 191 & 14.68 & $\mathbf{1 6 1}$ & 1110 & 88.39 \\
\hline 6 & Herrera-Viedma E & 14 & 191 & 14.68 & $\mathbf{1 6 1}$ & 1246 & 103.17 \\
\hline 7 & Majlender P & 3 & 166 & 13.29 & $\mathbf{1 6 1}$ & 266 & 21.20 \\
\hline 8 & Fuller R & 3 & 145 & 11.24 & $\mathbf{1 4 0}$ & 240 & 18.78 \\
\hline 9 & Da QL & 5 & 163 & 14.11 & $\mathbf{1 2 9}$ & 428 & 36.27 \\
\hline 10 & Casanovas M & 22 & 245 & 51.65 & $\mathbf{8 9}$ & 441 & 93.18 \\
\hline 11 & Verdegay JL & 4 & 99 & 5.20 & $\mathbf{8 8}$ & 618 & 32.39 \\
\hline 12 & Ahn BS & 14 & 116 & 16.94 & $\mathbf{8 4}$ & 162 & 23.60 \\
\hline 13 & Wang YM & 4 & 85 & 9.68 & $\mathbf{8 0}$ & 145 & 17.93 \\
\hline 14 & Chiclana F & 11 & 99 & 11.08 & $\mathbf{7 9}$ & 522 & 63.48 \\
\hline 15 & Gil-Lafuente AM & 18 & 183 & 37.83 & $\mathbf{7 3}$ & 338 & 70.73 \\
\hline 16 & Liu XW & 17 & 88 & 12.27 & $\mathbf{6 4}$ & 182 & 27.13 \\
\hline 17 & Alonso S & 5 & 64 & 7.11 & $\mathbf{5 3}$ & 432 & 51.65 \\
\hline 18 & Filev D & 1 & 50 & 2.50 & $\mathbf{4 9}$ & 92 & 4.60 \\
\hline 19 & Emrouznejad A & 5 & 55 & 8.55 & $\mathbf{4 6}$ & 91 & 14.42 \\
\hline 20 & Malczewski J & 4 & 52 & 5.92 & $\mathbf{4 6}$ & 156 & 19.30 \\
\hline
\end{tabular}

\section{Lournal statistics}

Table 3 shows the top 20 most active journals that publish OWA papers. The top five journals in this area are International Journal of Intelligent Systems, Information Science, Fuzzy Sets, Systems and Expert Systems with Applications and Computers \& Industrial Engineering. Journals are ranked considering the TGCS and considering time (TGCS/t).

Table 3. Top 20 most influential journals in the OWA field ranked according to their TLCS/t Number of

\begin{tabular}{llccccc} 
& Journals & record & TLCS & TLCS/t & TGCS & TGCS/t \\
\hline 1 & International Journal of Intelligent Systems & 42 & 429 & 51.27 & 1086 & $\mathbf{1 2 4 . 5 9}$ \\
2 & Information Sciences & 19 & 371 & 46.31 & 1105 & $\mathbf{1 2 0 . 1 6}$
\end{tabular}




\begin{tabular}{lllllll}
\hline 3 & Fuzzy Sets and Systems & 20 & 517 & 37.77 & 1476 & $\mathbf{1 0 7 . 6 5}$ \\
\hline 4 & Expert Systems with Applications & 27 & 157 & 37.73 & 366 & $\mathbf{8 7 . 8 7}$ \\
\hline 5 & Computers \& Industrial Engineering & 12 & 167 & 32.06 & 308 & $\mathbf{6 0 . 6 6}$ \\
\hline 6 & $\begin{array}{l}\text { IEEE Transactions on Systems Man and } \\
\text { Cybernetics }\end{array}$ & 1 & 451 & 16.70 & 2029 & $\mathbf{7 5 . 1 5}$ \\
\hline 7 & IEEE Transactions on Fuzzy Systems & 18 & 154 & 16.06 & 669 & $\mathbf{7 7 . 4 4}$ \\
\hline 8 & International Journal on Fuzzy Systems & 6 & 66 & 13.42 & 136 & $\mathbf{2 7 . 2 3}$ \\
\hline 9 & $\begin{array}{l}\text { IEEE Transactions on Systems Man and } \\
\text { Cybernetics Part B-Cybernetics }\end{array}$ & 9 & 157 & 12.22 & 488 & $\mathbf{4 3 . 7 1}$ \\
\hline 10 & International Journal of Approximate Reasoning & 10 & 88 & 11.59 & 234 & $\mathbf{2 7 . 0 7}$ \\
\hline 11 & European Journal of Operational Research & 12 & 96 & 11.05 & 370 & $\mathbf{4 2 . 7 2}$ \\
\hline 12 & $\begin{array}{l}\text { International Journal of Uncertainty Fuzziness } \\
\text { and Knowledge-based Systems }\end{array}$ & 17 & 97 & 10.54 & 262 & $\mathbf{2 9 . 2 5}$ \\
\hline 13 & Group Decision and Negotiation & 8 & 32 & 7.19 & 185 & $\mathbf{2 8 . 8 6}$ \\
\hline 14 & $\begin{array}{l}\text { International Journal of Computational } \\
\text { Intelligence Systems }\end{array}$ & 3 & 33 & 7.15 & 80 & $\mathbf{1 6 . 9 5}$ \\
\hline 15 & Journal of Systems Engineering and Electronics & 7 & 35 & 6.75 & 61 & $\mathbf{1 1 . 8 0}$ \\
\hline 16 & Information Fusion & 5 & 48 & 6.68 & 162 & $\mathbf{2 4 . 0 2}$ \\
\hline 17 & Cybernetics and Systems & 4 & 35 & 6.33 & 65 & $\mathbf{1 1 . 4 6}$ \\
\hline 18 & International Journal of General Systems & 9 & 87 & 5.93 & 203 & $\mathbf{1 5 . 3 3}$ \\
\hline 19 & Knowledge-based Systems & 10 & 22 & 4.96 & 71 & $\mathbf{1 6 . 5 0}$ \\
\hline 20 & $\begin{array}{l}\text { Economic Computation and Economic } \\
\text { Cybernetics Studies and Research }\end{array}$ & 4 & 15 & 4.25 & 30 & $\mathbf{8 . 2 5}$ \\
\hline
\end{tabular}

\section{OWA knowledge accumulation using Critical Path Method}

Figure 4 shows the result of CPM, which captures the evolution and direction of knowledge accumulation. The graph aims at showing the sequence of knowledge contributions and differently from the historiograph here we do not have differences in shapes dimension to mean a different influence played by one on another. Here the emphasis is on the evolution of the discipline and its direction. 


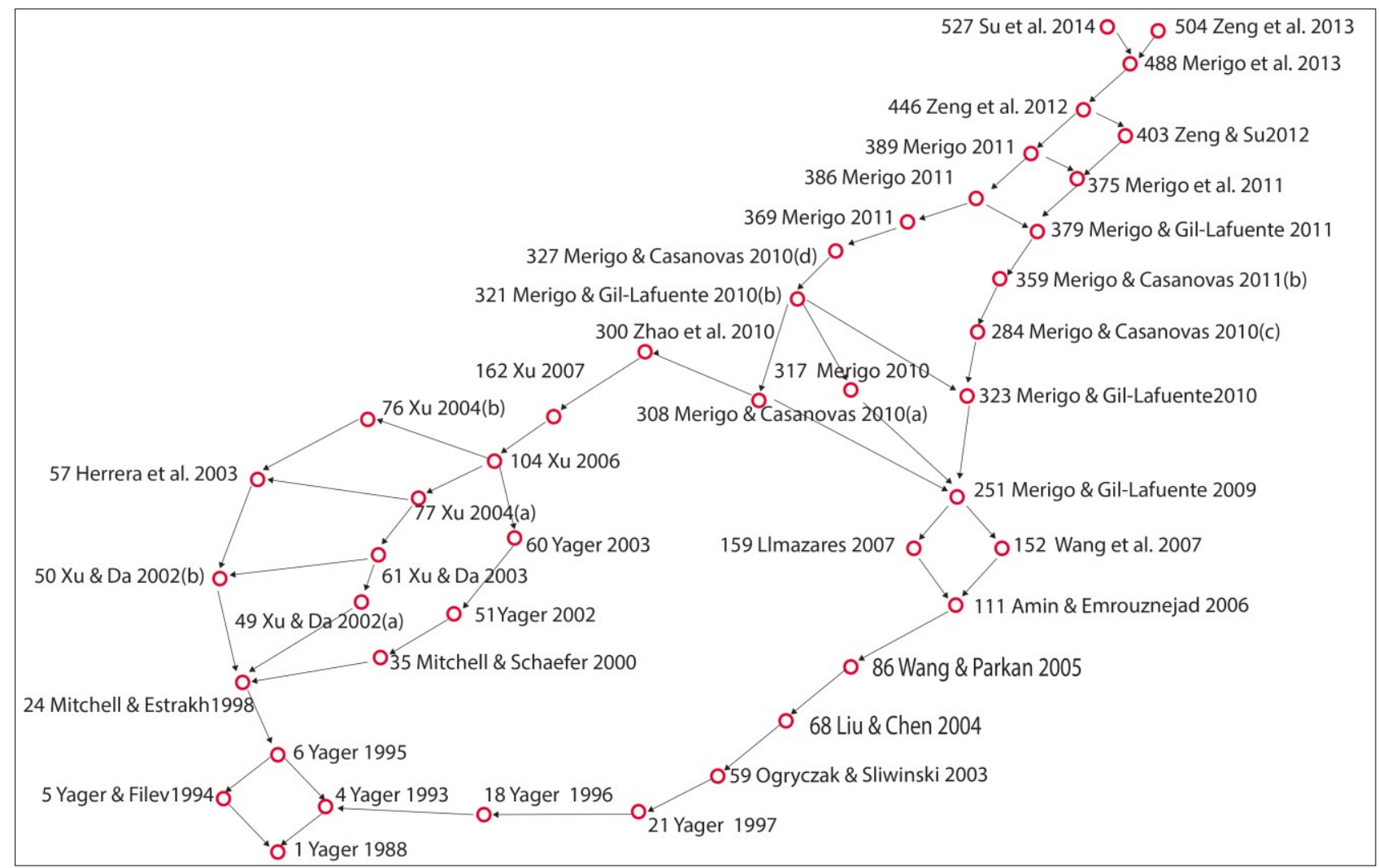

Figure 4. Critical Path Method of OWA development

After examining the title, abstract, and keywords ${ }^{4}$ of these papers (Table 4) we describe the development of this discipline and its major areas of research. The analysis of the content reveals the efforts of researchers focused on two major directions.

\section{Table 4. Papers on the CPM}

\begin{tabular}{|c|c|c|c|c|c|}
\hline Id & Authors & Title & Journal & Keywords & $\begin{array}{l}\text { Year } \\
\text { published }\end{array}$ \\
\hline 1 & Yager, R.R. & $\begin{array}{l}\text { On ordered weighted } \\
\text { averaging operators in } \\
\text { multicriteria decision- } \\
\text { making }\end{array}$ & $\begin{array}{l}\text { IEEE Transactions on } \\
\text { Systems Man and } \\
\text { Cybernetics }\end{array}$ & $\begin{array}{l}\text { Ordered weighted } \\
\text { averaging operators, } \\
\text { decision making }\end{array}$ & 1988 \\
\hline 4 & Yager, R. R. & Families of OWA operators & $\begin{array}{l}\text { Fuzzy Sets and } \\
\text { Systems }\end{array}$ & $\begin{array}{l}\text { Aggregation; fuzzy } \\
\text { sets; averaging } \\
\text { operators; linguistic } \\
\text { quantifiers; logical } \\
\text { operators }\end{array}$ & 1993 \\
\hline 5 & $\begin{array}{l}\text { Yager, R. } \\
\text { R.; Filev, D } \\
\text { R. }\end{array}$ & $\begin{array}{l}\text { Parameterized and-like and } \\
\text { or-like OWA operators }\end{array}$ & $\begin{array}{l}\text { International Journal } \\
\text { of General Systems }\end{array}$ & $\begin{array}{l}\text { Aggregation } \\
\text { operators; decision } \\
\text { making; averaging } \\
\text { operators; fuzzy set } \\
\text { theory; fuzzy logic }\end{array}$ & 1994 \\
\hline
\end{tabular}

\footnotetext{
${ }^{4}$ Some journals such as International Journal of Intelligent Systems and IEEE Transactions on Systems Man and Cybernetics, do not provide keywords. In these cases we propose keywords as recurrent words along the papers and use Italic font to highlight them.
} 


\begin{tabular}{|c|c|c|c|c|c|}
\hline & & & & control & \\
\hline 6 & Yager, R.R. & $\begin{array}{l}\text { Measures of entropy and } \\
\text { fuzziness related to } \\
\text { aggregation operators }\end{array}$ & Information Sciences & Entropy measures & 1995 \\
\hline 18 & Yager, R. R. & $\begin{array}{l}\text { Constrained OWA } \\
\text { aggregation }\end{array}$ & $\begin{array}{l}\text { Fuzzy Sets and } \\
\text { Systems }\end{array}$ & $\begin{array}{l}\text { Fuzzy mathematical } \\
\text { programming; linguistic } \\
\text { quantifiers; } \\
\text { constrained } \\
\text { optimization; OWA } \\
\text { operators }\end{array}$ & 1996 \\
\hline 21 & Yager, R. R. & $\begin{array}{l}\text { On the analytic } \\
\text { representation of the } \\
\text { Leximin ordering and its } \\
\text { application to flexible } \\
\text { constraint propagation }\end{array}$ & $\begin{array}{l}\text { European Journal of } \\
\text { Operational Research }\end{array}$ & $\begin{array}{l}\text { Aggregation; } \\
\text { constraint } \\
\text { propagation; fuzzy } \\
\text { sets; OWA operators; } \\
\text { Leximin; mathematical } \\
\text { programming }\end{array}$ & 1997 \\
\hline 24 & $\begin{array}{l}\text { Mitchell, H } \\
\text { B.; Estrakh, } \\
\text { D. D. }\end{array}$ & $\begin{array}{l}\text { An OWA operator with } \\
\text { fuzzy ranks }\end{array}$ & $\begin{array}{l}\text { International Journal } \\
\text { of Intelligent Systems }\end{array}$ & Fuzzy ranks & 1998 \\
\hline 35 & $\begin{array}{l}\text { Mitchell, H } \\
\text { B.; Schaefer, } \\
\text { P. A. }\end{array}$ & $\begin{array}{l}\text { Multiple priorities in an } \\
\text { induced ordered weighted } \\
\text { averaging operator }\end{array}$ & $\begin{array}{l}\text { International Journal } \\
\text { of Intelligent Systems }\end{array}$ & Multiple fuzzy priorities & 2000 \\
\hline 49 & $\begin{array}{l}\text { Xu, Z.S.; } \\
\text { Da, Q. L. }\end{array}$ & $\begin{array}{l}\text { The uncertain OWA } \\
\text { operator }\end{array}$ & $\begin{array}{l}\text { International Journal } \\
\text { of Intelligent Systems }\end{array}$ & $\begin{array}{l}\text { Internal numbers; } \\
\text { uncertain OWA operator }\end{array}$ & 2002 \\
\hline 50 & $\begin{array}{l}\text { Xu,, Z.S.; } \\
\mathrm{Da}, \mathrm{Q} \text {. L. }\end{array}$ & $\begin{array}{l}\text { The ordered weighted } \\
\text { geometric averaging } \\
\text { operators }\end{array}$ & $\begin{array}{l}\text { International Journal } \\
\text { of Intelligent Systems }\end{array}$ & $\begin{array}{l}\text { Ordered weighted } \\
\text { geometric averaging } \\
\text { operators }\end{array}$ & 2002 \\
\hline 51 & Yager, R. R. & $\begin{array}{l}\text { Using fuzzy methods to } \\
\text { model nearest neighbour } \\
\text { rules }\end{array}$ & $\begin{array}{l}\text { IEEE Transactions on } \\
\text { Systems Man and } \\
\text { Cybernetics part B- } \\
\text { Cybernetics }\end{array}$ & $\begin{array}{l}\text { Nearest-neighbour } \\
\text { models }\end{array}$ & 2002 \\
\hline 57 & $\begin{array}{l}\text { Herrera, F., } \\
\text { Herrera- } \\
\text { Viedma, E., } \\
\text { Chiclana, F. }\end{array}$ & $\begin{array}{l}\text { A study of the origin and } \\
\text { uses of the ordered } \\
\text { weighted Geometric } \\
\text { operator in multicriteria } \\
\text { decision making }\end{array}$ & $\begin{array}{l}\text { International Journal } \\
\text { of Intelligent Systems }\end{array}$ & $\begin{array}{l}\text { Ordered weighted } \\
\text { geometric operator; } \\
\text { multicriteria decision } \\
\text { making }\end{array}$ & 2003 \\
\hline 59 & $\begin{array}{l}\text { Ogryczak, } \\
\text { W.; } \\
\text { Sliwinski, } \\
\text { T. }\end{array}$ & $\begin{array}{l}\text { On solving linear programs } \\
\text { with the ordered weighted } \\
\text { averaging objective }\end{array}$ & $\begin{array}{l}\text { European Journal of } \\
\text { Operational Research }\end{array}$ & $\begin{array}{l}\text { Equity; lexicographic } \\
\text { maximin; linear } \\
\text { programming; multiple } \\
\text { criteria; ordered } \\
\text { weighted averaging }\end{array}$ & 2003 \\
\hline 60 & Yager, R. R. & $\begin{array}{l}\text { Induced aggregation } \\
\text { operators }\end{array}$ & $\begin{array}{l}\text { Fuzzy Sets and } \\
\text { Systems }\end{array}$ & $\begin{array}{l}\text { IOWA operator; OWA } \\
\text { aggregation operators; } \\
\text { best yesterday models }\end{array}$ & 2003 \\
\hline 61 & $\begin{array}{l}\text { Xu, Z. S.; } \\
\text { Da, Q. L. }\end{array}$ & $\begin{array}{l}\text { An overview of operators } \\
\text { for aggregating information }\end{array}$ & $\begin{array}{l}\text { International Journal } \\
\text { of Intelligent Systems }\end{array}$ & $\begin{array}{l}\text { Survey; aggregation } \\
\text { operators }\end{array}$ & 2003 \\
\hline 68 & $\begin{array}{l}\text { Liu, X. W.; } \\
\text { Chen, L. H. }\end{array}$ & $\begin{array}{l}\text { On the properties of } \\
\text { parametric geometric OWA } \\
\text { operator }\end{array}$ & $\begin{array}{l}\text { International Journal } \\
\text { of Approximate } \\
\text { Reasoning }\end{array}$ & $\begin{array}{l}\text { OWA operator; } \\
\text { geometric OWA } \\
\text { operator; maximum } \\
\text { entropy OWA } \\
\text { operator }\end{array}$ & 2004 \\
\hline 76 & Xu, Z.S. & EOWA and EOWG & International Journal & Group decision & 2004 \\
\hline
\end{tabular}




\begin{tabular}{|c|c|c|c|c|c|}
\hline & & $\begin{array}{l}\text { operators for aggregating } \\
\text { linguistic labels based on } \\
\text { linguistic preference } \\
\text { relations }\end{array}$ & $\begin{array}{l}\text { of Uncertainty } \\
\text { Fuzziness and } \\
\text { Knowledge-based } \\
\text { Systems }\end{array}$ & $\begin{array}{l}\text { making; multiplicative } \\
\text { linguistic preference } \\
\text { relations; additive } \\
\text { linguistic preference } \\
\text { relations; extended } \\
\text { ordered weighted } \\
\text { averaging (EOWA) } \\
\text { operator }\end{array}$ & \\
\hline 77 & Xu, Z.S. & $\begin{array}{l}\text { Uncertain linguistic } \\
\text { aggregation operators } \\
\text { based approach to multiple } \\
\text { attribute group decision } \\
\text { making under uncertain } \\
\text { linguistic environment }\end{array}$ & Information Sciences & $\begin{array}{l}\text { Aggregation; multiple } \\
\text { attribute group } \\
\text { decision making; } \\
\text { uncertain linguistic } \\
\text { ordered weighted } \\
\text { averaging (ULOWA) } \\
\text { operator; uncertain } \\
\text { linguistic hybrid } \\
\text { aggregation (ULHA) } \\
\text { operator }\end{array}$ & 2004 \\
\hline 86 & $\begin{array}{l}\text { Wang, Y. } \\
\text { M.; Parkan, } \\
\text { C. }\end{array}$ & $\begin{array}{l}\text { A minimax disparity } \\
\text { approach for obtaining } \\
\text { OWA operator weights }\end{array}$ & Information Sciences & $\begin{array}{l}\text { OWA operator; } \\
\text { Operator weights; } \\
\text { Degree of orness; } \\
\text { Minimax }\end{array}$ & 2005 \\
\hline $\begin{array}{l}10 \\
4\end{array}$ & Xu, Z.S. & $\begin{array}{l}\text { On generalized induced } \\
\text { linguistic aggregation } \\
\text { operators }\end{array}$ & $\begin{array}{l}\text { International Journal } \\
\text { of General Systems }\end{array}$ & $\begin{array}{l}\text { Generalized induced } \\
\text { linguistic aggregation } \\
\text { operators, linguistic } \\
\text { variable, uncertain } \\
\text { linguistic variable, } \\
\text { operational laws }\end{array}$ & 2006 \\
\hline $\begin{array}{l}11 \\
1\end{array}$ & $\begin{array}{l}\text { Amin, G. } \\
\text { R., } \\
\text { Emrouzneja } \\
\text { d, A. }\end{array}$ & $\begin{array}{l}\text { An extended minimax } \\
\text { disparity to determine the } \\
\text { OWA operator weights }\end{array}$ & $\begin{array}{l}\text { Computers \& } \\
\text { Industrial Engineering }\end{array}$ & $\begin{array}{l}\text { OWA operator } \\
\text { weights; duality of } \\
\text { linear programming }\end{array}$ & 2006 \\
\hline $\begin{array}{l}15 \\
2\end{array}$ & $\begin{array}{l}\text { Wang, Y. } \\
\text { M.; Luo, Y.; } \\
\text { Hua, Z. }\end{array}$ & $\begin{array}{l}\text { Aggregating preference } \\
\text { rankings using OWA } \\
\text { operator weights }\end{array}$ & Information Sciences & $\begin{array}{l}\text { Preference ranking; } \\
\text { preference } \\
\text { aggregation; OWA } \\
\text { operator weights; } \\
\text { orness degree }\end{array}$ & 2007 \\
\hline $\begin{array}{l}15 \\
9\end{array}$ & $\begin{array}{l}\text { Llamazares, } \\
\text { B. }\end{array}$ & $\begin{array}{l}\text { Choosing OWA operator } \\
\text { weights in the field of } \\
\text { Social Choice }\end{array}$ & Information Sciences & $\begin{array}{l}\text { Ordered weighted } \\
\text { averaging operators; } \\
\text { aggregation operator } \\
\text { weights; majority rules }\end{array}$ & 2007 \\
\hline $\begin{array}{l}16 \\
2\end{array}$ & Xu, S. Z. & $\begin{array}{l}\text { Intuitionistic fuzzy } \\
\text { aggregation operators }\end{array}$ & $\begin{array}{l}\text { IEEE Transactions on } \\
\text { Fuzzy Systems }\end{array}$ & $\begin{array}{l}\text { Intuitionistic fuzzy } \\
\text { hybrid aggregation, } \\
\text { intuitionistic fuzzy } \\
\text { ordered weighted } \\
\text { averaging (IFOWA) }\end{array}$ & 2007 \\
\hline $\begin{array}{l}25 \\
0\end{array}$ & $\begin{array}{l}\text { Merigó, J. } \\
\text { M.; Gil- } \\
\text { Lafuente, } \\
\text { A. M. }\end{array}$ & $\begin{array}{l}\text { The induced generalized } \\
\text { OWA operator }\end{array}$ & Information Sciences & $\begin{array}{l}\text { Aggregation } \\
\text { operators; OWA } \\
\text { operators; generalized } \\
\text { mean; quasi-arithmetic } \\
\text { mean; decision- } \\
\text { making }\end{array}$ & 2009 \\
\hline
\end{tabular}




\begin{tabular}{|c|c|c|c|c|c|}
\hline $\begin{array}{l}28 \\
4\end{array}$ & $\begin{array}{l}\text { Merigó, J. } \\
\text { M.; } \\
\text { Casanovas, } \\
\text { M. }\end{array}$ & $\begin{array}{l}\text { The fuzzy generalized } \\
\text { OWA operator and its } \\
\text { application in strategic } \\
\text { decision making }\end{array}$ & $\begin{array}{l}\text { Cybernetics and } \\
\text { Systems }\end{array}$ & $\begin{array}{l}\text { Aggregation } \\
\text { operators; decision } \\
\text { making; fuzzy OWA } \\
\text { operator; selection of } \\
\text { strategies }\end{array}$ & 2010 \\
\hline $\begin{array}{l}30 \\
0\end{array}$ & $\begin{array}{l}\text { Zhao, H.; } \\
\text { Xu, Z.; Ni, } \\
\text { M.; Liu, S. }\end{array}$ & $\begin{array}{l}\text { Generalized aggregation } \\
\text { operators for intuitionistic } \\
\text { fuzzy sets }\end{array}$ & $\begin{array}{l}\text { International Journal } \\
\text { of Intelligent Systems }\end{array}$ & $\begin{array}{l}\text { Generalized } \\
\text { intuitionistic fuzzy } \\
\text { weighted averaging } \\
\text { operator }\end{array}$ & 2010 \\
\hline $\begin{array}{l}30 \\
8\end{array}$ & $\begin{array}{l}\text { Merigó, J. } \\
\text { M.; } \\
\text { Casanovas, } \\
\text { M. }\end{array}$ & $\begin{array}{l}\text { Fuzzy generalized hybrid } \\
\text { aggregation operators and } \\
\text { its application in fuzzy } \\
\text { decision making }\end{array}$ & $\begin{array}{l}\text { International Journal } \\
\text { of Fuzzy Systems }\end{array}$ & $\begin{array}{l}\text { Aggregation } \\
\text { operators; fuzzy } \\
\text { numbers; hybrid } \\
\text { averaging; OWA } \\
\text { operator; decision } \\
\text { making }\end{array}$ & 2010 \\
\hline $\begin{array}{l}31 \\
6\end{array}$ & $\begin{array}{l}\text { Merigó, J. } \\
\text { M. }\end{array}$ & $\begin{array}{l}\text { Fuzzy decision making } \\
\text { with immediate } \\
\text { probabilities }\end{array}$ & $\begin{array}{l}\text { Computers \& } \\
\text { Industrial Engineering }\end{array}$ & $\begin{array}{l}\text { Decision-making; } \\
\text { immediate } \\
\text { probabilities; OWA } \\
\text { operator; fuzzy } \\
\text { numbers; strategic } \\
\text { selection }\end{array}$ & 2010 \\
\hline $\begin{array}{l}32 \\
1\end{array}$ & $\begin{array}{l}\text { Merigó, J. } \\
\text { M.; } \\
\text { Casanovas, } \\
\text { M. }\end{array}$ & $\begin{array}{l}\text { Induced and heavy } \\
\text { aggregation operators with } \\
\text { distance measures }\end{array}$ & $\begin{array}{l}\text { Journal of Systems } \\
\text { Engineering and } \\
\text { Electronics }\end{array}$ & $\begin{array}{l}\text { It is called the induced } \\
\text { heavy ordered } \\
\text { weighted averaging } \\
\text { (OWA) distance } \\
\text { (IHOWAD) operator. }\end{array}$ & 2010 \\
\hline $\begin{array}{l}32 \\
3\end{array}$ & $\begin{array}{l}\text { Merigó, J. } \\
\text { M.; Gil- } \\
\text { Lafuente, } \\
\text { A. M. }\end{array}$ & $\begin{array}{l}\text { New decision-making } \\
\text { techniques and their } \\
\text { application in the selection } \\
\text { of financial products }\end{array}$ & Information Sciences & $\begin{array}{l}\text { Decision making; } \\
\text { OWA operator; } \\
\text { selection of financial } \\
\text { products; hamming } \\
\text { distance }\end{array}$ & 2010 \\
\hline $\begin{array}{l}32 \\
7\end{array}$ & $\begin{array}{l}\text { Merigó, J. } \\
\text { M.; } \\
\text { Casanovas, } \\
\text { M. }\end{array}$ & $\begin{array}{l}\text { Decision making with } \\
\text { distance measures and } \\
\text { linguistic aggregation } \\
\text { operators }\end{array}$ & $\begin{array}{l}\text { International Journal } \\
\text { of Fuzzy Systems }\end{array}$ & $\begin{array}{l}\text { Linguistic ordered } \\
\text { weighted averaging } \\
\text { distance (LOWAD) } \\
\text { operator }\end{array}$ & 2010 \\
\hline $\begin{array}{l}35 \\
9\end{array}$ & $\begin{array}{l}\text { Merigó, J. } \\
\text { M.; } \\
\text { Casanovas, } \\
\text { M. }\end{array}$ & $\begin{array}{l}\text { Decision-making with } \\
\text { distance measures and } \\
\text { induced aggregation } \\
\text { operators }\end{array}$ & $\begin{array}{l}\text { Computers \& } \\
\text { Industrial Engineering }\end{array}$ & $\begin{array}{l}\text { Decision-making; } \\
\text { OWA operator; } \\
\text { distance measures; } \\
\text { induced aggregation } \\
\text { operators }\end{array}$ & 2011 \\
\hline $\begin{array}{l}36 \\
9\end{array}$ & $\begin{array}{l}\text { Merigó, J. } \\
\text { M.; } \\
\text { Casanovas, } \\
\text { M. }\end{array}$ & $\begin{array}{l}\text { Induced aggregation } \\
\text { operators in the Euclidean } \\
\text { distance and its application } \\
\text { in financial decision } \\
\text { making }\end{array}$ & $\begin{array}{l}\text { Expert Systems with } \\
\text { Applications }\end{array}$ & $\begin{array}{l}\text { Induced aggregation } \\
\text { operators; Euclidean } \\
\text { distance; decision } \\
\text { making; selection of } \\
\text { investment }\end{array}$ & 2011 \\
\hline $\begin{array}{l}37 \\
5\end{array}$ & $\begin{array}{l}\text { Merigó, J. } \\
\text { M.; Gil- } \\
\text { Lafuente, } \\
\text { A. M.; Gil- } \\
\text { Aluja, J. }\end{array}$ & $\begin{array}{l}\text { Soft computing techniques } \\
\text { for decision making with } \\
\text { induced aggregation } \\
\text { operators }\end{array}$ & $\begin{array}{l}\text { Information-An } \\
\text { International } \\
\text { International Journal }\end{array}$ & $\begin{array}{l}\text { Induced aggregation } \\
\text { operators; induced } \\
\text { ordered weighted } \\
\text { averaging; induced } \\
\text { ordered weighted } \\
\text { averaging adequacy }\end{array}$ & 2011 \\
\hline
\end{tabular}




\begin{tabular}{|c|c|c|c|c|c|}
\hline & & & & coefficient operator & \\
\hline $\begin{array}{l}37 \\
9\end{array}$ & $\begin{array}{l}\text { Merigó, J. } \\
\text { M.; Gil- } \\
\text { Lafuente, } \\
\text { A. M. }\end{array}$ & $\begin{array}{l}\text { Fuzzy induced generalized } \\
\text { aggregation operators and } \\
\text { its application in multi- } \\
\text { person decision making }\end{array}$ & $\begin{array}{l}\text { Expert Systems with } \\
\text { Applications }\end{array}$ & $\begin{array}{l}\text { Aggregation operator; } \\
\text { OWA operator; fuzzy } \\
\text { numbers; } \\
\text { multi-person decision } \\
\text { making }\end{array}$ & 2011 \\
\hline $\begin{array}{l}38 \\
6\end{array}$ & $\begin{array}{l}\text { Merigó, J. } \\
\text { M. }\end{array}$ & $\begin{array}{l}\text { A unified model between } \\
\text { the weighted average and } \\
\text { the induced OWA operator }\end{array}$ & $\begin{array}{l}\text { Expert Systems with } \\
\text { Applications }\end{array}$ & $\begin{array}{l}\text { Weighted average; } \\
\text { OWA operator; } \\
\text { aggregation operators; } \\
\text { multi-person decision } \\
\text { making }\end{array}$ & 2011 \\
\hline $\begin{array}{l}38 \\
9\end{array}$ & $\begin{array}{l}\text { Merigó, J. } \\
\text { M. }\end{array}$ & $\begin{array}{l}\text { Fuzzy multi-person } \\
\text { decision making with fuzzy } \\
\text { probabilistic aggregation } \\
\text { operators }\end{array}$ & $\begin{array}{l}\text { International Journal } \\
\text { of Fuzzy Systems }\end{array}$ & $\begin{array}{l}\text { Multi-person decision } \\
\text { making; Fuzzy } \\
\text { probabilistic OWA }\end{array}$ & 2011 \\
\hline $\begin{array}{l}40 \\
3\end{array}$ & $\begin{array}{l}\text { Zeng, S. Z.; } \\
\text { Su W. }\end{array}$ & $\begin{array}{l}\text { Linguistic induced } \\
\text { generalized aggregation } \\
\text { distance operators and their } \\
\text { application to decision } \\
\text { making }\end{array}$ & $\begin{array}{l}\text { Economic } \\
\text { Computation and } \\
\text { Economic Cybernetics } \\
\text { Studies and Research }\end{array}$ & $\begin{array}{l}\text { Linguistic variables; } \\
\text { OWA operator; } \\
\text { distance measure; } \\
\text { decision making; } \\
\text { human resource } \\
\text { management }\end{array}$ & 2012 \\
\hline $\begin{array}{l}44 \\
6\end{array}$ & $\begin{array}{l}\text { Zeng, S.; } \\
\text { Su, W.; Le, } \\
\text { A. }\end{array}$ & $\begin{array}{l}\text { Fuzzy generalized ordered } \\
\text { weighted averaging } \\
\text { distance operator and its } \\
\text { application to decision } \\
\text { making }\end{array}$ & $\begin{array}{l}\text { International Journal } \\
\text { of Fuzzy Systems }\end{array}$ & $\begin{array}{l}\text { FGOWADO; } \\
\text { Hamming distance, } \\
\text { fuzzy Euclidean OWA } \\
\text { distance }\end{array}$ & 2012 \\
\hline $\begin{array}{l}48 \\
8\end{array}$ & $\begin{array}{l}\text { Merigó, J. } \\
\text { M.; Xu, Y.; } \\
\text { Zeng, S. }\end{array}$ & $\begin{array}{l}\text { Group decision making } \\
\text { with distance measures and } \\
\text { probabilistic information }\end{array}$ & $\begin{array}{l}\text { Knowledge-based } \\
\text { Systems }\end{array}$ & $\begin{array}{l}\text { Decision making; } \\
\text { selection of policies; } \\
\text { probability; Hamming } \\
\text { distance; aggregating } \\
\text { operators }\end{array}$ & 2013 \\
\hline $\begin{array}{l}50 \\
4\end{array}$ & $\begin{array}{l}\text { Zeng, S.; } \\
\text { Merigó, J. } \\
\text { M.; Su, W. }\end{array}$ & $\begin{array}{l}\text { The uncertain probabilistic } \\
\text { OWA distance operator } \\
\text { and its application in group } \\
\text { decision making }\end{array}$ & $\begin{array}{l}\text { Applied Mathematical } \\
\text { Modelling }\end{array}$ & $\begin{array}{l}\text { Probability; OWA } \\
\text { operator; distance } \\
\text { measures; uncertainty; } \\
\text { group decision- } \\
\text { making }\end{array}$ & 2013 \\
\hline $\begin{array}{l}52 \\
7\end{array}$ & $\begin{array}{l}\text { Su, W.; Li, } \\
\text { W.; Zeng, S. }\end{array}$ & $\begin{array}{l}\text { Atanassov's intuitionistic } \\
\text { linguistic ordered weighted } \\
\text { averaging distance operator } \\
\text { and its application to } \\
\text { decision making }\end{array}$ & $\begin{array}{l}\text { Journal of Intelligent \& } \\
\text { Fuzzy Systems }\end{array}$ & $\begin{array}{l}\text { Distance measures, } \\
\text { OWA operator, } \\
\text { Atanassov's } \\
\text { intuitionistic linguistic } \\
\text { variables, multi- } \\
\text { person decision } \\
\text { making }\end{array}$ & 2014 \\
\hline
\end{tabular}

The first works by Yager (1988, 1993, 1995b) and Yager and Filev (1994) constitute the knowledge base over which future works developed and further applied the OWA method. They lay out the foundation of this research topic. Yager (1988) deals with the problem of aggregating multiple criteria to form an overall decision function and introduces the 'orness', 
which refers to the 'and-like' or 'or-like' aggregation result of an OWA operator. Thus the operator lies between two extremes, 1 ('and-like') and 0 ('or-like'), the former relates to the situation in which all criteria are satisfied. Differently the latter refers to the situation in which at least one of the criteria has to be satisfied. The eleven values between 0 and 1 depend on the decision maker expertise and are suppose to reflect his degree of optimism. The 'orness' concept itself received great attention and further specification (Marichal, 1999; Fernández Salido and Murakami, 2003; Yager, 2004). Two lines of research depart from this knowledge base, mainly dealing with different approaches to obtain the associated weights.

On the one hand we identify a branch of literature including a group of works that generalize the OWA operator to include the case of real-number and fuzzy ranks (Mitchell and Estrakh, 1998); use a multiple priority induced OWA operator (Mitchell and Schaefer, 2000); propose ne classes of aggregation operators such as the ordered weighted geometric averaging (OWGA) operators (Xu and $\mathrm{Da}, 2002 \mathrm{a}$ ) investigate the uncertain OWA operator in which the associated weighting parameters cannot be specified, but value ranges can be obtained and each input argument is given in the form of an interval of numerical values ( $\mathrm{Xu}$ and $\mathrm{Da}$, 2002b); investigate the ordered weighted geometric (OWG) operator and its relationship to the OWA operator in multi-criteria decision making (MCDM) (Herrera et al., 2003). Within this area we can find two other works of Yager. A paper dealing with fuzzy methods to model nearest neighbour rules (Yager, 2002) and a second one about induced OWA operators (IOWA) (Yager, 2003) that receive further attention in this sub area identified and great development later as we will show. $\mathrm{Xu}$ and $\mathrm{Da}$ propose the induced ordered weighted geometric averaging (IOWGA) operator (2003) as new aggregator and the generalized induced linguistic aggregation operators $(\mathrm{Xu}, 2006)$. Other two papers of $\mathrm{Xu}$ and $\mathrm{Da}$ extend the OWA proposing the (EOWA) operator and the uncertain linguistic ordered weighted 
averaging (ULOWA) operator and the uncertain linguistic hybrid aggregation (ULHA) operator.

The subsequently line focuses on fuzzy aggregation and fuzzy-set theory. Within this group the CPM highlights the following as the most significant contributions. Xu (2007) propose an intuitionistic fuzzy version of the OWA operator (IFOWA); Zhao et al. (2010) paper extends the generalized OWA operators introduce by Yager (2004) to the intuitionistic fuzzy information. Merigó and Casanovas (2010a) present a series of operators, the fuzzy generalized hybrid averaging (FGHA) operator, the fuzzy induced generalized hybrid averaging (FIGHA) operator, the Quasi-FHA operator and the Quasi-FIHA operator, with the advantage of generalize a wide range of fuzzy aggregation operators so that can be used in different applications such as decision making problems.

On the other hand we see Yager (1996) paper on the problem of maximizing an OWA aggregation of a group of variables interrelated and constrained by a collection of linear inequality. In this paper, Yager proposes to model this problem as a linear programming (LP) problem. Subsequently the OWA operator is proposed to as analytic formulation for the Leximin method, overcoming its lack of analytic formulation (Yager, 1997). Following these conceptualizations researchers worked on the linear programming formulations with the OWA objective functions (Ogryczak and Śliwiński, 2003; Liu and Chen, 2004; Wang and Parkan, 2005; Amin and Emrouznejad, 2006). However there are differences among various approaches using the linear programming. According to Ogryczak and Śliwiński (2003) the LP problem with the OWA objective can be performed as a standard linear problem and two alternative LP formulations are introduced the max-min and the deviation model. Liu and Chen (2004) propose the concept of parametric geometric OWA operator (PGOWA) and parametric maximum entropy OWA operator (PMEOWA) showing the consistence of the orness level and the aggregation value for an aggregated elements with PGOWA. The 
equivalence between PGOWA and PMEOWA is also proven. Wang and Parkan (2005) paper represents the first attempt to propose the minimax disparity approach as a method to identify OWA operator weights using LP under a give level of 'orness'. According to this approach OWA operator weights have been determined by minimizing the maximum difference between two adjacent weights, under a give level of 'orness'. Within this line of research, Amin and Emrouznejad (2006) extend the minimax disparity to determine the OWA model based on LP and introduce the minimax disparity approach between any distinct pairs of the weights. Drawing on this works, the sub area that we find between 2007 and 2009 (Llamazares, 2007; Wang et al., 2007; Merigó and Gil-Lafuente, 2009) make a step further in this direction developing models that slightly different the previous ones. More specifically, Wang et al. (2007) paper deals with the determination of the weights of different ranking places. Their model allows the weights associated with different ranking places to be determined in terms of a decision maker (DM)'s optimism level, which is characterized by an orness degree. Llamazares (2007) aims to determine the OWA operator weights that allow to extend, through the OWA operator, some classes of majority rules obtained when individuals do not grade their preferences between two alternatives. Subsequently we find Merigó and Gil-Lafuente (2009), which can be seen as a bridge between the previous areas of research. This new area relies on both lines of previous research and comprises works mainly dealing with induced and fuzzy OWA operators. Merigó and Gil-Lafuente (2009) and Merigó and Casanovas (2010b) build on the previous line of research to introduce the induced generalized ordered weighted averaging (IGOWA) operator. It is a new aggregation operator that generalizes the OWA operator, including the main characteristics of both the generalized OWA and the induced OWA operator. They propose the application of the IGOWA in a financial decision-making problem. Merigó (2010) develop a decision-making model with probabilistic information and use the concept of the immediate probability to aggregate the 
information and applies it to the selection of strategies. Merigó and Gil-Lafuente (2010) introduce the ordered weighted averaging distance (OWAD) operator and the ordered weighted averaging adequacy coefficient (OWAAC) operator to the selection of financial products. This line of research has been further exploited by Merigó and hi co-authors that successfully applied the proposed models to other disciplinary context, such as strategic and business decision making (Merigó and Casanovas, 2010c, 2011a). Within this line of research they develop also decision-making model with distance measures by using linguistic aggregation operators. In doing so they propose linguistic ordered weighted averaging distance (LOWAD) operator and apply it to support decision makers in human resource management (Merigó and Casanovas, 2010d). Subsequently they further developed a OWA model based using distance measures and induced aggregation operators (Merigó and Casanovas, 2011b). This model provides a parameterized family of distance aggregation operators between the maximum and the minimum distance based on a complex reordering process that reflects the complex attitudinal character of the decision-maker. The fuzzy induced generalized aggregation operators (FIGOWA) has been also proposed in strategic multi-person decision making (Merigó and Gil-Lafuente, 2011). Merigó also work on a model that uses the weighted average (WA) and the induced ordered weighted averaging (IOWA) operator in the same formulation and apply it in multi-person decision-making in political management (Merigó, 2011).

The 50 most frequently co-cited publications have been listed in table 55. Yager's first OWA paper is the most frequently co-cited with other references. It is often co-cited with his other papers (Yager, 1993; 1996; 1999) and with the following publications, Filev and Yager (1998); Xu and Da (2003); Xu (2005); Merigo and Gil-Lafuente (2009).

Table 5. Most frequent reference citation and associated highest co-citations

\footnotetext{
${ }^{5}$ In this table we use only first author's name to indicate the pubblication.
} 


\begin{tabular}{|c|c|c|}
\hline Publication & Co-cit value & Publication most co-cited with \\
\hline Yager R, 1988, IEEE T Syst Man Cyb & 162 & Yager R, 1993, Fuzzy Set Syst \\
\hline Yager R, 1997, Ordered Weighted Ave & 148 & Yager R, 1988, IEEE T Syst Man Cyb \\
\hline Yager R, 1988, IEEE T Syst Man Cyb & 122 & Yager R, 1996, Int J Intell Syst \\
\hline Yager R, 1988, IEEE T Syst Man Cyb & 116 & Yager R, 1999, IEEE T Syst Man Cy B \\
\hline Xu Z, 2003, Int J Intell Syst & 95 & Yager R, 1988, IEEE T Syst Man Cyb \\
\hline Filev D, 1998, Fuzzy Set Syst & 86 & Yager R, 1988, IEEE T Syst Man Cyb \\
\hline Xu Z, 2005, Int J Intell Syst & 82 & Yager R, 1988, IEEE T Syst Man Cyb \\
\hline Yager R, 1997, Ordered Weighted Ave & 76 & Yager R, 1993, Fuzzy Set Syst \\
\hline Merigo J, 2009, Inform Sciences & 74 & Yager R, 1988, IEEE T Syst Man Cyb \\
\hline Fuller R, 2001, Fuzzy Set Syst & 71 & Yager R, 1988, IEEE T Syst Man Cyb \\
\hline Beliakov G, 2007, Aggregation Function & 68 & Yager R, 1988, IEEE T Syst Man Cyb \\
\hline Yager R, 1993, Fuzzy Set Syst & 67 & Yager R, 1999, IEEE T Syst Man Cy B \\
\hline Yager R, 1997, Ordered Weighted Ave & 67 & Yager R, 1999, IEEE T Syst Man Cy B \\
\hline O'Hagan M, 1988, Ann Ieee As C S & 65 & Yager R, 1988, IEEE T Syst Man Cyb \\
\hline Fuller R, 2003, Fuzzy Set Syst & 64 & Yager R, 1988, IEEE T Syst Man Cyb \\
\hline Yager R, 2004, Fuzzy Optim Decis Ma & 63 & Yager R, 1988, IEEE T Syst Man Cyb \\
\hline Merigo J, 2009, Inform Sciences & 63 & Yager R, 1993, Fuzzy Set Syst \\
\hline Yager R, 1988, IEEE T Syst Man Cyb & 62 & Zadeh L, 1983, Comput Math Appl \\
\hline Torra V, 1997, Int J Intell Syst & 62 & Yager R, 1988, IEEE T Syst Man Cyb \\
\hline Xu Z, 2003, Int J Intell Syst & 60 & Yager R, 1993, V59, P125, Fuzzy Set Syst \\
\hline Xu Z, 2003, Int J Intell Syst & 60 & Yager R, 1997, Ordered Weighted Ave \\
\hline Yager R, 1988, IEEE T Syst Man Cyb & 59 & Zadeh L, 1965, Inform Control \\
\hline Yager R, 1993, Fuzzy Set Syst & 59 & Yager R, 1996, Int J Intell Syst \\
\hline Filev D, 1998, Fuzzy Set Syst & 57 & Yager R, 1993, Fuzzy Set Syst \\
\hline Xu Z, 2005, Int J Intell Syst & 57 & Yager R, 1993, Fuzzy Set Syst \\
\hline Merigo J, 2009, Inform Sciences & 56 & Yager R, 1997, Ordered Weighted Ave \\
\hline Beliakov G, 2007, Aggregation Function & 53 & Yager R, 1993, Fuzzy Set Syst \\
\hline Yager R, 1988, IEEE T Syst Man Cyb & 51 & Yager R, 2003, Fuzzy Set Syst \\
\hline Xu Z, 2003, Int J Intell Syst & 51 & Yager R, 1999, IEEE T Syst Man Cy B \\
\hline Merigo J, 2010, Inform Sciences & 51 & Yager R, 1988, IEEE T Syst Man Cyb \\
\hline Yager R, 1997, Ordered Weighted Ave & 51 & Yager R, 1996, Int J Intell Syst \\
\hline Filev D, 1998, Fuzzy Set Syst & 50 & Fuller R, 2001, Fuzzy Set Syst \\
\hline Yager R, 1988, IEEE T Syst Man Cyb & 49 & Yager R, 2007, Soft Comput \\
\hline Yager R, 1988, IEEE T Syst Man Cyb & 49 & Zadeh L, 1975, Inform Sciences \\
\hline Beliakov G, 2007, Aggregation Function & 49 & Merigo J, 2009, Inform Sciences \\
\hline Beliakov G, 2007, Aggregation Function & 49 & Yager R, 1997, Ordered Weighted Ave \\
\hline Xu Z, 2002, Int J Intell Syst & 48 & Yager R, 1988, IEEE T Syst Man Cyb \\
\hline Wang Y, 2005, Inform Sciences & 48 & Yager R, 1988, IEEE T Syst Man Cyb \\
\hline Merigo J, 2009, Inform Sciences & 48 & Yager R, 1999, IEEE T Syst Man Cy B \\
\hline Merigo J, 2009, Inform Sciences & 48 & Xu Z, 2003,IEEE Int J Intell Syst \\
\hline Filev D, 1995, Inform Sciences & 47 & Yager R, 1988, IEEE T Syst Man Cyb \\
\hline
\end{tabular}




\begin{tabular}{l|l|l} 
Yager R, 2004, Fuzzy Optim Decis Ma & 47 & Yager R, 1993, Fuzzy Set Syst \\
\hline Yager R, 1999, IEEE T Syst Man Cy B & 45 & Yager R, 2003, V137, P59, Fuzzy Set Syst \\
\hline Merigo J, 2009, Int J Intell Syst & 44 & Yager R, 1988, IEEE T Syst Man Cyb \\
\hline Beliakov G, 2007, Aggregation Function & 43 & Xu Z, 2003, Int J Intell Syst \\
\hline Merigo J, 2009, Int J Intell Syst & 43 & Yager R, 1993, Fuzzy Set Syst \\
\hline Fodor J, 1995, IEEE T Fuzzy Syst & 43 & Yager R, 1988, IEEE T Syst Man Cyb \\
\hline Merigo J, 2009, Inform Sciences & 43 & Yager R, 2004, Fuzzy Optim Decis Ma \\
\hline Calvo T, 2002, Aggregation Operator & 42 & Yager R, 1988, IEEE T Syst Man Cyb \\
\hline
\end{tabular}

Figure 5 helps in understanding the intensity of such co-citation frequency. Old papers appear on the left while the newer ones are located to the right. The right side shows a higher degree of concentration and a higher number of ties. This informs about the most co-cited publications, while the biggest shape indicates the highest number of total citations received. In fact Yager (1988) is the most cited, but also the most co-cited.

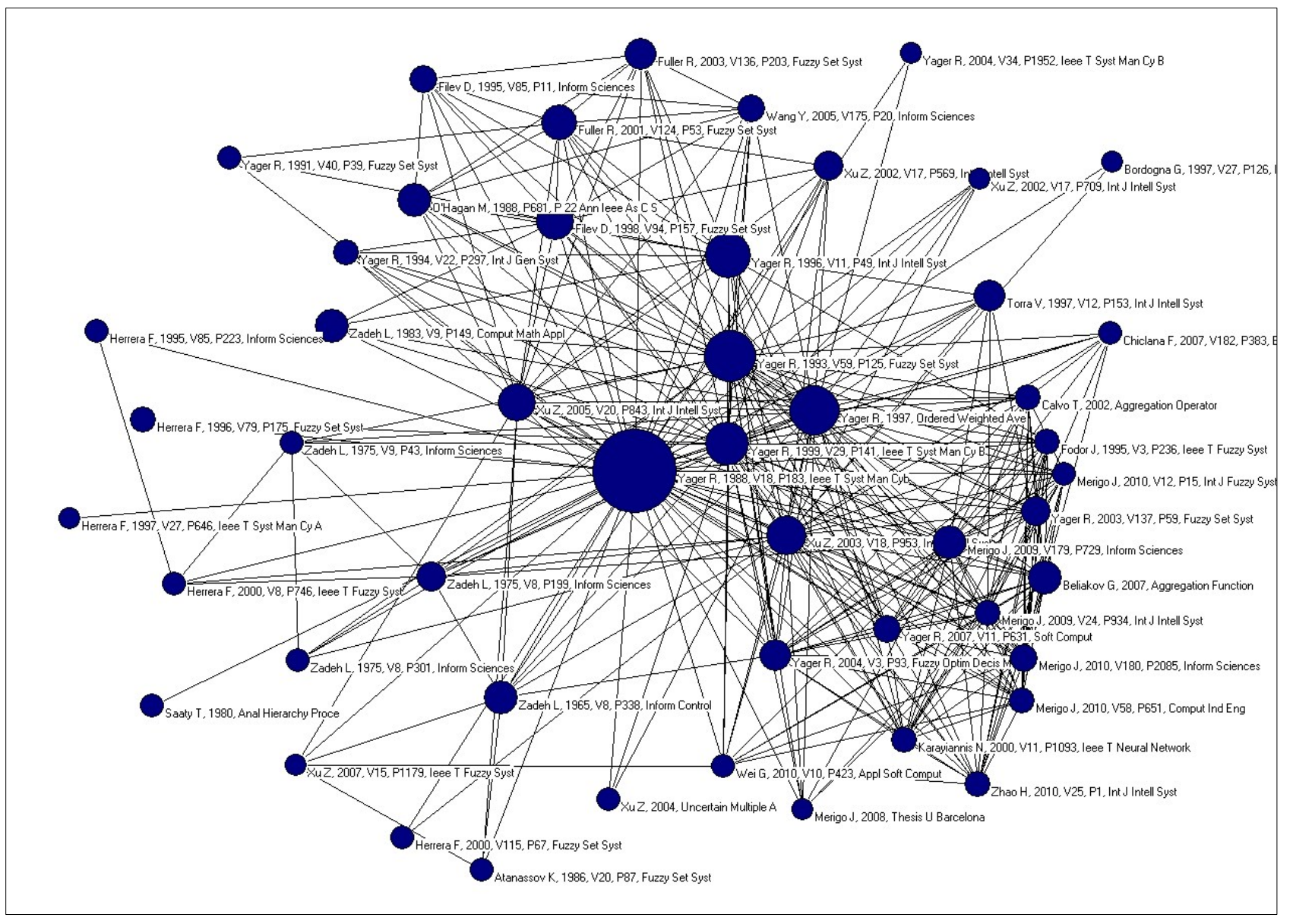

Figure 5. Map of most co-cited publications 


\section{Conclusion}

This study investigates the dominant direction within the OWA literature. As it is the first systematic review of this topic, we focus on the dominant direction instead of describing the several areas of applications of the OWA. Despite this, we have been also able to identify within the dominant direction some sub areas of research that are strongly represented within the OWA CPM result and for this reason we expect to be further exploited by researchers in the future development of the discipline.

First we show the historiograph to provide a descriptive and chronological reconstruction of publications dealing with this topic. The second step of the analysis consists with the description of the CPM results that give a more fine-grained picture of the evolution of studies using the OWA operators, allowing us to suggest future line of research.

Major efforts have been dedicated by scholars to determining the OWA operator weights.

While over the first 22 years two clear lines of research emerged and have been developed by different authors, the last 4 years, as mapped by the CPM algorithm, do not show a clear path of research but remark the previous two. Furthermore the most recent applications of OWA operators are in different disciplines, from financial to strategic decision-making and human resource management (Merigó and Gil-Lafuente, 2010; Merigó and Casanovas, 2011a; Zeng et al., 2013).

The OWA research is growing in different fields ranging from computer science to operational research to and economics. A great part of the literature deals with different approaches proposed to obtain the associated weights.

It is worth noting that scholars active in this area of research belong mainly to two main disciplinary areas, operational research and computer science on the one hand and economics on the other. 
The analysis of core papers along the intellectual trajectory of the OWA field shows that

among the most active journals, two published the most important papers in terms of core knowledge contributors, International Journal of Intelligent Systems and Information Science.

\section{Supplement}

List of all 537 references are available in the online supplement document.

\section{References}

Amin, G.R., Emrouznejad, A. 2006. An extended minimax disparity to determine the OWA operator weights. Computers \& Industrial Engineering 50(3): 312-316.

Calero-Medina, C., Noyons, E.C.M. 2008. Combining mapping and citation network analysis for a better understanding of the scientific development: The case of the absorptive capacity field. Journal of Informetrics 2(4): 272-279.

Ding, Y., Liu, X., Guo, C., Cronin, B. 2013. The distribution of references across texts: Some implications for citation analysis. Journal of Informetrics 7(3): 583-592.

Fernández Salido J.M., Murakami, S. 2003. Extending Yager's orness concept for the OWA aggregators to other mean operators. Fuzzy Sets and Systems 139(3): 515-542.

Filev, D., Yager, R.R. On the issue of obtaining OWA operator weights. Fuzzy Sets and Systems 94(2): 157-169.

Garfield, E. 2003. Why do we need algorithmic historiography? Journal of American Society for Information Science and Technology 54(3): 400-412.

Garfield, E. 2009. From the science of science to Scientometrics visualizing the history of science with HistCite software. Journal of Informetrics 3(3): 21-26.

Garfield, E., Sher, I., Torpie, R. 1964. The use of citation data in writing the history of science. Institute for Scientific Information, Philadelphia Obtained from: www.garfield.library.upenn.edu/papers/useofcitdatawritinghistofsci.pdf.

Herrera, F., Herrera-Viedma, E., Chiclana, F. 2003. A study of the origin and uses of the ordered weighted geometric operator in multicriteria decision making. International Journal of Intelligent Systems 18(6): 689-707.

Herrera-Viedma, E., Cordón, O., Luque M, Lopez AG, Muñoz AM. 2003. A model of fuzzy linguistic IRS based on multigranular linguistic information. International Journal of Approximate Reasoning 34(2-3): 221-239.

Hummon, N.P., Doreian, P. 1989. Connectivity in a citation network: The development of the DNA theory. Social Networks 11(1): 39-63.

Kacprzyk, J., Zadrożny, S. 2001. Computing with words in intelligent database querying: standalone and Internet-based applications. Information Sciences 134(1): 71-109.

Kejžar, N., Černe, S.K., Batagelj, V. 2010. Network analysis of works on clustering and classification from Web of Science. In Classification as a Tool for Research, Studies in Classification, Data Analysis, and Knowledge Organization, Locarek-Junge H, Weihs C (eds). Springer Berlin Heidelberg: Berlin, Heidelberg: 525-536.

Lee, J.D., Baek, C., Kim, H.S., Lee, J-S. 2014. Development pattern of the DEA research field: a social network analysis approach. Journal of Productivity Analysis 41(2): 175-186.

Leydesdorff, L., Vaughan, L. 2006. Co-occurrence matrices and their applications in information science: Extending ACA to the web environment. Journal of the American Society for Information Science \& Technology, 57(12): 1616-1628.

Liu, J.S., Lu, L., Lu, W.M., Lin B.J.Y. 2013. Data envelopment analysis 1978-2010: A citation-based literature survey. Omega 41(1): 3-15.

Liu, X., Chen, L. 2004. On the properties of parametric geometric OWA operator. International Journal of Approximate Reasoning 35(2): 163-178.

Llamazares, B. 2007. Choosing OWA operator weights in the field of Social Choice. Information Sciences 177(21): 47454756. 
Marichal, J. 1999. Aggregation operators for multicriteria decision aid. PhD thesis, Institute of Mathematics, University of Liège, Liège, Belgium.

Merigó, J.M. 2010. Fuzzy decision making with immediate probabilities. Computers \& Industrial Engineering 58(4): 651657.

Merigó, J.M. 2011. A unified model between the weighted average and the induced OWA operator. Expert Systems with Applications 38(9): 11560-11572.

Merigó, J.M., Casanovas, M. 2010a. Fuzzy generalized hybrid aggregation operators and its application in fuzzy decision making. International Journal of Fuzzy Systems 12(1): 15-24.

Merigó, J.M., Casanovas, M. 2010b. Decision making with distance measures and linguistic aggregation operators. International Journal of Fuzzy Systems 12(3): 190-198.

Merigó, J.M., Casanovas, M. 2010c. Induced and heavy aggregation operators with distance measures. Systems Engineering and Electronics 21(3): 431-439.

Merigó, J.M., Casanovas, M. 2010d. The fuzzy generalized OWA operator and its application in strategic decision making. Cybernetics and Systems 41(5): 359-370.

Merigó, J.M., Casanovas, M. 2011a. Decision-making with distance measures and induced aggregation operators. Computers \& Industrial Engineering 60(1): 66-76.

Merigó, J.M., Casanovas, M. 2011b. Induced aggregation operators in the Euclidean distance and its application in financial decision making. Expert Systems with Applications 38(6): 7603-7608.

Merigó, J.M., Gil-Lafuente, A.M. 2009. The induced generalized OWA operator. Information Sciences 179(6): $729-741$.

Merigó, J.M., Gil-Lafuente, A.M. 2010. New decision-making techniques and their application in the selection of financial products. Information Sciences 180(11): 2085-2094.

Merigó, J.M., Gil-Lafuente, A.M. 2011. Fuzzy induced generalized aggregation operators and its application in multiperson decision making. Expert Systems with Applications 38(8): 9761-9772.

Mitchell, H.B., Estrakh, D.D. 1998. An OWA operator with fuzzy ranks. International Journal of Intelligent Systems 13(1): 69-81.

Mitchell, H.B., Schaefer, P.A. 2000. Multiple priorities in an induced ordered weighted averaging operator. International Journal of Intelligent Systems 15(4): 317-327.

Ogryczak, W., Śliwiński, T. 2003. On solving linear programs with the ordered weighted averaging objective. European Journal of Operational Research 148(1): 80-91.

De Stefano, D., Giordano, G., Vitale, M.P. 2011. Issues in the analysis of co-authorship networks. Quality \& Quantity 45(5): 1091-1107.

Torra, V. 2004. OWA Operators in Data Modeling and Reidentification. IEEE Transactions on Fuzzy Systems 12(5): 652660.

Wang, Y.M., Luo, Y., Hua, Z. 2007. Aggregating preference rankings using OWA operator weights. Information Sciences 177(16): 3356-3363.

Wang, Y.M., Parkan, C. 2005. A minimax disparity approach for obtaining OWA operator weights. Information Sciences 175(1): 20-29.

Xu, Z. 2005. An overview of methods for determining OWA weights. International Journal of Intelligent Systems 20(8): 843-865.

$\mathrm{Xu}, \mathrm{Z}$. 2006. On generalized induced linguistic aggregation operators. International Journal of General Systems. 35(1): $17-28$.

Xu, Z.S. 2007. Intuitionistic Fuzzy Aggregation Operators. IEEE Transactions on Fuzzy Systems 15(6): 1179-1187.

Xu, Z.S., Da, Q.L. 2002a. The uncertain OWA operator. International Journal of Intelligent Systems 17(6): 569-575.

$\mathrm{Xu}$, Z.S., Da, Q.L. 2002b. The ordered weighted geometric averaging operators. International Journal of Intelligent Systems 17(7): 709-716. 
Xu, Z.S., Da, Q.L. 2003. An overview of operators for aggregating information. International Journal of Intelligent Systems 18(9): 953-969.

Yager, R.R. 1996. Constrained OWA aggregation. Fuzzy Sets and Systems 81(1): 89-101.

Yager, R.R. 1997. On the analytic representation of the Leximin ordering and its application to flexible constraint propagation. European Journal of Operational Research 102(1): 176-192.

Yager, R.R., Kreinovich, V. 1999. Decision making under interval probabilities. International Journal of Approximate Reasoning 22(3): 195-215.

Yager, R.R., 1988. On ordered weighted averaging aggregation operators in multicriteria decisionmaking. IEEE Transactions on Systems, Man, and Cybernetics 18(1): 183-190.

Yager, R.R. 1993. Families of OWA operators. Fuzzy Sets and Systems 59(2): 125-148.

Yager, R.R. 1995a. An approach to ordinal decision making. International Journal of Approximate Reasoning 12(3): 237261.

Yager, R.R. 1995b. Measures of entropy and fuzziness related to aggregation operators. Information Sciences 82(3-4): 147-166.

Yager, R.R. 1999. Induced ordered weighted averaging operators. IEEE Transactions Systems, Man, and Cybernetics, Part B: Cybernetics 29(2): 141-150.

Yager, R.R. 2002. Using fuzzy methods to model nearest neighbor rules. IEEE Transactions on systems, man, and cybernetics. Part B-Cybernetics 32(4): 512-25.

Yager, R.R. 2003. Induced aggregation operators. Fuzzy Sets and Systems 137(1): 59-69.

Yager, R.R. 2004. Generalized OWA Aggregation Operators. Fuzzy Optimization and Decision Making 3(1): 93-107.

Yager, R.R., Filev D.P. 1994. Parametrized and-like and or-like operators. International Journal of General Systems. 22(3): 297-316.

Zeng, S., Merigó, J.M., Su, W. 2013. The uncertain probabilistic OWA distance operator and its application in group decision making. Applied Mathematical Modelling 37(9): 6266-6275.

Zhao, H., Xu, Z., Ni, M., Liu, S. 2010. Generalized aggregation operators for intuitionistic fuzzy sets. International Journal of Intelligent Systems 25: 1-30. 


\title{
Supplement document
}

\section{Ordered Weighted Averaging Operators 1988-2014: A citation-based literature survey}

\author{
Ali Emrouznejad*and Marianna Marra \\ Aston Business School, Aston University, Birmingham, UK
}

1. Acar, E., Arslan, S., Yazici, A. 2008. Slim-Tree and BitMatrix index structures in image retrieval system using MPEG-7 Descriptors Book Group Authors: IEEE Conference: International Workshop on Content-Based Multimedia Indexing.

2. Afshinmanesh, F., Marandi, A., Shahabadi, M. 2008. Design of a single-feed dual-band dual-polarized printed microstrip antenna using a Boolean particle swarm optimization. IEE Transactions on Antennas and Propagation 567: 1845-1852.

3. Ahn, B. S. 2006. On the properties of OWA operator weights functions with constant level of orness. IEEE Transactions on Fuzzy Systems 144: 511-515.

4. Ahn, B. S. 2006. The uncertain OWA aggregation with weighting functions having a constant level of orness. International Journal of Intelligent Systems 215: 469-483.

5. Ahn, B. S. 2007. The OWA aggregation with uncertain descriptions on weights and input arguments. IEEE Transactions on Fuzzy Systems 156: 1130-1134.

6. Ahn, B. S. 2008. Preference relation approach for obtaining OWA operators weights. International Journal of Approximate Reasoning 472: 166-178.

7. Ahn, B. S. 2008. Some quantifier functions from weighting functions with constant value of orness. IEEE Transactions on Systems Man and Cybernetics Part B-Cybernetics 382: 540-546.

8. Ahn, B. S. 2009. Some Remarks on the LSOWA Approach for Obtaining OWA Operator Weights. International Journal of Intelligent Systems 2412: 1265-1279.

9. Ahn, B. S. 2010. A priori identification of preferred alternatives of OWA operators by relational analysis of arguments. Information Sciences 18023: 4572-4581.

10. Ahn, B. S. 2010. Determining OWA Operator Weights from Ordinal Relation on Criteria. IEEE International Conference on Systems, Man and Cybernetics: 3290-3293.

11. Ahn, B. S. 2010. Parameterized OWA operator weights: An extreme point approach. International Journal of Approximate Reasoning 517: 820-831.

12. Ahn, B. S. 2011. Compatible weighting method with rank order centroid: Maximum entropy ordered weighted averaging approach. European Journal of Operational Research 2123: 552-559.

13. Ahn, B. S. 2012. Programming-Based OWA Operator Weights With Quadratic Objective Function. IEEE Transactions on Fuzzy Systems 205: 986-992.

14. Ahn, B. S., Park, H. 2008. An Efficient Pruning Method for Decision Alternatives of OWA Operators. IEEE Transactions on Fuzzy Systems 166: 1542-1549.

\footnotetext{
${ }^{*}$ Corresponding author Email: A.Emrouznejad@aston.ac.uk
} 
15. Ahn, B. S., Park, H. 2008. Least-squared ordered weighted averaging operator weights. International Journal of Intelligent Systems 231: 33-49.

16. Ahn, B. S., S. H. Choi. 2012. Aggregation of ordinal data using ordered weighted averaging operator weights. Annals of Operations Research 2011: 1-16.

17. Al Hichri, H., Bazi, Y., Alajlan, N., Melgani, F., Malek, S., Yager, R. R. 2013. A novel fusion approach based on induced ordered weighted averaging operators for chemometric data analysis. Journal of Chemometrics 2712: 447-456.

18. Alajlan, N., Bazi, Y., Al Hichri, H. S. 2013. Using OWA Fusion Operators for the Classification of Hyperspectral Images. IEEE Journal of Selected Topics in Applied Earth Observations and Remote Sensing 62: 602-614.

19. Alonso, J. M., Magdalena, L. 2010. Combining user's preferences and quality criteria into a new index for guiding the design of fuzzy systems with a good interpretability-accuracy trade-off. IEEE International Conference on Fuzzy Systems Fuzz-IEEE 2010.

20. Amin, G. R., Emrouznejad, A. 2006. An extended minimax disparity to determine the OWA operator weights. Computers \& Industrial Engineering 503: 312-316.

21. Amin, G. R., Emrouznejad, A. 2011. Parametric aggregation in ordered weighted averaging. International Journal of Approximate Reasoning 526: 819-827.

22. Amiri, M. J., Mahiny, A. S., Hosseini, S. M. 2013. OWA Analysis for Ecological Capability Assessment in Watersheds. International Journal of Environmental Research 71: 241-254.

23. Arami, A., Barre, A., Berthelin, R., 2013. Estimation of Prosthetic Knee Angles via Data Fusion of Implantable and Wearable Sensors. IEEE International Conference on Body Sensor Networks Location: MIT Media Lab, Cambridge.

24. Aristondo, O., Luis Garcia-Lapresta, J., Lasso de la Vega, C. 2012. The gini index, the dual decomposition of aggregation functions, and the consistent measurement of inequality. International Journal of Intelligent Systems 272: 132-152.

25. Averna Valente, R. d. O., Vettorazzi, C. A. 2008. Definition of priority areas for forest conservation through the ordered weighted averaging method. Forest Ecology and Management 2566: 1408-1417.

26. Averna Valente, R. d. O., Vettorazzi, C. A. 2009. Comparison between sensibility analysis methods, used in the decision-making process through the multicriteria evaluation. Scientia Forestalis 3782: 197211.

27. Aydin, N. Y., Kentel, E., Duzgun, H. S. 2013. GIS-based site selection methodology for hybrid renewable energy systems: A case study from western Turkey. Energy Conversion and Management 701: 90-106.

28. Aymerich, F. X., Alonso, J., Cabanas, M. E.2011. Decision tree based fuzzy classifier of H-1 magnetic resonance spectra from cerebrospinal fluid samples. Fuzzy Sets and Systems 1701: 43-63.

29. Badea, A. C., Rocco S, Claudio M. Tarantola, S., Bolado, R. 2011. Composite indicators for security of energy supply using ordered weighted averaging. Reliability Engineering \& System Safety 966: 651662.

30. Badello, M. R., Moshiri, B., Araabi, B. N., Tebianian, H. 2011. A novel detection and navigation approach based on OWA fusion method. Sensor Review 314: 328-340.

31. Balezentis, A., Balezentis, T. 2011. A novel method for group multi-attribute decision making with two-tuple linguistic computing: Supplier evaluation under uncertainty. Economic Computation and Economic Cybernetics Studies and Research 454: 5-29.

32. Ballester, M. A., Luis Garcia-Lapresta, J. 2009. A recursive group decision-making procedure for choosing qualified individuals. International Journal of Intelligent Systems 248: 889-901. 
33. Basu, A., Nachtegael, M. 2009. OWA filters: A Robust Filtering Method and its Application to Color Images. IEEE Symposium on Computational Intelligence in Image and Signal Processing.

34. Beg, M. M. S., N. Ahmad, N. 2005. Measuring user satisfaction in web searching. Computational Intelligence for Modelling and Prediction. Eds S. Halgamuge and L. Wang. 2: 321-336.

35. Beliakov, G., Bustince, H., James, S., Calvo, T., Fernandez, J. 2012. Aggregation for Atanassov's intuitionistic and interval valued fuzzy sets: The median operator. IEEE Transactions on Fuzzy Systems 203: 487-498.

36. Beliakov, G., James, S. 2013. On extending generalized Bonferroni means to Atanassov orthopairs in decision making contexts. Fuzzy Sets and Systems 211: 84-98.

37. Beliakov, G., James, S., Li, G. 2011. Learning Choquet-integral-based metrics for semisupervised clustering. IEEE Transactions on Fuzzy Systems 193: 562-574.

38. Belles-Sampera, J., Merigo, J .M., Monserrat, G., Santolino, M. 2013. The connection between distortion risk measures and ordered weighted averaging operators. Insurance Mathematics \& Economics 522: 411-420.

39. Belles-Sampera, J., Merigo, J .M., Monserrat, G., Santolino, M. 2013. Some new definitions of indicators for the Choquet Integral. Aggregation Functions in Theory and in Practise. Eds H. Bustince, J. Fernandez, R. Mesiar and T. Calco. 228: 467-476.

40. Bjork, K. M. 2008. Obtaining minimum variability OWA operators under a fuzzy level of orness. Conference Proceedings: 5th International Conference on Informatics in Control, Automation and Robotics

41. Blanco, V., Ben Ali, S. E.H., Puerto, J. 2013. Minimizing ordered weighted averaging of rational functions with applications to continuous location. Computers \& Operations Research 405: 1448-1460.

42. Boongoen, T., Shen, Q. 2009. Semi-supervised OWA aggregation for link-based similarity evaluation and alias detection. EEE International Conference on Fuzzy Systems 13: 288-293.

43. Boongoen, T., Shen, Q. 2010. Nearest-neighbor guided evaluation of data reliability and its applications. IEEE Transactions on Systems Man and Cybernetics Part B-Cybernetics 406: 1622-1633.

44. Bordogna, G., Pasi, G. 2005. Personalised indexing and retrieval of heterogeneous structured documents. Information Retrieval 82: 301-318.

45. Boroushaki, S., Malczewski, J. 2008. Implementing an extension of the analytical hierarchy process using ordered weighted averaging operators with fuzzy quantifiers in ArcGIS. Computers \& Geosciences 344: 399-410.

46. Boroushaki, S., Malczewski, J. 2010. Using the fuzzy majority approach for GIS-based multicriteria group decision-making. Computers \& Geosciences 363(1): 302-312.

47. Calvo, T., Mayor, G., Torrens, J., Suner, J., Mas, M., Carbonell, M. 2000. Generation of weighting triangles associated with aggregation functions. International Journal of Uncertainty Fuzziness and Knowledge-Based Systems 84(4): 417-451.

48. Carrara, P., Bordogna, G., Boschetti, M., Brivio, P. A., Nelson, A., Stroppiana, D. 2008. A flexible multisource spatial-data fusion system for environmental status assessment at continental scale. International Journal of Geographical Information Science 22(7): 781-799.

49. Casanovas, M., Merigo, J. M. 2012. Fuzzy aggregation operators in decision making with DempsterShafer belief structure. Expert Systems with Applications 39(8): 7138-7149.

50. Chang, J. R. Shu-Ying, L., Ching-Hsue, C. 2007. Situational ME-LOWA aggregation model for evaluating the best main battle tank. 
51. Chang, J. R., Ho, T. H., Cheng, C. H., Chen, A. P. 2006. Dynamic fuzzy OWA model for group multiple criteria decision making. Soft Computing 10(7): 543-554.

52. Chang, K. H., Cheng, C. H. 2011. Evaluating the risk of failure using the fuzzy OWA and DEMATEL method. Journal of Intelligent Manufacturing 22(2): 113-129.

53. Chang, K. H., Cheng, C. H., Chang, Y. C. 2008. Reliability assessment of an aircraft propulsion system using IFS and OWA tree. Engineering Optimization 40(10): 907-921.

54. Chang, K.H., Wen, T. C. 2010. A novel efficient approach for DFMEA combining 2-tuple and the OWA operator. Expert Systems with Applications 37(3): 2362-2370.

55. Chang, S. L., Wang, R. C., Wang, S. Y. 2007. Applying a direct multi-granularity linguistic and strategy-oriented aggregation approach on the assessment of supply performance. European Journal of Operational Research 177(2): 1013-1025.

56. Chang, Y.C., Chang, K. H., Liaw, C. S. 2009. Innovative reliability allocation using the maximal entropy ordered weighted averaging method. Computers \& Industrial Engineering 57(4): 1274-1281.

57. Chen, H., Zhou, L. 2011. An approach to group decision making with interval fuzzy preference relations based on induced generalized continuous ordered weighted averaging operator. Expert Systems with Applications 38(10): 13432-13440.

58. Chen, H., Zhou, L. 2012. A relative entropy approach to group decision making with interval reciprocal relations based on COWA Operator. Group Decision and Negotiation 21(4): 585-599.

59. Chen, J., Zhu, Q., Liu, W. 2008. Safety Evaluation of City Land Use with GM-based Ordered Weighted Averaging Method. In (Eds) Li, SC; Wang, YJ; An, Y; et al. PROGRESS IN SAFETY SCIENCE AND TECHNOLOGY SERIES.

60. Chen, L., Xu, Z., Yu, X.. 2013. The ordered multiplicative modular geometric operator. KnowledgeBased Systems 39: 144-150.

61. Chen, L.-H., Hung, C. C., Tu, C. C. 2012. Considering the decision maker's attitudinal character to solve multi-criteria decision-making problems in an intuitionistic fuzzy environment. KnowledgeBased Systems 36: 129-138.

62. Chen, Q., Soc, I. C. 2009. The evaluation of ecological environment condition in mining area based on GIS and fuzzy-OWA model. Proceedings IEEE Computer Soc Conference: International Conference on Environmental Science and Information Application Technology, 3: 478-481.

63. Chen, S. M., Niou, S. J. 2011. Fuzzy multiple attributes group decision-making based on fuzzy induced OWA operators. Expert Systems with Applications 38(4): 4097-4108.

64. Chen, S. M., Wang, C. H. 2009. A generalized model for prioritized multicriteria decision making systems. Expert Systems with Applications 36(3): 4773-4783.

65. Chen, T.Y. 2012. Multiple criteria group decision-making with generalized interval-valued fuzzy numbers based on signed distances and incomplete weights. Applied Mathematical Modelling 36(7): 3023-3046.

66. Chen, Y. H., Cheng, C. H., Liu, J. 2008. Intelligent preference selection for evaluating students' learning achievement. Proceedings Third International Conference of Convergence and Hybrid Information Technology 2: 1214-1219.

67. Chen, Y. H., Cheng, C. H., Liu, J. W. 2010. Intelligent preference selection model based on NRE for evaluating student learning achievement. Computers \& Education 54(4): 916-926.

68. Chen, Y., et al. 2008. Irrigation intensification or extensification assessment: A GIS-based spatial fuzzy multi-criteria evaluation. 
69. Chen, Y., Khan, S., Paydar, Z. 2010. To retire or to expand? A fuzzy GIS-based spatial multi-criteria evaluation framework for irrigated agriculture. Irrigation and Drainage 59(2): 174-188.

70. Chen, Y., Li, W. K., Liu, S. 2011. An OWA-TOPSIS method for multiple criteria decision analysis. Expert Systems with Applications 38(5): 5205-5211.

71. Chen, Y., Paydar, Z. 2012. Evaluation of potential irrigation expansion using a spatial fuzzy multicriteria decision framework. Environmental Modelling \& Software 38: 147-157.

72. Chen, Y., Zeng, X., Happiette, M., Bruniaux, P., Ng, R. 2008. A new method of ease allowance generation for personalization of garment design. International Journal of Clothing Science and Technology 20(3): 161-173.

73. Cheng, C. H., Chang, J. R., Ho, T. H., Chen. A. P. 2005. Evaluating the airline service quality by fuzzy OWA operators. Modeling Decisions for Artificial Intelligence, Lecture Notes in Computer Science 3558: 77-88.

74. Cheng, C. H., Wang, J. W., Wu, M. C. 2009. OWA-weighted based clustering method for classification problem. Expert Systems with Applications 36(3): 4988-4995.

75. Cheng, C. H., Wei, L.Y., Liu, J. W., Chen, T. L. 2013. OWA-based ANFIS model for TAIEX forecasting. Economic Modelling 30(1): 442-448.

76. Cheng, C.H., Chang, J. R. 2006. MCDM aggregation model using situational ME-OWA and MEOWGA operators. International Journal of Uncertainty Fuzziness and Knowledge-Based Systems 14(4): 421-443.

77. Cheng, C.H., Chang, J. R., Ho, T. H. 2006. Dynamic fuzzy OWA model for evaluating the risks of software development. Cybernetics and Systems 37(8): 791-813.

78. Cheng, M., Zeng, S. 2012. Decision-Making Scheme Based on LIOWAD. Information Computing and Applications, 30(8): 236-242.

79. Cheng, M., Zeng, S. 2012. Efficient Decision-Making Scheme Based on LIOWAD. Information Computing and Applications, 30(7): 265-272.

80. Chiclana, F., Herrera, F., Herrera-Viedma, E. 2004. Rationality of induced ordered weighted operators based on the reliability of the source of information in group decision-making. Kybernetika 40(1): 121142.

81. Chiclana, F., Herrera, F., Herrera-Viedma, E., Alonso, F. 2004. Induced ordered weighted geometric operators and their use in the aggregation of multiplicative preference relations. International Journal of Intelligent Systems 19(3): 233-255.

82. Chiclana, F., Herrera, F., Herrera-Viedma, E., Alonso, F. 2007. Some induced ordered weighted averaging operators and their use for solving group decision-making problems based on fuzzy preference relations. European Journal of Operational Research 182(1): 383-399.

83. Chiclana, F., Zhou, S. M. 2013. Type-reduction of general type-2 fuzzy sets: The type-1 OWA approach. International Journal of Intelligent Systems 28(5): 505-522.

84. Cho, S. B. 1995. Fuzzy aggregation of modular neural networks with ordered weighted averaging operator. International Journal of Approximate Reasoning 13(4): 359-375.

85. Chuu, S. J. 2007. Evaluating the flexibility in a manufacturing system using fuzzy multi-attribute group decision-making with multi-granularity linguistic information. International Journal of Advanced Manufacturing Technology 323(4): 409-421.

86. Cooper, J. A., et al. 1997. Improved safety analysis through enhanced mathematical structures. Conference Proceedings IEEE International Conference on Systems, Man, and Cybernetics, 1(5): 16561661. 
87. Cuong, B. G. 1999. On group decision making under linguistic assessments. International Journal of Uncertainty Fuzziness and Knowledge-Based Systems 74: 301-308.

88. Darzentas, J., Tsagaris, C. 2000. Application of a modified OWA operator to a designer decision aiding system DDAS. International Journal of General Systems 29(1): 103-121.

89. De Marco, G., Morgan, J. 2014. On Ordered Weighted Averaging Social Optima. Journal of Optimization Theory and Applications 160(2): 623-635.

90. del Amo, A., Montero, J. Molina, E. 2001. Representation of consistent recursive rules. European Journal of Operational Research 130(1): 29-53.

91. Diaz, E. D., et al. 2005. A comprehensive OWA-based framework for result merging in metasearch. Rough Sets, Fuzzy Sets, Data Mining, and Granular Computing, Pt 2, Proceedings. D. Slezak, J. T. Yao, J. F. Peters, W. Ziarko and X. Hu. 3642: 193-201.

92. Dong, Q., Guo, Y. 2013. Multiperiod multiattribute decision-making method based on trend incentive coefficient. International Transactions in Operational Research 20(1): 141-152.

93. Dong, Y., Xu, Y., Li, H. Feng, B. 2010. The OWA-based consensus operator under linguistic representation models using position indexes. European Journal of Operational Research 203(2): 455463.

94. Dong, Y., Xu, Y., Yu, S. 2009. Linguistic multiperson decision making based on the use of multiple preference relations. Fuzzy Sets and Systems 160(5): 603-623.

95. Dursun, M., Karsak, E. E. 2010. A fuzzy MCDM approach for personnel selection. Expert Systems with Applications 37(6): 4324-4330.

96. Dursun, M., Karsak, E. E., Karadayi, M. A. 2011. A fuzzy multi-criteria group decision making framework for evaluating health-care waste disposal alternatives. Expert Systems with Applications 38(9): 11453-11462.

97. Eldrandaly, K. A. 2013. Exploring multi-criteria decision strategies in GIS with linguistic quantifiers: an extension of the analytical network process using ordered weighted averaging operators. International Journal of Geographical Information Science 271(2): 2455-2482.

98. Emrouznejad, A. 2008. MP-OWA: The most preferred OWA operator. Knowledge-Based Systems 21(8): 847-851.

99. Emrouznejad, A. 2010. SAS/OWA: ordered weighted averaging in SAS optimization. Soft Computing 14(4): 379-386.

100. Emrouznejad, A., Amin, G. R. 2010. Improving minimax disparity model to determine the OWA operator weights. Information Sciences 180(8): 1477-1485.

101. Engemann, K. J., Filev, D. P., Yager, R. R. 1996. Modelling decision making using immediate probabilities. International Journal of General Systems 24(3): 281-294.

102. Engemann, K. J., Miller, H. E., Yager, R. R. 1996. Decision making with belief structures: An application in risk management. International Journal of Uncertainty Fuzziness and Knowledge-Based Systems 4(1): 1-25.

103. Engemann, K. J., Yager, R. R. 2001. A general approach to decision making with interval probabilities. International Journal of General Systems 30(6): 623-647.

104. Fields, E. B., Okudan, G. E., Ashour, O. M. 2013. Rank aggregation methods comparison: A case for triage prioritization. Expert Systems with Applications 40(4): 1305-1311.

105. Filev, D., Yager, R. R. 1995. Analytic properties of maximum-entropy OWA operators. Information Sciences 851(3): 11-27. 
106. Fodor, J. M. Roubens 1995. On meaningfulness of means. Journal of Computational and Applied Mathematics 641-2: 103-115.

107. Fodor, J., Marichal, J. L., Roubens, M. 1995. Characterization of the ordered weighted averaging operators. IEEE Transactions on Fuzzy Systems 32: 236-240.

108. Fonooni, B., I. C. Soc 2007. Rational-emotional agent decision making algorithm design with OWA. 19th IEEE International Conference on Tools with Artificial Intelligence, Vol Ii, Proceedings: 63-66.

109. Fonooni, B., Moghadam, S. J. M. 2008. Designing financial market intelligent monitoring system based on OWA. Proceedings of the WSEAS International Conference on Applied Computing Conference, 3539.

110. Fonooni, B., Moghadam, S. J. M. 2009. Applying Induced Aggregation Operator in Designing Intelligent Monitoring System for Financial Market.

111. Fonooni, B., Moghadam, S. J. M. 2009. Automated Trading Based On Uncertain OWA In Financial Markets. Proceedings of the WSEAS International Conference on Mathematics and computers in business and economics.

112. Fuller, R. 2007. On obtaining OWA operator weights: A sort survey of recent developments. International Conference on Computational Cybernetics.

113. Fuller, R. Majlender, P. 2003. On obtaining minimal variability OWA operator weights. Fuzzy Sets and Systems 136(2): 203-215.

114. Fuller, R., Majlender, P. 2001. An analytic approach for obtaining maximal entropy OWA operator weights. Fuzzy Sets and Systems 124(1): 53-57.

115. Gader, P. D., Lee, W. H., Zhang, X. 2004. Renyi entropy with respect to Choquet capacities. IEE International Conference on Fuzzy Systems

116. Gagolewski, M., Grzegorzewski, P. 2010. Arity-Monotonic Extended Aggregation Operators. Information Processing and Management of Uncertainty in Knowledge-Based Systems: Theory and Methods, Pt 1. E. Hullermeir, R. Kruse and F. Hoffmann. 80: 693-702.

117. Garcia-Lapresta, J. L., Llamazares, B. 2001. Majority decisions based on difference of votes. Journal of Mathematical Economics 35(3): 463-481.

118. Gbanie, S. P.,Tengbe, P. B., Momoh, J. S., Medo, J., Kabba, T. B. 2013. Modelling landfill location using Geographic Information Systems GIS and Multi-Criteria Decision Analysis MCDA: Case study Bo, Southern Sierra Leone. Applied Geography 36(1): 3-12.

119. Gheysari, K., Khoei, A., Hadidi, K., Mokarram, M. 2008. Analog CMOS Implementation of order weight Average operator for fuzzy logic controller chip. IEEE Conference on Intelligent Systems 1: 222.

120. Gheysari, K., Mashoufi, B. 2011. Implementation of CMOS flexible fuzzy logic controller chip in current mode. Fuzzy Sets and Systems 185(1): 125-137.

121. Gong, Y. 2011. A combination approach for obtaining the minimize disparity OWA operator weights. Fuzzy Optimization and Decision Making 10(4)ì: 311-321.

122. Gorsevski, P. V., Jankowski, P. Gessler, P. E. 2006. An heuristic approach for mapping landslide hazard by integrating fuzzy logic with analytic hierarchy process. Control and Cybernetics 35(1): 121146.

123. Hao, J., Wang, J. H. 2008. On weighted p-quantile aggregation. International Journal of Intelligent Systems 23(3): 332-354.

124. Hermans, E., et al. 2008. Evaluation of road safety performance indicators using OWA operators. 
125. Hermans, E., Ruan, D., Brijs, T., Wets, G., Vanhoof, K. 2010. Road safety risk evaluation by means of ordered weighted averaging operators and expert knowledge. Knowledge-Based Systems 23(1): 48-52.

126. Herrera, F., Herrera-Viedma, E., Chiclana, F. 2003. A study of the origin and uses of the ordered weighted geometric operator in multicriteria decision making. International Journal of Intelligent Systems 18(6): 689-707.

127. Herrera, F., Herrera-Viedma, E., Verdegay, J. L. 1995. A sequential selection process in group decision making with a linguistic assessment approach. Information Sciences 85(4): 223-239.

128. Herrera, F., Herrera-Viedma, E., Verdegay, J. L. 1996. A linguistic decision process in group decision making. Group Decision and Negotiation 5(2): 165-176.

129. Herrera, F., Herrera-Viedma, E., Verdegay, J. L. 1996. Direct approach processes in group decision making using linguistic OWA operators. Fuzzy Sets and Systems 79(2): 175-190.

130. Herrera, F., Herrera-Viedma, E., Verdegay, J. L. 1998. Choice processes for non-homogeneous group decision making in linguistic setting. Fuzzy Sets and Systems 94(3): 287-308.

131. Herrera-Viedma, E. Peis, E. 2003. Evaluating the informative quality of documents in SGML format from judgements by means of fuzzy linguistic techniques based on computing with words. Information Processing \& Management 39(2): 233-249.

132. Herrera-Viedma, E., Alonso, S., Chiclana, F., Herrera, F., 2007. A consensus model for group decision making with incomplete fuzzy preference relations. IEEE Transactions on Fuzzy Systems 15(5): 863877.

133. Herrera-Viedma, E., Pasi, G., Lopez-Herrera, A. G., 2006. Evaluating the information quality of Web sites: A methodology based on fuzzy computing with words. Journal of the American Society for Information Science and Technology 57(4): 538-549.

134. Herrera-Viedma, E.; Alonso, S., Chiclana, F., Herrera, F., 2007. Group decision-making model with incomplete fuzzy preference relations based on additive consistency. IEEE Transactions on Systems Man and Cybernetics Part B-Cybernetics 37(1): 176-189.

135. Herrera-Viedma, E.; Peis, E.; Morales-del-Castillo, J. M. 2007. A fuzzy linguistic model to evaluate the quality of Web sites that store XML documents. International Journal of Approximate Reasoning 46(1): 226-253.

136. Hong, D. H. 2006. A note on the minimal variability OWA operator weights. International Journal of Uncertainty Fuzziness and Knowledge-Based Systems 14(6): 747-752.

137. Hong, D. H. 2011. On proving the extended minimax disparity OWA problem. Fuzzy Sets and Systems 168(1): 35-46.

138. Hu, Y. C. 2007. Fusing fuzzy association rule-based classifiers using Sugeno integral with ordered weighted averaging operators. International Journal of Uncertainty Fuzziness and Knowledge-Based Systems 15(6): 717-735.

139. Huang, S. F., Cheng, C. H. 2008. Forecasting the air quality using OWA based time series model. Proceedings of the International Conference on Machine Learning and Cybernetics 1-7: 3254-3259

140. Hurkala, J., Sliwinski, T. 2012. Fair flow optimization with advanced aggregation operators in Wireless Mesh Networks. Federated Conference on Computer Science and Information Systems Fedcsis: 415-421.

141. Huynh, V. N., Yan, H., Nakamori, Y. 2010. A target-based decision-making approach to consumeroriented evaluation model for Japanese traditional crafts. IEEE Transactions on Engineering Management 57(4): 575-588.

142. Isern, D., Marin, L., Vallas, A. 2010. The Unbalanced Linguistic Ordered Weighted Averaging Operator. Proceedingsof the IEEE International Conference on Fuzzy Systems. 
143. Jacas, J., Recasens, J. 2003. Aggregation of T-transitive relations. International Journal of Intelligent Systems 1812: 1193-1214.

144. Janev, M., Pekar, D., Jakovljevic, N. 2010. Eigenvalues Driven Gaussian Selection in continuous speech recognition using HMMs with full covariance matrices. Applied Intelligence 332: 107-116.

145. Jayaram, J., Malhotr, M. K. 2010. The differential and contingent impact of concurrency on new product development project performance: A holistic examination. Decision Sciences 41(1): 147-196.

146. Ji, Q., Liu, W., Qi, G., Bell, D.A. 2006. LCS: A linguistic combination system for ontology matching. In Knowledge Science, Engineering and Management (Eds) J. Lang, F. Lin and J. Wang, 176-189.

147. Jiang, G., Liu, Y. 2012. Research on Collaborative Forecasting Model Based on CPFR. Software Engineering and Knowledge Engineering: Theory and Practice, 11(4): 523-529.

148. Jiang, Y. P., Yu, Z. C.; Fan, Z. P. 2005. The evaluation of the customer service quality in a supply chain based on the LOWA aggregation operator. IEEE International Engineering Management Conference, 1(2): 415-418.

149. Jiang, Y., Li, B. 2006. A new ULOWA aggregation operator and its application in comprehensive evaluation. Conference proceedings International Conference on Industrial Engineering and Engineering Management Location, (Eds) Wang, XY; Shen, J. 1(5): 2316-2319.

150. Kacprzyk, J. 1996. Supporting consensus reaching under fuzziness via ordered weighted averaging OWA operators. Proceedings of Fuzzy Systems Symposium on Soft Computing in Intelligent Systems and Information processing, 453 - 458

151. Kacprzyk, J., Wilbik, A., Zadrozny, S. 2007. Linguistic summaries of time series via an OWA operator based aggregation of partial trends. 2007 IEEE International Conference on Fuzzy Systems, 1(4) 466471.

152. Kacprzyk, J., Zadrozny, S. 2001. Computing with words in intelligent database querying: standalone and Internet-based applications. Information Sciences 134(1-4): 71-109.

153. Kacprzyk, J., Zadrozny, S. 2010. Supporting Consensus Reaching Processes under Fuzzy Preferences and a Fuzzy Majority via Linguistic Summaries. Preferences and Decisions: Models and Applications. S. Greco, R. A. M. Pereira, M. Squillante, R. R. Yager and J. Kacprzyk. 257: 261-279.

154. Karakosta, C., Askounis, D. 2010. Developing countries' energy needs and priorities under a sustainable development perspective: A linguistic decision support approach. Energy for Sustainable Development 144: 330-338.

155. Kasperski, A., Zielinski, P. 2013. Bottleneck combinatorial optimization problems with uncertain costs and the OWA criterion. Operations Research Letters 416: 639-643.

156. Kazai, G., et al. 2001. A model for the representation and focussed retrieval of structured documents based on fuzzy aggregation.

157. Kazemian, M., et al. 2005. Protein secondary structure classifiers fusion using OWA. Biological and Medical Data Analysis, Proceedings. J. L. Oliveira, V. Maojo, F. MartinSanchez and A. S. Pereira. 3745: 338-345.

158. Keikha, M. F. Crestani 2009. Effectiveness of Aggregation Methods in Blog Distillation. Flexible Query Answering Systems: 8th International Conference, Fqas 2009. T. reasen, R. R. Yager, H. Bulskov, H. Christiansen and H. L. Larsen. 5822: 157-167.

159. Keikha, M. 2010. Investigation on Smoothing and Aggregation Methods in Blog Retrieval.

160. Keikha, M., Crestani, F. 2012. Linguistic aggregation methods in blog retrieval. Information Processing \& Management 483: 467-475.

161. Keikha, M., Crestani. F. 2009. Experimental results on the aggregation Methods in Blog Distillation. 
162. Kentel, E., Aral, M. M. 2007. Fuzzy multiobjective decision-making approach for groundwater resources management. Journal of Hydrologic Engineering 122: 206-217.

163. Keyhanipour, A. H., Moshiri, B., Kazemian, M., Piroozman, M., Caro, L. 2007. Aggregation of web search engines based on users' preferences in WebFusion. Knowledge-Based Systems 20(4): 321-328.

164. Khan, J. A., Sait, S. M. 2002. Fuzzy aggregating functions for multiobjective VLSI placement. Proceedings of the 2002 IEEE International Conferences on Fuzzy Systems 1-2: 831-836

165. Khan, S. A. Engelbrecht, A. P. 2007. A new fuzzy operator and its application to topology design of distributed local area networks. Information Sciences 177(13): 2692-2711.

166. Khilwani, N., Shankar, R., Tiwari, M. K 2008. Facility layout problem: an approach based on a group decision-making system and psychoclonal algorithm. International Journal of Production Research 464: 895-927.

167. Kim, Z. V. P. Singh 2014. Assessment of Environmental Flow Requirements by Entropy-Based MultiCriteria Decision. Water Resources Management 282: 459-474.

168. Klement, E. P. R. Mesiar 2011. Integral-Based Modifications of OWA-Operators. Nonlinear Mathematics for Uncertainty and Its Applications. S. Li, X. Wang, Y. Okazaki et al. 100: 325-331.

169. Koeppen, M., et al. 2011. Fuzzy Fusion Fairness Relations for the Evaluation of User Preference. IEEE International Conference on Fuzzy Systems Fuzz 2011: 2566-2574.

170. Koeppen, M., et al. 2012. Comparative Study on Meta-Heuristics for Achieving Parabolic Fairness in Wireless Channel Allocation.

171. Kojadinovic, I. J.-L. Marichal 2007. On the moments and the distribution of the Choquet integral.

172. Kojadinovic, I. J.-L. Marichal 2009. On the moments and distribution of discrete Choquet integrals from continuous distributions. Journal of Computational and Applied Mathematics 2301: 83-94.

173. Koppen, M. K. Franke 2000. Fuzzy morphologies revisited.

174. Kostreva, M. M., et al. 2004. Equitable aggregations and multiple criteria analysis. European Journal of Operational Research 1582: 362-377.

175. Kurowski, K., et al. 2010. Multicriteria, multi-user scheduling in grids with advance reservation. Journal of Scheduling 135: 493-508.

176. Kusumadewi, et al. 2007. Sensitivity Analysis of Multi-Attribute Decision Making Methods in Clinical Group Decision Support System.

177. Lai, J., et al. 2010. Aggregating Multiple Ontology Similarity Based on IOWA Operator.

178. Lamata, M. T. 2004. Ranking of alternatives with ordered weighted averaging operators. International Journal of Intelligent Systems 195: 473-482.

179. Lan, J., et al. 2013. Group decision making based on induced uncertain linguistic OWA operators. Decision Support Systems 551: 296-303.

180. Larsen, H. L. 1999. Importance weighted OWA aggregation of multicriteria queries.

181. Larsen, H. L. 2009. Multiplicative and implicative importance weighted averaging aggregation operators with accurate andness direction.

182. Le, C. A., et al. 2007. Combining classifiers for word sense disambiguation based on Dempster-Shafer theory and OWA operators. Data \& Knowledge Engineering 632: 381-396.

183. Leski, J. M. N. Henzel 2012. Generalized ordered linear regression with regularization. Bulletin of the Polish Academy of Sciences-Technical Sciences 603: 481-489.

184. Li, C., et al. 2012. Safety Risk Assessment of Complex Socio-technical System Based on Fuzzy Cognitive Maps. 
185. Li, D.-F. 2009. MULTIATTRIBUTE GROUP DECISION MAKING METHOD USING EXTENDED LINGUISTIC VARIABLES. International Journal of Uncertainty Fuzziness and Knowledge-Based Systems 176: 793-806.

186. Li, D.-F. 2010. Multiattribute decision making method based on generalized OWA operators with intuitionistic fuzzy sets. Expert Systems with Applications 3712: 8673-8678.

187. Li, D.-F. 2011. The GOWA operator based approach to multiattribute decision making using intuitionistic fuzzy sets. Mathematical and Computer Modelling 535-6: 1182-1196.

188. Li, D.-F., et al. 2010. GROUP DECISION MAKING METHODOLOGY BASED ON THE ATANASSOV'S INTUITIONISTIC FUZZY SET GENERALIZED OWA OPERATOR. International Journal of Uncertainty Fuzziness and Knowledge-Based Systems 186: 801-817.

189. Li, N. X. Huang 2012. A Combination of Inference Method for Rule Based Fuzzy Classification. Software Engineering and Knowledge Engineering: Theory and Practice, Vol 1. Y. W. Wu. 114: 411416.

190. Li, Q. IEEE 2008. A Triangular Fuzzy Number-Based Approach to Group Decision Making with Linguistic Preference Information.

191. Li, Q. IEEE 2008. An approach to multi-criteria group decision making with linguistic preference information. Proceedings of 2008 IEEE International Conference on Networking, Sensing and Control, Vols 1 and 2: 494-497.

192. Li, Q. 2008. A Method for Multi-criteria Decision Making with Linguistic Preference Information on Criteria and Alternatives.

193. Li, Q. 2011. A Study on Evalution of HR Outsourcing Providers Based on Multi-criteria Decision Making with Linguistic Preference Information. Smart Materials and Intelligent Systems, Pts 1 and 2. H. Wang, B. J. Zhang, X. Z. Liu, D. Z. Luo and S. B. Zhong. 143-144: 499-502.

194. Li, X. J. Du 2013. Adaptive and attribute-based trust model for service-level agreement guarantee in cloud computing. Iet Information Security 71: 39-50.

195. Li, X., et al. 2008. Linguistic-valued aggregation operators applied to multiple attribute group decision making.

196. Li, X., et al. 2010. A METHOD FOR MULTIPLE ATTRIBUTE GROUP DECISION MAKING BASED ON LINGUISTIC-VALUED AGGREGATION OPERATORS.

197. Li, X., et al. 2011. A multi-dimensional trust evaluation model for large-scale P2P computing. Journal of Parallel and Distributed Computing 716: 837-847.

198. Li, X., et al. 2011. RESEARCH ON TRUST PREDICTION MODEL FOR SELECTING WEB SERVICES BASED ON MULTIPLE DECISION FACTORS. International Journal of Software Engineering and Knowledge Engineering 218: 1075-1096.

199. Li, X.-Y. X.-L. Gui 2009. A Comprehensive and Adaptive Trust Model for Large-Scale P2P Networks. Journal of Computer Science and Technology 245: 868-882.

200. Li, Z., et al. 2009. Identification of Web Information using Concept Hierarchies and On-line Updates of Concept Importance. Proceedings of the Joint 2009 International Fuzzy Systems Association World Congress and 2009 European Society of Fuzzy Logic and Technology Conference: 1583-1588.

201. Liaw, C.-S., et al. 2011. ME-OWA based DEMATEL reliability apportionment method. Expert Systems with Applications 388: 9713-9723.

202. Lin, R. G. Wei 2008. Dependent Linguistic OWGA Operator. 
203. Liu, G.-h., et al. 2012. The Application of Multiple Attribute Decision Making on Radio Signal Searching. Measuring Technology and Mechatronics Automation Iv, Pts 1 and 2. Z. X. Hou. 128-129: 714-717.

204. Liu, H., et al. 2007. An approach to robot motion behaviour representation. 2007 IEEE International Conference on Fuzzy Systems, Vols 1-4: 961-966.

205. Liu, H., et al. 2013. The importance weighted continuous generalized ordered weighted averaging operator and its application to group decision making. Knowledge-Based Systems 48: 24-36.

206. Liu, H.-C., et al. 2013. Assessment of health-care waste disposal methods using a VIKOR-based fuzzy multi-criteria decision making method. Waste Management 3312: 2744-2751.

207. Liu, H.-C., et al. 2013. Induced aggregation operators in the VIKOR method and its application in material selection. Applied Mathematical Modelling 379: 6325-6338.

208. Liu, J., et al. 2013. The Continuous Quasi-OWA Operator and its Application to Group Decision Making. Group Decision and Negotiation 224: 715-738.

209. Liu, J.-W., et al. 2010. OWA rough set model for forecasting the revenues growth rate of the electronic industry. Expert Systems with Applications 371: 610-617.

210. Liu, P. R. Hu 2007. Research on evaluation of e-commerce websites based on linguistic ordered weighted averaging operator.

211. Liu, P. X. Wu 2013. Multi-attribute group decision-making method based on generalized aggregation operators in trapezoidal fuzzy linguistic variables. Journal of Computational Analysis and Applications 155: 807-816.

212. Liu, P. Y. Su 2010. The multiple-attribute decision making method based on the TFLHOWA operator. Computers \& Mathematics with Applications 609: 2609-2615.

213. Liu, W. Q. Li 2013. A Multi-criteria Decision Making Method Based on Linguistic Preference Information for IT Outsourcing Vendor Selection in Hospitals. Proceedings of the 2013 International Conference on Information, Business and Education Technology. L. Zhang, X. Li and J. Chen. 26: 341 344.

214. Liu, X. H. Lou 2008. On the equivalence of some approaches to the OWA operator and RIM quantifier determination. Fuzzy Sets and Systems 159(13): 1673-1688.

215. Liu, X. Q. Da 2008. On the properties of regular increasing monotone RIM quantifiers with maximum entropy. International Journal of General Systems 372: 167-179.

216. Liu, X. S. Yu 2012. On the Stress Function-Based OWA Determination Method With Optimization Criteria. IEEE Transactions on Systems Man and Cybernetics Part B-Cybernetics 421: 246-257.

217. Liu, X. 2008. A general model of parameterized OWA aggregation with given orness level. International Journal of Approximate Reasoning 482: 598-627.

218. Liu, X. 2010. The orness measures for two compound quasi-arithmetic mean aggregation operators. International Journal of Approximate Reasoning 513: 305-334.

219. Liu, X. 2010. THE RELATIONSHIPS BETWEEN TWO VARIABILITY AND ORNESS OPTIMIZATION PROBLEMS FOR OWA OPERATOR WITH RIM QUANTIFIER EXTENSIONS. International Journal of Uncertainty Fuzziness and Knowledge-Based Systems 185: 515-538.

220. Liu, X. 2012. Models to determine parameterized ordered weighted averaging operators using optimization criteria. Information Sciences 190: 27-55.

221. Liu, X. W. L. H. Chen 2004. On the properties of parametric geometric OWA operator. International Journal of Approximate Reasoning 352: 163-178. 
222. Liu, X. W. 2005. On the properties of equidifferent RIM quantifier with generating function. International Journal of General Systems 345: 579-594.

223. Liu, X. W., et al. 2004. Generating function representation of RIM quantifiers.

224. Liu, Y., et al. 2013. IDENTIFYING PRIORITY AREAS FOR THE CONSERVATION OF ECOSYSTEM SERVICES USING GIS-BASED MULTICRITERIA EVALUATION. Polish Journal of Ecology 613: 415430.

225. Llamazares, B. 2004. Simple and absolute special majorities generated by OWA operators. European Journal of Operational Research 1583: 707-720.

226. Llamazares, B. 2007. Choosing OWA operator weights in the field of Social Choice. Information Sciences 17721: 4745-4756.

227. Llamazares, B. 2013. An Analysis of Some Functions That Generalizes Weighted Means and OWA Operators. International Journal of Intelligent Systems 284: 380-393.

228. Loboda, T. V. 2009. Modeling fire danger in data-poor regions: a case study from the Russian Far East. International Journal of Wildland Fire 181: 19-35.

229. Lopez-de-los-Mozsa, M. C., et al. 2008. A generalized model of equality measures in network location problems. Computers \& Operations Research 353: 651-660.

230. Luo, Y., et al. 2010. Fuzzy Evaluation of IP Network Running Quality Using WOWA. 2nd IEEE International Conference on Advanced Computer Control Icacc 2010, Vol. 4: 51-55.

231. Luukka, P. O. Kurama 2013. Similarity classifier with ordered weighted averaging operators. Expert Systems with Applications 404: 995-1002.

232. Luukka, P., et al. 2013. Fuzzy Scorecards, FHOWA, and a New Fuzzy Similarity Based Ranking Method for Selection of Human Resources. 2013 IEEE International Conference on Systems, Man, and Cybernetics: 601-606.

233. Ma, F.-M. Y.-J. Guo 2011. Density-Induced Ordered Weighted Averaging Operators. International Journal of Intelligent Systems 269: 866-886.

234. Ma, F.-M. Y.-J. Guo 2013. Determination of the Attitudinal Character by Self-Evaluation for the Maximum Entropy OWA Approach. International Journal of Intelligent Systems 2811: 1089-1098.

235. Ma, F.-M., et al. 2012. Analysis of the impact of attitudinal character on the multicriteria decision making with OWA operators. International Journal of Intelligent Systems 275: 502-518.

236. Ma, F.-M., et al. 2012. Cluster-reliability-induced OWA operators. International Journal of Intelligent Systems 279: 823-836.

237. Majdan, M. W. Ogryczak 2012. Determining OWA Operator Weights by Mean Absolute Deviation Minimization. Artificial Intelligence and Soft Computing, Pt I. L. Rutkowski, M. Korytkowski, R. Scherer et al. 7267: 283-291.

238. Majlender, P. 2005. OWA operators with maximal Renyi entropy. Fuzzy Sets and Systems 1553: 340360 .

239. Makropoulos, C. K. D. Butler 2006. Spatial ordered weighted averaging: incorporating spatially variable attitude towards risk in spatial multi-criteria decision-making. Environmental Modelling \& Software 211: 69-84.

240. Makropoulos, C. K., et al. 2003. Fuzzy logic spatial decision support system for urban water management. Journal of Water Resources Planning and Management-Asce 1291: 69-77.

241. Malczewski, J. 2006. Ordered weighted averaging with fuzzy quantifiers: GIS-based multicriteria evaluation for land-use suitability analysis. International Journal of Applied Earth Observation and Geoinformation 84: 270-277. 
242. Malczewski, J., et al. 2003. GIS - multicriteria evaluation with ordered weighted averaging OWA: case study of developing watershed management strategies. Environment and Planning A 3510: 1769-1784.

243. Marichal, J. L. P. Mathonet 1999. A characterization of the ordered weighted averaging functions based on the ordered bisymmetry property. IEEE Transactions on Fuzzy Systems 71: 93-96.

244. Mees, W. R. Heremans 2012. Multisensor data fusion for IED threat detection. Optics and Photonics for Counterterrorism, Crime Fighting, and Defence Viii. C. Lewis and D. Burgess. 8546.

245. Meng, D. Z. Pei 2013. On weighted unbalanced linguistic aggregation operators in group decision making. Information Sciences 223: 31-41.

246. Merigo, J. M. A. A. Gil-Lafuente 2008. THE LINGUISTIC GENERALIZED OWA OPERATOR AND ITS APPLICATION INSTRATEGIC DECISION MAKING.

247. Merigo, J. M. A. M. Gil-Lafuente 2009. The induced generalized OWA operator. Information Sciences 1796: 729-741.

248. Merigo, J. M. A. M. Gil-Lafuente 2010. DECISION MAKING TECHNIQUES IN A UNIFIED MODEL BETWEEN THE WEIGHTED AVERAGE AND THE OWA OPERATOR.

249. Merigo, J. M. A. M. Gil-Lafuente 2010. New decision-making techniques and their application in the selection of financial products. Information Sciences 18011: 2085-2094.

250. Merigo, J. M. A. M. Gil-Lafuente 2010. THE INDUCED GENERALIZED OWAWA DISTANCE OPERATOR.

251. Merigo, J. M. A. M. Gil-Lafuente 2011. Decision-making in sport management based on the OWA operator. Expert Systems with Applications 388: 10408-10413.

252. Merigo, J. M. A. M. Gil-Lafuente 2011. Fuzzy induced generalized aggregation operators and its application in multi-person decision making. Expert Systems with Applications 388: 9761-9772.

253. Merigo, J. M. A. M. Gil-Lafuente 2011. OWA OPERATORS IN HUMAN RESOURCE MANAGEMENT. Economic Computation and Economic Cybernetics Studies and Research 452: 153168.

254. Merigo, J. M. A. M. Gil-Lafuente 2012. A Method for Decision Making with the OWA Operator. Computer Science and Information Systems 91: 357-380.

255. Merigo, J. M. A. M. Gil-Lafuente 2013. A Method for Decision Making Based on Generalized Aggregation Operators. International Journal of Intelligent Systems 285: 453-473.

256. Merigo, J. M. A. M. Gil-Lafuente 2013. Induced 2-tuple linguistic generalized aggregation operators and their application in decision-making. Information Sciences 236: 1-16.

257. Merigo, J. M. G. Wei 2011. PROBABILISTIC AGGREGATION OPERATORS AND THEIR APPLICATION IN UNCERTAIN MULTI-PERSON DECISION-MAKING. Technological and Economic Development of Economy 172: 335-351.

258. Merigo, J. M. IEEE 2010. Fuzzy Generalized Aggregation Operators in a Unified Model between the Probability, the Weighted Average and the OWA Operator. 2010 IEEE International Conference on Fuzzy Systems Fuzz-IEEE 2010.

259. Merigo, J. M. K. J. Engemann 2010. FUZZY DECISION MAKING WITH PROBABILITIES AND INDUCED AGGREGATION OPERATORS.

260. Merigo, J. M. M. Casanovas 2008. Decision making with Dempster-Shafer belief structure using the 2tuple linguistic representation model.

261. Merigo, J. M. M. Casanovas 2008. Decision making with distance measures and induced aggregation operators. 
262. Merigo, J. M. M. Casanovas 2008. FUZZY INDUCED AGGREGATION OPERATORS IN DECISION MAKING WITH DEMPSTER-SHAFER BELIEF STRUCTURE.

263. Merigo, J. M. M. Casanovas 2008. THE GENERALIZED HYBRID AVERAGING OPERATOR AND ITS APPLICATION INFINANCIAL DECISION MAKING.

264. Merigo, J. M. M. Casanovas 2009. Induced Aggregation Operators in Decision Making with the Dempster-Shafer Belief Structure. International Journal of Intelligent Systems 248: 934-954.

265. Merigo, J. M. M. Casanovas 2010. A NEW DECISION MAKING METHOD BASED ON DISTANCE MEASURES AND ITS APPLICATION IN EDUCATIONAL MANAGEMENT. 4th International Technology, Education and Development Conference Inted 2010: 987-998.

266. Merigo, J. M. M. Casanovas 2010. DEALING WITH UNCERTAIN INFORMATION IN THE INDUCED PROBABILISTIC OWA OPERATOR.

267. Merigo, J. M. M. Casanovas 2010. Decision Making with Distance Measures and Linguistic Aggregation Operators. International Journal of Fuzzy Systems 123: 190-198.

268. Merigo, J. M. M. Casanovas 2010. FUZZY AGGREGATION OPERATORS AND ITS APPLICATION IN THE SELECTION OF PROFESSORS. 4th International Technology, Education and Development Conference Inted 2010: 975-986.

269. Merigo, J. M. M. Casanovas 2010. Fuzzy Generalized Hybrid Aggregation Operators and its Application in Fuzzy Decision Making. International Journal of Fuzzy Systems 121: 15-24.

270. Merigo, J. M. M. Casanovas 2010. Induced and heavy aggregation operators with distance measures. Journal of Systems Engineering and Electronics 213: 431-439.

271. Merigo, J. M. M. Casanovas 2010. The Fuzzy Generalized OWA Operator and Its Application in Strategic Decision Making. Cybernetics and Systems 415: 359-370.

272. Merigo, J. M. M. Casanovas 2010. USING DISTANCE MEASURES IN HEAVY AGGREGATION OPERATORS.

273. Merigo, J. M. M. Casanovas 2011. A New Minkowski Distance Based on Induced Aggregation Operators. International Journal of Computational Intelligence Systems 42: 123-133.

274. Merigo, J. M. M. Casanovas 2011. Decision-making with distance measures and induced aggregation operators. Computers \& Industrial Engineering 601: 66-76.

275. Merigo, J. M. M. Casanovas 2011. FUZZY GROUP DECISION MAKING IN RESEARCH MANAGEMENT. Edulearn11: 3rd International Conference on Education and New Learning Technologies. L. G. Chova, D. M. Belenguer and A. L. Martinez: 6057-6064.

276. Merigo, J. M. M. Casanovas 2011. Generalized Aggregation Operators in Decision Making with Dempster-Shafer Belief Structure. Information-an International Interdisciplinary Journal 148: 27112732.

277. Merigo, J. M. M. Casanovas 2011. Induced aggregation operators in the Euclidean distance and its application in financial decision making. Expert Systems with Applications 386: 7603-7608.

278. Merigo, J. M. M. Casanovas 2011. Induced and uncertain heavy OWA operators. Computers \& Industrial Engineering 601: 106-116.

279. Merigo, J. M. R. R. Yager 2013. GENERALIZED MOVING AVERAGES, DISTANCE MEASURES AND OWA OPERATORS. International Journal of Uncertainty Fuzziness and Knowledge-Based Systems 214: 533-559.

280. Merigo, J. M. 2009. On the Use of the OWA Operator in the Weighted Average and its Application in Decision Making. World Congress on Engineering 2009, Vols I and Ii. S. I. Ao, L. Gelman, D. W. L. Hukins, A. Hunter and A. M. Korsunsky: 82-87. 
281. Merigo, J. M. 2009. Probabilistic Decision Making with the OWA Operator and its Application in Investment Management. Proceedings of the Joint 2009 International Fuzzy Systems Association World Congress and 2009 European Society of Fuzzy Logic and Technology Conference: 1364-1369.

282. Merigo, J. M. 2010. A METHOD FOR DECISION MAKING BASED ON PROBABILISTIC INFORMATION AND DISTANCE MEASURES. Edulearn10: International Conference on Education and New Learning Technologies.

283. Merigo, J. M. 2010. Fuzzy decision making with immediate probabilities. Computers \& Industrial Engineering 584: 651-657.

284. Merigo, J. M. 2010. INDUCED GENERALIZED AGGREGATION OPERATORS IN THE WEIGHTED AVERAGE.

285. Merigo, J. M. 2010. INDUCED GENERALIZED PROBABILISTIC OWAWA OPERATOR.

286. Merigo, J. M. 2010. ON THE UNIFICATION BETWEEN THE PROBABILITY, THE WEIGHTED AVERAGE AND THE OWA OPERATOR.

287. Merigo, J. M. 2011. A unified model between the weighted average and the induced OWA operator. Expert Systems with Applications 389: 11560-11572.

288. Merigo, J. M. 2011. Fuzzy Multi-Person Decision Making with Fuzzy Probabilistic Aggregation Operators. International Journal of Fuzzy Systems 133: 163-174.

289. Merigo, J. M., et al. 2009. Induced Aggregation Operators in the Generalized Adequacy Coefficient. World Congress on Engineering 2009, Vols I and Ii. S. I. Ao, L. Gelman, D. W. L. Hukins, A. Hunter and A. M. Korsunsky: 7-11.

290. Merigo, J. M., et al. 2009. On the Use of the Uncertain Induced OWA Operator and the Uncertain Weighted Average and its Application in Tourism Management.

291. Merigo, J. M., et al. 2010. LINGUISTIC AGGREGATION OPERATORS FOR LINGUISTIC DECISION MAKING BASED ON THE DEMPSTER-SHAFER THEORY OF EVIDENCE. International Journal of Uncertainty Fuzziness and Knowledge-Based Systems 183: 287-304.

292. Merigo, J. M., et al. 2010. Probabilistic Aggregation Operators with the Induced Generalized OWA Operator. 2010 IEEE International Conference on Fuzzy Systems Fuzz-IEEE 2010.

293. Merigo, J. M., et al. 2011. DECISION MAKING WITH THE INDUCED GENERALIZED ADEQUACY COEFFICIENT. Applied and Computational Mathematics 102: 321-339.

294. Merigo, J. M., et al. 2011. Generalization of the linguistic aggregation operator and its application in decision making. Journal of Systems Engineering and Electronics 224: 593-603.

295. Merigo, J. M., et al. 2011. MAKING DECISIONS IN EDUCATIONAL MANAGEMENT WITH PROBABILISTIC AND IMPRECISE INFORMATION. Edulearn11: 3rd International Conference on Education and New Learning Technologies. L. G. Chova, D. M. Belenguer and A. L. Martinez: 60416051.

296. Merigo, J. M., et al. 2011. Soft Computing Techniques for Decision Making with Induced Aggregation Operators. Information-an International Interdisciplinary Journal 146: 2019-2039.

297. Merigo, J. M., et al. 2012. Decision making in the European Union under risk and uncertainty. European Journal of International Management 65: 590-609.

298. Merigo, J. M., et al. 2012. GROUP DECISION-MAKING WITH GENERALIZED AND PROBABILISTIC AGGREGATION OPERATORS. International Journal of Innovative Computing Information and Control 87A: 4823-4835.

299. Merigo, J. M., et al. 2012. Induced and Linguistic Generalized Aggregation Operators and Their Application in Linguistic Group Decision Making. Group Decision and Negotiation 214: 531-549. 
300. Merigo, J. M., et al. 2012. Uncertain induced aggregation operators and its application in tourism management. Expert Systems with Applications 391: 869-880.

301. Merigo, J. M., et al. 2013. DECISION MAKING WITH DEMPSTER-SHAFER BELIEF STRUCTURE AND THE OWAWA OPERATOR. Technological and Economic Development of Economy 19: S100S118.

302. Merigo, J. M., et al. 2013. DECISION MAKING WITH INDUCED AGGREGATION OPERATORS AND THE ADEQUACY COEFFICIENT. Economic Computation and Economic Cybernetics Studies and Research 471: 185-202.

303. Merigo, J. M., et al. 2013. Group decision making with distance measures and probabilistic information. Knowledge-Based Systems 40: 81-87.

304. Mesiar, R. S. Saminger 2004. Domination of ordered weighted averaging operators over t-norms. Soft Computing 88: 562-570.

305. Min, Z., et al. 2008. Dynamic Evaluation of Supplier Performance Based on Product Strategy.

306. Mitchell, H. B. D. D. Estrakh 1997. A modified OWA operator and its use in lossless DPCM image compression. International Journal of Uncertainty Fuzziness and Knowledge-Based Systems 54: 429436.

307. Mitchell, H. B. D. D. Estrakh 1998. An OWA operator with fuzzy ranks. International Journal of Intelligent Systems 131: 69-81.

308. Mitchell, H. B. P. A. Schaefer 2000. Multiple priorities in an induced ordered weighted averaging operator. International Journal of Intelligent Systems 154: 317-327.

309. Mokarram, M., et al. 2011. Land suitability evaluation using ordered weight averaging with fuzzy quantifier in Shavoor plain, Iran. Research on Crops 122: 593-599.

310. Moshiri, B., et al. 2006. Application of OWA based classifier fusion in diagnosis and treatment offering for female urinary incontinence. AI 2006: Advances in Artificial Intelligence, Proceedings. A. Sattar and B. H. Kang. 4304: 433-442.

311. Murata, T., et al. 1998. Formulation of multi-objective fuzzy scheduling problems using OWA operator.

312. Muzychuk, A. 2011. OWA Weight Updating in Repeated Decision Making under the Influence of Additional Information. International Journal of Intelligent Systems 267: 591-602.

313. Nadi, S. M. R. Delavar 2011. Multi-criteria, personalized route planning using quantifier-guided ordered weighted averaging operators. International Journal of Applied Earth Observation and Geoinformation 133: 322-335.

314. Naether, W. K. Waelder 2007. Applying fuzzy measures for considering interaction effects in root dispersal models. Fuzzy Sets and Systems 1585: 572-582.

315. Nasibov, E. C. Kandemir-Cavas 2011. OWA-based linkage method in hierarchical clustering: Application on phylogenetic trees. Expert Systems with Applications 3810: 12684-12690.

316. Nawaz, A. A. Khanum 2011. Ranked Neuro Fuzzy Inference System RNFIS for Information Retrieval. Advances in Neural Networks - Isnn 2011, Pt I. D. Liu, H. G. Zhang, M. Polycarpou, C. Alippi and H. He. 6675: 578-586.

317. Nemmour, H. Y. Chibani 2005. Neural network combination by fuzzy integral for robust change detection in remotely sensed imagery. Eurasip Journal on Applied Signal Processing 200514: 21872195.

318. Nettleton, D. R. Baeza-Yates 2008. Web Retrieval: Techniques for the Aggregation and Selection of Queries and Answers. International Journal of Intelligent Systems 2312: 1223-1234. 
319. Nusrat, E. K. Yamada 2013. A DESCRIPTIVE DECISION-MAKING MODEL UNDER UNCERTAINTY: COMBINATION OF DEMPSTER-SHAFER THEORY AND PROSPECT THEORY. International Journal of Uncertainty Fuzziness and Knowledge-Based Systems 211: 79-102.

320. Ogryczak, W. T. Sliwinski 2003. On solving linear programs with the ordered weighted averaging objective. European Journal of Operational Research 1481: 80-91.

321. Ogryczak, W. T. Sliwinski 2007. On decision support under risk by the WOWA optimization. Symbolic and Quantitative Approaches to Reasoning with Uncertainty, Proceedings. K. Mellouli. 4724: 779-790.

322. Ogryczak, W. T. Sliwinski 2007. On optimization of the importance weighted OWA aggregation of multiple criteria. Computational Science and Its Applications - ICCSA 2007, Pt 1, Proceedings. O. Gervasi and M. L. Gavrilova. 4705: 804-817.

323. Ogryczak, W. T. Sliwinski 2009. On efficient WOWA optimization for decision support under risk. International Journal of Approximate Reasoning 506: 915-928.

324. Ohagan, M. 1990. A FUZZY NEURON BASED ON MAXIMUM-ENTROPY ORDERED WEIGHTED AVERAGING. Twenty-Fourth Asilomar Conference on Signals, Systems \& Computers, Vols 1 and 2: 618-623.

325. Ohagan, M. 1991. A FUZZY NEURON BASED UPON MAXIMUM-ENTROPY ORDERED WEIGHTED AVERAGING. Lecture Notes in Computer Science 521: 598-609.

326. Ohagan, M. 1991. A FUZZY NEURON BASED UPON MAXIMUM-ENTROPY ORDERED WEIGHTED AVERAGING. Uncertainty in Knowledge Bases. B. Bouchonmeunier, R. R. Yager and L. A. Zadeh. 521: 598-609.

327. Okur, A., et al. 2009. Using OWA aggregation technique in QFD: a case study in education in a textile engineering department. Quality \& Quantity 436: 999-1009.

328. Pei, Z. L. Yi 2006. A new aggregation operator of linguistic information and its properties.

329. Pei, Z., et al. 2005. Gathering linguistic information in distributed intelligent agent on the Internet.

330. Pei, Z., et al. 2007. Handling linguistic web information based on a multi-agent system. International Journal of Intelligent Systems 225: 435-453.

331. Pei, Z., et al. 2013. A LINGUISTIC AGGREGATION OPERATOR INCLUDING WEIGHTS FOR LINGUISTIC VALUES AND EXPERTS IN GROUP DECISION MAKING. International Journal of Uncertainty Fuzziness and Knowledge-Based Systems 216: 927-943.

332. Pelaez, J. I. 2001. AMA: An OWA operator based on the majority process. Computational Intelligence: Theory and Applications, Proceedings. B. Reusch. 2206: 937-949.

333. Peng, D.-H., et al. 2013. A Direct Approach Based on C-2-IULOWA Operator for Group Decision Making with Uncertain Additive Linguistic Preference Relations. Journal of Applied Mathematics.

334. Preethi, G. A. C. Chandrasekar 2013. A Network Selection Algorithm Based on AHP-OWA Methods.

335. Qi, X.-W., et al. 2013. Some Generalized Dependent Aggregation Operators with Interval-Valued Intuitionistic Fuzzy Information and Their Application to Exploitation Investment Evaluation. Journal of Applied Mathematics.

336. Qian, G., et al. 2006. Extended IOWA operator and its application to group decision making with linguistic preference information.

337. Qu, Z. B. Ge 2008. Implementation of mail filtering based on multi-attribute group decision making.

338. Rahman, M. A., et al. 2012. A new spatial multi-criteria decision support tool for site selection for implementation of managed aquifer recharge. Journal of Environmental Management 99: 61-75. 
339. Rahman, M. A., et al. 2013. An integrated study of spatial multicriteria analysis and mathematical modelling for managed aquifer recharge site suitability mapping and site ranking at Northern Gaza coastal aquifer. Journal of Environmental Management 124: 25-39.

340. Rahmani, M. A. M. Zarghami 2013. A new approach to combine climate change projections by ordered weighting averaging operator; applications to northwestern provinces of Iran. Global and Planetary Change 102: 41-50.

341. Rahmanimanesh, M. S. Jalili 2013. ADAPTIVE ORDERED WEIGHTED AVERAGING FOR ANOMALY DETECTION IN CLUSTER-BASED MOBILE AD HOC NETWORKS. Iranian Journal of Fuzzy Systems 102: 83-109.

342. Rajabi, M., et al. 2012. Susceptibility mapping of visceral leishmaniasis based on fuzzy modelling and group decision-making methods. Geospatial Health 71: 37-50.

343. Reformat, M. R. R. Yager 2008. Building ensemble classifiers using belief functions and OWA operators. Soft Computing 126: 543-558.

344. Reformat, M. Z. S. K. Golmohammadi 2010. Rule- and OWA-based Semantic Similarity for User Profiling. International Journal of Fuzzy Systems 122: 87-102.

345. Reformat, M. Z., et al. 2011. Human-inspired Identification of High-level Concepts using OWA and Linguistic Quantifiers. International Journal of Computers Communications \& Control 63: 473-502.

346. Renaud, J., et al. 2008. Weights determination of OWA operators by parametric identification. Mathematics and Computers in Simulation 775-6: 499-511.

347. Ribeiro, R. A. R. A. M. Pereira 2003. Generalized mixture operators using weighting functions: A comparative study with WA and OWA. European Journal of Operational Research 1452: 329-342.

348. Rinner, C., et al. 2010. The Role of Maps in Neighborhood-level Heat Vulnerability Assessment for the City of Toronto. Cartography and Geographic Information Science 371: 31-44.

349. Robinson, J. P. H. E. C. Amirtharaj 2012. A Search for the Correlation Coefficient of Triangular and Trapezoidal Intuitionistic Fuzzy Sets for Multiple Attribute Group Decision Making. Mathematical Modelling and Scientific Computation. P. Balasubramaniam and R. Uthayakumar. 283: 333-342.

350. Robinson, T. P., et al. 2010. Comparison of alternative strategies for invasive species distribution modeling. Ecological Modelling 22119: 2261-2269.

351. Rocco S, C. M., et al. 2010. Composite indicators for security of energy supply in Europe using ordered weighted averaging.

352. Rodger, J. A., et al. 2014. Decision making using a fuzzy induced linguistic ordered weighted averaging approach for evaluating risk in a supply chain. International Journal of Advanced Manufacturing Technology 701-4: 711-723.

353. Ryoke, M., et al. 2008. Personalized recommendation for traditional crafts using fuzzy correspondence analysis with kansei data and OWA operator. Interval / Probabilistic Uncertainty and Non-Classical Logics. V. N. Huynh, Y. Nakamori, H. Ono et al. 46: 311-325.

354. Sadiq, R. S. Tesfamariam 2007. Probability density functions based weights for ordered weighted averaging OWA operators: An example of water quality indices. European Journal of Operational Research 1823: 1350-1368.

355. Sadiq, R. S. Tesfamariam 2008. Developing environmental indices using fuzzy numbers ordered weighted averaging FN-OWA operators. Stochastic Environmental Research and Risk Assessment 224: 495-505.

356. Sadiq, R., et al. 2007. Water quality failures in distribution networks - Risk analysis using fuzzy logic and evidential reasoning. Risk Analysis 275: 1381-1394. 
357. Sadiq, R., et al. 2010. Integrating indicators for performance assessment of small water utilities using ordered weighted averaging OWA operators. Expert Systems with Applications 377: 4881-4891.

358. Sait, S. M., et al. 2001. Fuzzy simulated evolution for power and performance optimization of VLSI placement. Ijcnn'01: International Joint Conference on Neural Networks, Vols 1-4, Proceedings: 738743.

359. Salahshoor, K., et al. 2010. Fault detection and diagnosis of an industrial steam turbine using fusion of SVM support vector machine and ANFIS adaptive neuro-fuzzy inference system classifiers. Energy 3512: 5472-5482.

360. Salguero, A. F. Araque 2010. Integration of Similar Evolving Data Sources for Supporting Decision Making Tasks. Journal of Universal Computer Science 161: 22-36.

361. Sanchez-Hernandez, G., et al. 2013. Ranking and selection of unsupervised learning marketing segmentation. Knowledge-Based Systems 44: 20-33.

362. Sang, X., et al. 2014. Parametric Weighting Function for WOWA Operator and Its Application in Decision Making. International Journal of Intelligent Systems 292: 119-136.

363. Sener, Z. E. E. Karsak 2012. A decision model for setting target levels in software quality function deployment to respond to rapidly changing customer needs. Concurrent Engineering-Research and Applications 201: 19-29.

364. Sharifnasab, H., et al. 2009. DECISION SUPPORT SYSTEM BY ORDERED WEIGHT AVERAGING OWA METHOD. Computer and Computing Technologies in Agriculture Ii, Vol 1. D. Li and C. Zhao. 293: 613-623.

365. Sharma, S. K., et al. 2012. Choosing the best Twenty20 cricket batsmen using ordered weighted averaging. International Journal of Performance Analysis in Sport 123: 614-628.

366. Shen, W.-J., et al. 2013. An effective and effecient peptide binding prediction approach for a broad set of HLA-DR molecules based on ordered weighted averaging of binding pocket profiles. Proteome Science 11.

367. Sliwinski, T. 2013. Fair Resource Allocation in Multi-commodity Networks. New Trends in Databases and Information Systems. M. Pechenizkiy and M. Wojciechowski. 185: 261-269.

368. Smith, P. N. 2006. Flexible aggregation in multiple attribute decision making: Application to the Kuranda Range Road upgrade. Cybernetics and Systems 371: 1-22.

369. Smolikova, R. M. P. Wachowiak 2002. Aggregation operators for selection problems. Fuzzy Sets and Systems 1311: 23-34.

370. Snasel, V., et al. 2007. Fusing data and optimizing queries for intelligent search.

371. Squillante, M. V. Ventre 2010. Assessing False Consensus Effect in a Consensus Enhancing Procedure. International Journal of Intelligent Systems 253: 274-285.

372. Su, W., et al. 2013. A method for fuzzy group decision making based on induced aggregation operators and Euclidean distance. International Transactions in Operational Research 204: 579-594.

373. Su, W., et al. 2013. UNCERTAIN GROUP DECISION-MAKING WITH INDUCED AGGREGATION OPERATORS AND EUCLIDEAN DISTANCE. Technological and Economic Development of Economy 193: 431-447.

374. Su, W., et al. 2014. Atanassov's intuitionistic linguistic ordered weighted averaging distance operator and its application to decision making. Journal of Intelligent \& Fuzzy Systems 263: 1491-1502.

375. Su, Z.-x., et al. 2011. Some induced intuitionistic fuzzy aggregation operators applied to multiattribute group decision making. International Journal of General Systems 408: 805-835. 
376. Su, Z.-x., et al. 2012. Induced generalized intuitionistic fuzzy OWA operator for multi-attribute group decision making. Expert Systems with Applications 392: 1902-1910.

377. Suo, M. Q., et al. 2012. Multicriteria decision making under uncertainty: An advanced ordered weighted averaging operator for planning electric power systems. Engineering Applications of Artificial Intelligence 251: 72-81.

378. Szidarovszky, F. M. Zarghami 2009. COMBINING FUZZY QUANTIFIERS AND NEAT OPEPRATORS FOR SOFT COMPUTING. Iranian Journal of Fuzzy Systems 61: 15-25.

379. Taber, R., et al. 2001. Small-sample quantization effects on the equilibrium behavior of combined fuzzy cognitive maps.

380. Taber, R., et al. 2007. Quantization effects on the equilibrium behavior of combined fuzzy cognitive maps. International Journal of Intelligent Systems 222: 181-202.

381. Tan, C. X. Chen 2010. Induced Choquet Ordered Averaging Operator and Its Application to Group Decision Making. International Journal of Intelligent Systems 251: 59-82.

382. Teresa Lamata, M. E. Cables Perez 2012. Obtaining OWA operators starting from a linear order and preference quantifiers. International Journal of Intelligent Systems 273: 242-258.

383. Tesfamariam, S. R. Sadiq 2008. Probabilistic risk analysis using ordered weighted averaging OWA operators. Stochastic Environmental Research and Risk Assessment 221: 1-15.

384. Tokhmechi, B., et al. 2009. A novel approach proposed for fractured zone detection using petrophysical logs. Journal of Geophysics and Engineering 64: 365-373.

385. Torra, V. Z. Lv 2009. On the WOWA Operator and Its Interpolation Function. International Journal of Intelligent Systems 2410: 1039-1056.

386. Triantakonstantis, D. P., et al. 2013. Autologistic regression and multicriteria evaluation models for the prediction of forest expansion. New Forests 442: 163-181.

387. Victor, P., et al. 2011. Practical aggregation operators for gradual trust and distrust. Fuzzy Sets and Systems 1841: 126-147.

388. Wang, C., et al. 2009. Fuzzy Group Decision Making Method and Its Application. Advances in Neural Networks - Isnn 2009, Pt 1, Proceedings. W. Yu, H. He and N. Zhang. 5551: 1090-1097.

389. Wang, C.-H. H. Luh 2006. Network dimensioning problems of applying achievement functions.

390. Wang, H., et al. 2014. PRIORITIZED AGGREGATION FOR NON-HOMOGENEOUS GROUP DECISION MAKING IN WATER RESOURCE MANAGEMENT. Economic Computation and Economic Cybernetics Studies and Research 481: 247-257.

391. Wang, J.-H. J. Hao 2009. An approach to aggregation of ordinal information in multi-criteria multiperson decision making using Choquet integral of Fubini type. Fuzzy Optimization and Decision Making 84: 365-380.

392. Wang, J.-Q., et al. 2012. MULTI-CRITERIA DECISION-MAKING METHOD BASED ON INDUCED INTUITIONISTIC NORMAL FUZZY RELATED AGGREGATION OPERATORS. International Journal of Uncertainty Fuzziness and Knowledge-Based Systems 204: 559-578.

393. Wang, Q., et al. 2010. A Numerical Method of Evaluating Brownfields using Fuzzy Boundaries and Fuzzy Real Options. IEEE International Conference on Systems, Man and Cybernetics.

394. Wang, S., et al. 2009. Generalized ordered weighted averaging operators based methods for MADM in intuitionistic fuzzy set setting. Journal of Systems Engineering and Electronics 206: 1247-1254.

395. Wang, S.-Y. 2008. Applying 2-tuple multigranularity linguistic variables to determine the supply performance in dynamic environment based on product-oriented strategy. IEEE Transactions on Fuzzy Systems 161: 29-39. 
396. Wang, W. X. Liu 2012. Intuitionistic Fuzzy Information Aggregation Using Einstein Operations. IEEE Transactions on Fuzzy Systems 205: 923-938.

397. Wang, W. X. Liu 2013. Interval-valued intuitionistic fuzzy hybrid weighted averaging operator based on Einstein operation and its application to decision making. Journal of Intelligent \& Fuzzy Systems 252: $279-290$.

398. Wang, W. 2014. Comment on Some hybrid weighted averaging operators and their application to decision making. Information Fusion 16: 84-85.

399. Wang, W., et al. 2012. Interval-valued intuitionistic fuzzy aggregation operators. Journal of Systems Engineering and Electronics 234: 574-580.

400. Wang, X. 2008. Fuzzy number intuitionistic fuzzy arithmetic aggregation operators. International Journal of Fuzzy Systems 102: 104-111.

401. Wang, X.-F., et al. 2012. General fuzzy number intuitionistic fuzzy arithmetic aggregation operators based on fuzzy structured element. Proceedings of the 2012 24th Chinese Control and Decision Conference: 2640-2645.

402. Wang, X.-F., et al. 2014. Multi-criteria group decision making method based on intuitionistic linguistic aggregation operators. Journal of Intelligent \& Fuzzy Systems 261: 115-125.

403. Wang, X.-q., et al. 2008. Some New Aggregation Operators and Their Application in Group Decisionmaking Based on Fuzzy Preference Relations.

404. Wang, Y. M. C. Parkan 2005. A minimax disparity approach for obtaining OWA operator weights. Information Sciences 1751-2: 20-29.

405. Wang, Y.-M. K.-S. Chin 2011. The use of OWA operator weights for cross-efficiency aggregation. Omega-International Journal of Management Science 395: 493-503.

406. Wang, Y.-M., et al. 2007. Aggregating preference rankings using OWA operator weights. Information Sciences 17716: 3356-3363.

407. Wang, Y.-M., et al. 2007. Two new models for determining OWA operator weights. Computers \& Industrial Engineering 522: 203-209.

408. Wang, Z., et al. 2011. An Information Fusion Based Multi-Agent Control System for Indoor Energy and Comfort Management in Smart and Green Buildings. 2011 IEEE Power and Energy Society General Meeting.

409. Wang, Z., et al. 2012. Multi-agent control system with information fusion based comfort model for smart buildings. Applied Energy 99: 247-254.

410. Wei, C. X. Tang 2012. Generalized prioritized aggregation operators. International Journal of Intelligent Systems 276: 578-589.

411. Wei, G. H. Yao 2006. Extended IOWA operator and its application to group decision making with linguistic information.

412. Wei, G. U. Alfred 2007. Dependent OWGA operator.

413. Wei, G. U. Alfred 2007. Induced uncertain pure linguistic OWA operator and its application.

414. Wei, G. X. Zhao 2012. Some dependent aggregation operators with 2-tuple linguistic information and their application to multiple attribute group decision making. Expert Systems with Applications 395: 5881-5886.

415. Wei, G. X. Zhao 2013. Induced hesitant interval-valued fuzzy Einstein aggregation operators and their application to multiple attribute decision making. Journal of Intelligent \& Fuzzy Systems 244: 789-803. 
416. Wei, G., et al. 2013. Some hesitant interval-valued fuzzy aggregation operators and their applications to multiple attribute decision making. Knowledge-Based Systems 46: 43-53.

417. Wei, G., et al. 2014. Hesitant triangular fuzzy information aggregation in multiple attribute decision making. Journal of Intelligent \& Fuzzy Systems 263: 1201-1209.

418. Wei, H., et al. 2010. Inoperability Input-Output Modeling IIM of Disruptions to Supply Chain Networks. Systems Engineering 134: 324-339.

419. Wong, W. K., et al. 2009. A fashion mix-and-match expert system for fashion retailers using fuzzy screening approach. Expert Systems with Applications 362: 1750-1764.

420. Wu, J., et al. 2009. A linear programming model for determining ordered weighted averaging operator weights with maximal Yager's entropy. Computers \& Industrial Engineering 573: 742-747.

421. Wu, J., et al. 2009. The induced continuous ordered weighted geometric operators and their application in group decision making. Computers \& Industrial Engineering 564: 1545-1552.

422. Wu, Y.-h., et al. 2009. A Learning Evaluation System Based on Classifier fusion for E-learning.

423. Wu, Y.-h., et al. 2009. A New Method for Fish disease Diagnosis System Based on Rough Set and Classifier Fusion.

424. Wu, Z. Y. Chen 2007. The maximizing deviation method for group multiple attribute decision making under linguistic environment. Fuzzy Sets and Systems 15814: 1608-1617.

425. Xia, M. Z. Xu 2010. Generalized Point Operators for Aggregating Intuitionistic Fuzzy Information. International Journal of Intelligent Systems 2511: 1061-1080.

426. Xia, Y.-q. R.-p. Zhu 2009. Research on Gift Design and Decision-making Approach Based on Value Engineering Theory.

427. Xian, S. 2012. Fuzzy Linguistic Induced Ordered Weighted Averaging Operator and Its Application. Journal of Applied Mathematics.

428. Xu, J., et al. 2004. TOPSIS for group decision making under linguistic information and its application to CS evaluation. Proceedings of the Third International Conference on Information and Management Sciences. L. Liu, X. Zhao, M. Gen, L. Li and Y. Li. 3: 467-472.

429. Xu, W. X., et al. 2008. A new approach to decision-making with key constraint and its application in enterprise information systems. Enterprise Information Systems 23: 287-308.

430. $\mathrm{Xu}, \mathrm{Y} . \mathrm{H}$. Wang 2012. The induced generalized aggregation operators for intuitionistic fuzzy sets and their application in group decision making. Applied Soft Computing 123: 1168-1179.

431. Xu, Y., et al. 2010. Linear goal programming approach to obtaining the weights of intuitionistic fuzzy ordered weighted averaging operator. Journal of Systems Engineering and Electronics 216: 990-994.

432. $\mathrm{Xu}, \mathrm{Y}$., et al. 2010. Some properties of linguistic preference relation and its ranking in group decision making. Journal of Systems Engineering and Electronics 212: 244-249.

433. Xu, Y.-j., et al. 2007. A Priority Method Based on Induced Trapezoidal Fuzzy Ordered Weighted Averaging ITFOWA Operator for Fuzzy Linguistic Decision-Making Problems.

434. Xu, Z. J. Chen 2008. ORDERED WEIGHTED DISTANCE MEASURE. Journal of Systems Science and Systems Engineering 174: 432-445.

435. Xu, Z. 2006. A C-OWA operator-based approach to decision making with interval fuzzy preference relation. International Journal of Intelligent Systems 2112: 1289-1298.

436. Xu, Z. 2006. A note on linguistic hybrid arithmetic averaging operator in multiple attribute group decision making with linguistic information. Group Decision and Negotiation 156: 593-604. 
437. Xu, Z. 2006. Induced uncertain linguistic OWA operators applied to group decision making. Information Fusion 72: 231-238.

438. $\mathrm{Xu}, \mathrm{Z}$. 2007. Group decision making with triangular fuzzy linguistic variables. Intelligent Data Engineering and Automated Learning - Ideal 2007. H. Yin, P. Tino, E. Corchado, W. Byrne and X. Yao. 4881: 17-26.

439. Xu, Z. 2007. Intuitionistic fuzzy aggregation operators. IEEE Transactions on Fuzzy Systems 156: 11791187.

440. $\mathrm{Xu}, \mathrm{Z}$. 2008. Dependent uncertain ordered weighted aggregation operators. Information Fusion 92: 310-316.

441. Xu, Z. 2008. Hybrid Weighted Distance Measures and Their Application to Pattern Recognition. Intelligent Data Engineering and Automated Learning - Ideal 2008. C. Fyfe, D. Kim, S. Y. Lee and H. Yin. 5326: 17-23.

442. Xu, Z. 2010. A Deviation-Based Approach to Intuitionistic Fuzzy Multiple Attribute Group Decision Making. Group Decision and Negotiation 191: 57-76.

443. Xu, Z. 2010. Uncertain Bonferroni Mean Operators. International Journal of Computational Intelligence Systems 36: 761-769.

444. Xu, Z. 2012. A Survey and Prospects of OWA Aggregation with Intuitionistic Fuzzy Information. Information-an International Interdisciplinary Journal 1511B: 4763-4776.

445. Xu, Z. S. Q. L. Da 2002. The uncertain OWA operator. International Journal of Intelligent Systems 176: 569-575.

446. Xu, Z. S. Q. L. Da 2003. An overview of operators for aggregating information. International Journal of Intelligent Systems 189: 953-969.

447. Xu, Z. S. W. L. Da 2002. The ordered weighted geometric averaging operators. International Journal of Intelligent Systems 177: 709-716.

448. Xu, Z. S. 2004. EOWA and EOWG operators for aggregating linguistic labels based on linguistic preference relations. International Journal of Uncertainty Fuzziness and Knowledge-Based Systems 126: 791-810.

449. Xu, Z. S. 2004. Uncertain linguistic aggregation operators based approach to multiple attribute group decision making under uncertain linguistic environment. Information Sciences 1681-4: 171-184.

450. Xu, Z. S. 2006. Dependent OWA operators. Modeling Decisions for Artificial Intelligence. V. Torra, Y. Narukawa, A. Valls and J. DomingoFerrer. 3885: 172-178.

451. Xu, Z. S. 2006. On generalized induced linguistic aggregation operators. International Journal of General Systems 351: 17-28.

452. Xu, Z.-S. J. Chen 2007. An interactive method for fuzzy multiple attribute group decision making. Information Sciences 1771: 248-263.

453. Yager, R. R. D. P. Filev 1994. Parameterized and-like and or-like OWA operators. International Journal of General Systems 223: 297-316.

454. Yager, R. R. D. P. Filev 1999. Induced ordered weighted averaging operators. IEEE Transactions on Systems Man and Cybernetics Part B-Cybernetics 292: 141-150.

455. Yager, R. R. G. Beliakov 2010. OWA Operators in Regression Problems. IEEE Transactions on Fuzzy Systems 181: 106-113.

456. Yager, R. R. IEEE 2006. A human directed approach for data summarization. 2006 IEEE International Conference on Fuzzy Systems, Vols 1-5: 707-712. 
457. Yager, R. R. N. Alajlan 2014. Probabilistically Weighted OWA Aggregation. IEEE Transactions on Fuzzy Systems 221: 46-56.

458. Yager, R. R. V. Kreinovich 2002. Main ideas behind OWA lead to a universal and optimal approximation scheme. Proceedings of Fuzzy Information Processing Society, 428-433.

459. Yager, R. R. 1988. ON ORDERED WEIGHTED AVERAGING AGGREGATION OPERATORS IN MULTICRITERIA DECISION-MAKING. IEEE Transactions on Systems Man and Cybernetics 181: 183-190.

460. Yager, R. R. 1993. FAMILIES OF OWA OPERATORS. Fuzzy Sets and Systems 592: 125-148.

461. Yager, R. R. 1995. MEASURES OF ENTROPY AND FUZZINESS RELATED TO AGGREGATION OPERATORS. Information Sciences 823-4: 147-166.

462. Yager, R. R. 1996. Constrained OWA aggregation. Fuzzy Sets and Systems 811: 89-101.

463. Yager, R. R. 1996. Fuzzy set methods in multi-media storage and retrieval.

464. Yager, R. R. 1997. On the analytic representation of the Leximin ordering and its application to flexible constraint propagation. European Journal of Operational Research 1021: 176-192.

465. Yager, R. R. 1998. Fusion of ordinal information using weighted median aggregation. International Journal of Approximate Reasoning 181-2: 35-52.

466. Yager, R. R. 1998. Including importances in OWA aggregations using fuzzy systems modeling. IEEE Transactions on Fuzzy Systems 62: 286-294.

467. Yager, R. R. 2000. A hierarchical document retrieval language. Information Retrieval 34: 357-377.

468. Yager, R. R. 2002. Using fuzzy methods to model nearest neighbor rules. IEEE Transactions on Systems Man and Cybernetics Part B-Cybernetics 324: 512-525.

469. Yager, R. R. 2003. Induced aggregation operators. Fuzzy Sets and Systems 1371: 59-69.

470. Yager, R. R. 2003. Toward a language for specifying summarizing statistics. IEEE Transactions on Systems Man and Cybernetics Part B-Cybernetics 332: 177-187.

471. Yager, R. R. 2004. Modeling prioritized multicriteria decision making. IEEE Transactions on Systems Man and Cybernetics Part B-Cybernetics 346: 2396-2404.

472. Yager, R. R. 2004. Soft aggregation methods in case based reasoning. Applied Intelligence 21(3): 277288.

473. Yager, R. R. 2006. An extension of the naive Bayesian classifier. Information Sciences 176(5): 577-588.

474. Yager, R. R. 2007. Using stress functions to obtain OWA operators. IEEE Transactions on Fuzzy Systems 156: 1122-1129.

475. Yager, R. R. 2008. Time Series Smoothing and OWA Aggregation. IEEE Transactions on Fuzzy Systems 164: 994-1007.

476. Yager, R. R. 2009. OWA aggregation of intuitionistic fuzzy sets. International Journal of General Systems 386: 617-641.

477. Yager, R. R. 2009. Weighted Maximum Entropy OWA Aggregation With Applications to Decision Making Under Risk. IEEE Transactions on Systems Man and Cybernetics Part a-Systems and Humans 393: 555-564.

478. Yager, R. R., Kelman, A. 1999. An extension of the analytical hierarchy process using OWA operators. Journal of Intelligent \& Fuzzy Systems 7(4): 401-417.

479. Yager, R. R., Xu, Z. S. 2006. The continuous ordered weighted geometric operator and its application to decision making. Fuzzy Sets and Systems 157(10): 1393-1402. 
480. Yan, B., et al. 2013. A Combination Forecasting Model Based on IOWA Operator for Dam Safety Monitoring. 2013 Fifth International Conference on Measuring Technology and Mechatronics Automation: 5-8.

481. Yan, H. B., Huynh, V. N., Nakamori, Y., Murai, T. 2011. On prioritized weighted aggregation in multicriteria decision making. Expert Systems with Applications 38(1): 812-823.

482. Yang, J., et al. 2006. Filtering e-mail based on fuzzy support vector machines and aggregation operator. Neural Information Processing, Pt 1, Proceedings. I. King, J. Wang, L. Chan and D. L. Wang. 4232: 882-891.

483. Yang, J., Qian, W. 2013. Fuzzification of lower and upper approximations in fuzzy information systems. Proceedings of the Fuzzy Systems, Knowledge Discovery, and Natural Computation Symposium, 91-100.

484. Yang, W. Y. Pang 2014. The quasi-arithmetic triangular fuzzy OWA operator based on DempsterShafer theory. Journal of Intelligent \& Fuzzy Systems 263: 1123-1135.

485. Yang, W. Z. Chen 2012. The quasi-arithmetic intuitionistic fuzzy OWA operators. Knowledge-Based Systems 27: 219-233.

486. Yari, G. A. Chaji 2012. Determination of Ordered Weighted Averaging Operator Weights Based on the M-Entropy Measures. International Journal of Intelligent Systems 2712: 1020-1033.

487. Yari, G. A. R. Chaji 2012. Maximum Bayesian entropy method for determining ordered weighted averaging operator weights. Computers \& Industrial Engineering 631: 338-342.

488. Yeh, D.-Y., et al. 2007. Empirical research of the principal component analysis and ordered weighted averaging integrated evaluation model on software projects. Cybernetics and Systems 383: 289-303.

489. Yu, H. Q., et al. 2008. A Method for Automated Web Service Selection.

490. Yu, X. Z. Xu 2013. Prioritized intuitionistic fuzzy aggregation operators. Information Fusion 141: 108116.

491. Yu, X., et al. 2006. Research on association rules based group ranking model with fuzzy preference relation structure.

492. Yu, X., et al. 2012. Multicriteria decision making with 2-dimension linguistic aggregation techniques. International Journal of Intelligent Systems 276: 539-562.

493. Zadrozny, S. J. Kacprzyk 2009. Issues in the practical use of the OWA operators in fuzzy querying. Journal of Intelligent Information Systems 333: 307-325.

494. Zakeri, P., et al. 2011. Prediction of protein submitochondria locations based on data fusion of various features of sequences. Journal of Theoretical Biology 2691: 208-216.

495. Zarghaami, M., et al. 2007. Obtaining robust decisions under uncertainty by sensitivity analysis on OWA operator.

496. Zarghaami, M., et al. 2007. Sensitivity analysis of an information fusion tool: OWA operator - art. no. 65710P. Multisensor, Multisource Information Fusion: Architectures, Algorithms, and Applications 2007. B. V. Dasarathy. 6571: P5710-P5710.

497. Zarghami, M. F. Szidarovszky 2008. Fuzzy quantifiers in sensitivity analysis of OWA operator. Computers \& Industrial Engineering 544: 1006-1018.

498. Zarghami, M. F. Szidarovszky 2008. New approach in obtaining OWA weights for multi criteria decision making.

499. Zarghami, M. F. Szidarovszky 2009. Revising the OWA operator for multi criteria decision making problems under uncertainty. European Journal of Operational Research 1981: 259-265. 
500. Zarghami, M. F. Szidarovszky 2009. Stochastic-fuzzy multi criteria decision making for robust water resources management. Stochastic Environmental Research and Risk Assessment 233: 329-339.

501. Zarghami, M. F. Szidarovszky 2010. On the relation between Compromise Programming and Ordered Weighted Averaging operator. Information Sciences 18011: 2239-2248.

502. Zarghami, M. 2011. Soft computing of the Borda count by fuzzy linguistic quantifiers. Applied Soft Computing 111: 1067-1073.

503. Zarghami, M., et al. 2008. A fuzzy-stochastic OWA model for robust Multi-Criteria Decision Making. Fuzzy Optimization and Decision Making 71: 1-15.

504. Zarghami, M., et al. 2008. Extended OWA operator for group decision making on water resources projects. Journal of Water Resources Planning and Management-Asce 1343: 266-275.

505. Zarghami, M., et al. 2008. Sensitivity analysis of the OWA operator. IEEE Transactions on Systems Man and Cybernetics Part B-Cybernetics 382: 547-552.

506. Zarghami, M., et al. 2009. Multi-Attribute Decision Making on Inter-Basin Water Transfer Projects. Scientia Iranica Transaction E-Industrial Engineering 161: 73-80.

507. Zeng, S. J. Chen 2012. Intuitionistic Fuzzy Decision Making Based on OWA and Distance Measures. Information Computing and Applications, Pt 2. C. F. Liu, L. Z. Wang and A. M. Yang. 308: 243-248.

508. Zeng, S. W. Su 2012. LINGUISTIC INDUCED GENERALIZED AGGREGATION DISTANCE OPERATORS AND THEIR APPLICATION TO DECISION MAKING. Economic Computation and Economic Cybernetics Studies and Research 462: 155-172.

509. Zeng, S., et al. 2012. A Method Based on OWA Operator and Distance Measures for Multiple Attribute Decision Making with 2-Tuple Linguistic Information. Informatica 234: 665-681.

510. Zeng, S., et al. 2012. Fuzzy Generalized Ordered Weighted Averaging Distance Operator and Its Application to Decision Making. International Journal of Fuzzy Systems 143: 402-412.

511. Zeng, S., et al. 2013. EXTENDED INDUCED ORDERED WEIGHTED AVERAGING DISTANCE OPERATORS AND THEIR APPLICATION TO GROUP DECISION-MAKING. International Journal of Information Technology \& Decision Making 124: 789-811.

512. Zeng, S., et al. 2013. The uncertain probabilistic OWA distance operator and its application in group decision making. Applied Mathematical Modelling 379: 6266-6275.

513. Zeng, S., et al. 2014. Fuzzy decision making with induced heavy aggregation operators and distance measures. Journal of Intelligent \& Fuzzy Systems 261: 127-135.

514. Zhang, G., et al. 2011. Minimum-Cost Consensus Models Under Aggregation Operators. IEEE Transactions on Systems Man and Cybernetics Part a-Systems and Humans 416: 1253-1261.

515. Zhang, X., et al. 2008. Multi-Attribute Group Decision Making Model Based on Fuzzy Triangle Number.

516. Zhang, Z. P. Liu 2007. Research on evaluation of E-commerce websites based on linguistic ordered weighted averaging operator.

517. Zhang, Z. Z. Xu 2013. On Continuity of Ordered Aggregation Operators. International Journal of Intelligent Systems 284: 307-318.

518. Zhang, Z. L. C. Q. Zhang 2000. Decision aggregation in multi-agent systems. Advances in Intelligent Systems: Theory and Applications. M. Mohammadian. 59: 185-190.

519. Zhang, Z. L. 2006. Decision aggregation in an agent-based financial investment planning system. Modeling Decisions for Artificial Intelligence. V. Torra, Y. Narukawa, A. Valls and J. DomingoFerrer. 3885: 179-190. 
520. Zhang, Z., et al. 2014. Induced generalized hesitant fuzzy operators and their application to multiple attribute group decision making. Computers \& Industrial Engineering 67: 116-138.

521. Zhao, H., et al. 2010. Generalized Aggregation Operators for Intuitionistic Fuzzy Sets. International Journal of Intelligent Systems 251: 1-30.

522. Zhao, N., et al. 2013. Sensitivity Analysis of Multiple Criteria Decision Making Method Based on the OWA Operator. International Journal of Intelligent Systems 2811: 1124-1139.

523. Zhao, X., et al. 2014. Hesitant triangular fuzzy information aggregation based on Einstein operations and their application to multiple attribute decision making. Expert Systems with Applications 414: 1086-1094.

524. Zhou, H. a., et al. 2007. Method for uncertain multi-attribute decision-making with preference information in the form of interval numbers complementary judgment matrix. Journal of Systems Engineering and Electronics 182: 265-269.

525. Zhou, L. H. Chen 2013. On compatibility of uncertain additive linguistic preference relations based on the linguistic COWA operator. Applied Soft Computing 138: 3668-3682.

526. Zhou, L., et al. 2012. Generalized power aggregation operators and their applications in group decision making. Computers \& Industrial Engineering 624: 989-999.

527. Zhou, L., et al. 2013. Continuous Ordered Weighted Distance Measure and Its Application to Multiple Attribute Group Decision Making. Group Decision and Negotiation 224: 739-758.

528. Zhou, L., et al. 2013. Generalized Multiple Averaging Operators and their Applications to Group Decision Making. Group Decision and Negotiation 222: 331-358.

529. Zhou, L., et al. 2013. SOME ICOWA OPERATORS AND THEIR APPLICATIONS TO GROUP DECISION MAKING WITH INTERVAL FUZZY PREFERENCE RELATIONS. International Journal of Uncertainty Fuzziness and Knowledge-Based Systems 214: 579-601.

530. Zhou, L.-G. H.-Y. Chen 2011. Continuous generalized OWA operator and its application to decision making. Fuzzy Sets and Systems 1681: 18-34.

531. Zhou, L.-G., et al. 2012. Uncertain generalized aggregation operators. Expert Systems with Applications 391: 1105-1117.

532. Zhou, R., et al. 2008. A method for obtaining the maximum entropy OWA operator weights with uncertain orness measure.

533. Zhou, S.-M., et al. 2008. Type-2 OWA Operators - Aggregating Type-2 Fuzzy Sets in Soft Decision Making. 2008 IEEE International Conference on Fuzzy Systems, Vols 1-5: 625-630.

534. Zhou, S.-M., et al. 2010. On Aggregating Uncertain Information by Type-2 OWA Operators for Soft Decision Making. International Journal of Intelligent Systems 256: 540-558.

535. Zhou, S.-M., et al. 2011. Alpha-Level Aggregation: A Practical Approach to Type-1 OWA Operation for Aggregating Uncertain Information with Applications to Breast Cancer Treatments. IEEE Transactions on Knowledge and Data Engineering 2310: 1455-1468.

536. Zhu, Q. J. Chen 2011. Multi-Objective Decision Making in GIS-based Multi-Criteria Evaluation for Land Use. 2011 International Conference on Energy and Environmental Science-Icees 2011. X. Zhou. 11: 3634-3640.

537. Zhu, Q., et al. 2010. Risk assessment of land-use suitability and application to Tangshan City. International Journal of Environment and Pollution 424: 330-343. 


\title{
Ordered Weighted Averaging Operators 1988-2014: A citation-based literature survey
}

\author{
Ali Emrouznejad*and Marianna Marra
}

Aston Business School, Aston University, Birmingham, UK

1. Acar, E., Arslan, S., Yazici, A. 2008. Slim-Tree and BitMatrix index structures in image retrieval system using MPEG-7 Descriptors Book Group Authors: IEEE Conference: International Workshop on Content-Based Multimedia Indexing.

2. Afshinmanesh, F., Marandi, A., Shahabadi, M. 2008. Design of a single-feed dual-band dualpolarized printed microstrip antenna using a Boolean particle swarm optimization. IEE Transactions on Antennas and Propagation 567: 1845-1852.

3. Ahn, B. S. 2006. On the properties of OWA operator weights functions with constant level of orness. IEEE Transactions on Fuzzy Systems 144: 511-515.

4. Ahn, B. S. 2006. The uncertain OWA aggregation with weighting functions having a constant level of orness. International Journal of Intelligent Systems 215: 469-483.

5. Ahn, B. S. 2007. The OWA aggregation with uncertain descriptions on weights and input arguments. IEEE Transactions on Fuzzy Systems 156: 1130-1134.

6. Ahn, B. S. 2008. Preference relation approach for obtaining OWA operators weights. International Journal of Approximate Reasoning 472: 166-178.

7. Ahn, B. S. 2008. Some quantifier functions from weighting functions with constant value of orness. IEEE Transactions on Systems Man and Cybernetics Part B-Cybernetics 382: 540-546.

8. Ahn, B. S. 2009. Some Remarks on the LSOWA Approach for Obtaining OWA Operator Weights. International Journal of Intelligent Systems 2412: 1265-1279.

9. Ahn, B. S. 2010. A priori identification of preferred alternatives of OWA operators by relational analysis of arguments. Information Sciences 18023: 4572-4581.

10. Ahn, B. S. 2010. Determining OWA Operator Weights from Ordinal Relation on Criteria. IEEE International Conference on Systems, Man and Cybernetics: 3290-3293.

11. Ahn, B. S. 2010. Parameterized OWA operator weights: An extreme point approach. International Journal of Approximate Reasoning 517: 820-831.

12. Ahn, B. S. 2011. Compatible weighting method with rank order centroid: Maximum entropy ordered weighted averaging approach. European Journal of Operational Research 2123: 552559.

\footnotetext{
*Corresponding author Email: A.Emrouznejad@aston.ac.uk
} 
13. Ahn, B. S. 2012. Programming-Based OWA Operator Weights With Quadratic Objective Function. IEEE Transactions on Fuzzy Systems 205: 986-992.

14. Ahn, B. S., Park, H. 2008. An Efficient Pruning Method for Decision Alternatives of OWA Operators. IEEE Transactions on Fuzzy Systems 166: 1542-1549.

15. Ahn, B. S., Park, H. 2008. Least-squared ordered weighted averaging operator weights. International Journal of Intelligent Systems 231: 33-49.

16. Ahn, B. S., S. H. Choi. 2012. Aggregation of ordinal data using ordered weighted averaging operator weights. Annals of Operations Research 2011: 1-16.

17. Al Hichri, H., Bazi, Y., Alajlan, N., Melgani, F., Malek, S., Yager, R. R. 2013. A novel fusion approach based on induced ordered weighted averaging operators for chemometric data analysis. Journal of Chemometrics 2712: 447-456.

18. Alajlan, N., Bazi, Y., Al Hichri, H. S. 2013. Using OWA Fusion Operators for the Classification of Hyperspectral Images. IEEE Journal of Selected Topics in Applied Earth Observations and Remote Sensing 62: 602-614.

19. Alonso, J. M., Magdalena, L. 2010. Combining user's preferences and quality criteria into a new index for guiding the design of fuzzy systems with a good interpretability-accuracy trade-off. IEEE International Conference on Fuzzy Systems Fuzz-IEEE 2010.

20. Amin, G. R., Emrouznejad, A. 2006. An extended minimax disparity to determine the OWA operator weights. Computers \& Industrial Engineering 503: 312-316.

21. Amin, G. R., Emrouznejad, A. 2011. Parametric aggregation in ordered weighted averaging. International Journal of Approximate Reasoning 526: 819-827.

22. Amiri, M. J., Mahiny, A. S., Hosseini, S. M. 2013. OWA Analysis for Ecological Capability Assessment in Watersheds. International Journal of Environmental Research 71: 241-254.

23. Arami, A., Barre, A., Berthelin, R., 2013. Estimation of Prosthetic Knee Angles via Data Fusion of Implantable and Wearable Sensors. IEEE International Conference on Body Sensor Networks Location: MIT Media Lab, Cambridge.

24. Aristondo, O., Luis Garcia-Lapresta, J., Lasso de la Vega, C. 2012. The gini index, the dual decomposition of aggregation functions, and the consistent measurement of inequality. International Journal of Intelligent Systems 272: 132-152.

25. Averna Valente, R. d. O., Vettorazzi, C. A. 2008. Definition of priority areas for forest conservation through the ordered weighted averaging method. Forest Ecology and Management 2566: 1408-1417.

26. Averna Valente, R. d. O., Vettorazzi, C. A. 2009. Comparison between sensibility analysis methods, used in the decision-making process through the multicriteria evaluation. Scientia Forestalis 3782: 197-211.

27. Aydin, N. Y., Kentel, E., Duzgun, H. S. 2013. GIS-based site selection methodology for hybrid renewable energy systems: A case study from western Turkey. Energy Conversion and Management 701: 90-106.

28. Aymerich, F. X., Alonso, J., Cabanas, M. E.2011. Decision tree based fuzzy classifier of H-1 magnetic resonance spectra from cerebrospinal fluid samples. Fuzzy Sets and Systems 1701: 43-63. 
29. Badea, A. C., Rocco S, Claudio M. Tarantola, S., Bolado, R. 2011. Composite indicators for security of energy supply using ordered weighted averaging. Reliability Engineering \& System Safety 966: 651-662.

30. Badello, M. R., Moshiri, B., Araabi, B. N., Tebianian, H. 2011. A novel detection and navigation approach based on OWA fusion method. Sensor Review 314: 328-340.

31. Balezentis, A., Balezentis, T. 2011. A novel method for group multi-attribute decision making with two-tuple linguistic computing: Supplier evaluation under uncertainty. Economic Computation and Economic Cybernetics Studies and Research 454: 5-29.

32. Ballester, M. A., Luis Garcia-Lapresta, J. 2009. A recursive group decision-making procedure for choosing qualified individuals. International Journal of Intelligent Systems 248: 889-901.

33. Basu, A., Nachtegael, M. 2009. OWA filters: A Robust Filtering Method and its Application to Color Images. IEEE Symposium on Computational Intelligence in Image and Signal Processing.

34. Beg, M. M. S., N. Ahmad, N. 2005. Measuring user satisfaction in web searching. Computational Intelligence for Modelling and Prediction. Eds S. Halgamuge and L. Wang. 2: 321-336.

35. Beliakov, G., Bustince, H., James, S., Calvo, T., Fernandez, J. 2012. Aggregation for Atanassov's intuitionistic and interval valued fuzzy sets: The median operator. IEEE Transactions on Fuzzy Systems 203: 487-498.

36. Beliakov, G., James, S. 2013. On extending generalized Bonferroni means to Atanassov orthopairs in decision making contexts. Fuzzy Sets and Systems 211: 84-98.

37. Beliakov, G., James, S., Li, G. 2011. Learning Choquet-integral-based metrics for semisupervised clustering. IEEE Transactions on Fuzzy Systems 193: 562-574.

38. Belles-Sampera, J., Merigo, J .M., Monserrat, G., Santolino, M. 2013. The connection between distortion risk measures and ordered weighted averaging operators. Insurance Mathematics \& Economics 522: 411-420.

39. Belles-Sampera, J., Merigo, J .M., Monserrat, G., Santolino, M. 2013. Some new definitions of indicators for the Choquet Integral. Aggregation Functions in Theory and in Practise. Eds H. Bustince, J. Fernandez, R. Mesiar and T. Calco. 228: 467-476.

40. Bjork, K. M. 2008. Obtaining minimum variability OWA operators under a fuzzy level of orness. Conference Proceedings: 5th International Conference on Informatics in Control, Automation and Robotics

41. Blanco, V., Ben Ali, S. E.H., Puerto, J. 2013. Minimizing ordered weighted averaging of rational functions with applications to continuous location. Computers \& Operations Research 405: 1448-1460.

42. Boongoen, T., Shen, Q. 2009. Semi-supervised OWA aggregation for link-based similarity evaluation and alias detection. EEE International Conference on Fuzzy Systems 13: 288-293.

43. Boongoen, T., Shen, Q. 2010. Nearest-neighbor guided evaluation of data reliability and its applications. IEEE Transactions on Systems Man and Cybernetics Part B-Cybernetics 406: 1622-1633.

44. Bordogna, G., Pasi, G. 2005. Personalised indexing and retrieval of heterogeneous structured documents. Information Retrieval 82: 301-318. 
45. Boroushaki, S., Malczewski, J. 2008. Implementing an extension of the analytical hierarchy process using ordered weighted averaging operators with fuzzy quantifiers in ArcGIS. Computers \& Geosciences 344: 399-410.

46. Boroushaki, S., Malczewski, J. 2010. Using the fuzzy majority approach for GIS-based multicriteria group decision-making. Computers \& Geosciences 363(1): 302-312.

47. Calvo, T., Mayor, G., Torrens, J., Suner, J., Mas, M., Carbonell, M. 2000. Generation of weighting triangles associated with aggregation functions. International Journal of Uncertainty Fuzziness and Knowledge-Based Systems 84(4): 417-451.

48. Carrara, P., Bordogna, G., Boschetti, M., Brivio, P. A., Nelson, A., Stroppiana, D. 2008. A flexible multi-source spatial-data fusion system for environmental status assessment at continental scale. International Journal of Geographical Information Science 22(7): 781-799.

49. Casanovas, M., Merigo, J. M. 2012. Fuzzy aggregation operators in decision making with Dempster-Shafer belief structure. Expert Systems with Applications 39(8): 7138-7149.

50. Chang, J. R. Shu-Ying, L., Ching-Hsue, C. 2007. Situational ME-LOWA aggregation model for evaluating the best main battle tank.

51. Chang, J. R., Ho, T. H., Cheng, C. H., Chen, A. P. 2006. Dynamic fuzzy OWA model for group multiple criteria decision making. Soft Computing 10(7): 543-554.

52. Chang, K. H., Cheng, C. H. 2011. Evaluating the risk of failure using the fuzzy OWA and DEMATEL method. Journal of Intelligent Manufacturing 22(2): 113-129.

53. Chang, K. H., Cheng, C. H., Chang, Y. C. 2008. Reliability assessment of an aircraft propulsion system using IFS and OWA tree. Engineering Optimization 40(10): 907-921.

54. Chang, K.H., Wen, T. C. 2010. A novel efficient approach for DFMEA combining 2-tuple and the OWA operator. Expert Systems with Applications 37(3): 2362-2370.

55. Chang, S. L., Wang, R. C., Wang, S. Y. 2007. Applying a direct multi-granularity linguistic and strategy-oriented aggregation approach on the assessment of supply performance. European Journal of Operational Research 177(2): 1013-1025.

56. Chang, Y.C., Chang, K. H., Liaw, C. S. 2009. Innovative reliability allocation using the maximal entropy ordered weighted averaging method. Computers \& Industrial Engineering 57(4): 1274-1281.

57. Chen, H., Zhou, L. 2011. An approach to group decision making with interval fuzzy preference relations based on induced generalized continuous ordered weighted averaging operator. Expert Systems with Applications 38(10): 13432-13440.

58. Chen, H., Zhou, L. 2012. A relative entropy approach to group decision making with interval reciprocal relations based on COWA Operator. Group Decision and Negotiation 21(4): 585599.

59. Chen, J., Zhu, Q., Liu, W. 2008. Safety Evaluation of City Land Use with GM-based Ordered Weighted Averaging Method. In (Eds) Li, SC; Wang, YJ; An, Y; et al. PROGRESS IN SAFETY SCIENCE AND TECHNOLOGY SERIES.

60. Chen, L., Xu, Z., Yu, X.. 2013. The ordered multiplicative modular geometric operator. Knowledge-Based Systems 39: 144-150. 
61. Chen, L.-H., Hung, C. C., Tu, C. C. 2012. Considering the decision maker's attitudinal character to solve multi-criteria decision-making problems in an intuitionistic fuzzy environment. Knowledge-Based Systems 36: 129-138.

62. Chen, Q., Soc, I. C. 2009. The evaluation of ecological environment condition in mining area based on GIS and fuzzy-OWA model. Proceedings IEEE Computer Soc Conference: International Conference on Environmental Science and Information Application Technology, 3: 478-481.

63. Chen, S. M., Niou, S. J. 2011. Fuzzy multiple attributes group decision-making based on fuzzy induced OWA operators. Expert Systems with Applications 38(4): 4097-4108.

64. Chen, S. M., Wang, C. H. 2009. A generalized model for prioritized multicriteria decision making systems. Expert Systems with Applications 36(3): 4773-4783.

65. Chen, T.Y. 2012. Multiple criteria group decision-making with generalized interval-valued fuzzy numbers based on signed distances and incomplete weights. Applied Mathematical Modelling 36(7): 3023-3046.

66. Chen, Y. H., Cheng, C. H., Liu, J. 2008. Intelligent preference selection for evaluating students' learning achievement. Proceedings Third International Conference of Convergence and Hybrid Information Technology 2: 1214-1219.

67. Chen, Y. H., Cheng, C. H., Liu, J. W. 2010. Intelligent preference selection model based on NRE for evaluating student learning achievement. Computers \& Education 54(4): 916-926.

68. Chen, Y., et al. 2008. Irrigation intensification or extensification assessment: A GIS-based spatial fuzzy multi-criteria evaluation.

69. Chen, Y., Khan, S., Paydar, Z. 2010. To retire or to expand? A fuzzy GIS-based spatial multicriteria evaluation framework for irrigated agriculture. Irrigation and Drainage 59(2): 174188.

70. Chen, Y., Li, W. K., Liu, S. 2011. An OWA-TOPSIS method for multiple criteria decision analysis. Expert Systems with Applications 38(5): 5205-5211.

71. Chen, Y., Paydar, Z. 2012. Evaluation of potential irrigation expansion using a spatial fuzzy multi-criteria decision framework. Environmental Modelling \& Software 38: 147-157.

72. Chen, Y., Zeng, X., Happiette, M., Bruniaux, P., Ng, R. 2008. A new method of ease allowance generation for personalization of garment design. International Journal of Clothing Science and Technology 20(3): 161-173.

73. Cheng, C. H., Chang, J. R., Ho, T. H., Chen. A. P. 2005. Evaluating the airline service quality by fuzzy OWA operators. Modeling Decisions for Artificial Intelligence, Lecture Notes in Computer Science 3558: 77-88.

74. Cheng, C. H., Wang, J. W., Wu, M. C. 2009. OWA-weighted based clustering method for classification problem. Expert Systems with Applications 36(3): 4988-4995.

75. Cheng, C. H., Wei, L.Y., Liu, J. W., Chen, T. L. 2013. OWA-based ANFIS model for TAIEX forecasting. Economic Modelling 30(1): 442-448.

76. Cheng, C.H., Chang, J. R. 2006. MCDM aggregation model using situational ME-OWA and ME-OWGA operators. International Journal of Uncertainty Fuzziness and Knowledge-Based Systems 14(4): 421-443. 
77. Cheng, C.H., Chang, J. R., Ho, T. H. 2006. Dynamic fuzzy OWA model for evaluating the risks of software development. Cybernetics and Systems 37(8): 791-813.

78. Cheng, M., Zeng, S. 2012. Decision-Making Scheme Based on LIOWAD. Information Computing and Applications, 30(8): 236-242.

79. Cheng, M., Zeng, S. 2012. Efficient Decision-Making Scheme Based on LIOWAD. Information Computing and Applications, 30(7): 265-272.

80. Chiclana, F., Herrera, F., Herrera-Viedma, E. 2004. Rationality of induced ordered weighted operators based on the reliability of the source of information in group decision-making. Kybernetika 40(1): 121-142.

81. Chiclana, F., Herrera, F., Herrera-Viedma, E., Alonso, F. 2004. Induced ordered weighted geometric operators and their use in the aggregation of multiplicative preference relations. International Journal of Intelligent Systems 19(3): 233-255.

82. Chiclana, F., Herrera, F., Herrera-Viedma, E., Alonso, F. 2007. Some induced ordered weighted averaging operators and their use for solving group decision-making problems based on fuzzy preference relations. European Journal of Operational Research 182(1): 383399.

83. Chiclana, F., Zhou, S. M. 2013. Type-reduction of general type-2 fuzzy sets: The type-1 OWA approach. International Journal of Intelligent Systems 28(5): 505-522.

84. Cho, S. B. 1995. Fuzzy aggregation of modular neural networks with ordered weighted averaging operator. International Journal of Approximate Reasoning 13(4): 359-375.

85. Chuu, S. J. 2007. Evaluating the flexibility in a manufacturing system using fuzzy multiattribute group decision-making with multi-granularity linguistic information. International Journal of Advanced Manufacturing Technology 323(4): 409-421.

86. Cooper, J. A., et al. 1997. Improved safety analysis through enhanced mathematical structures. Conference Proceedings IEEE International Conference on Systems, Man, and Cybernetics, 1(5): 1656-1661.

87. Cuong, B. G. 1999. On group decision making under linguistic assessments. International Journal of Uncertainty Fuzziness and Knowledge-Based Systems 74: 301-308.

88. Darzentas, J., Tsagaris, C. 2000. Application of a modified OWA operator to a designer decision aiding system DDAS. International Journal of General Systems 29(1): 103-121.

89. De Marco, G., Morgan, J. 2014. On Ordered Weighted Averaging Social Optima. Journal of Optimization Theory and Applications 160(2): 623-635.

90. del Amo, A., Montero, J. Molina, E. 2001. Representation of consistent recursive rules. European Journal of Operational Research 130(1): 29-53.

91. Diaz, E. D., et al. 2005. A comprehensive OWA-based framework for result merging in metasearch. Rough Sets, Fuzzy Sets, Data Mining, and Granular Computing, Pt 2, Proceedings. D. Slezak, J. T. Yao, J. F. Peters, W. Ziarko and X. Hu. 3642: 193-201.

92. Dong, Q., Guo, Y. 2013. Multiperiod multiattribute decision-making method based on trend incentive coefficient. International Transactions in Operational Research 20(1): 141-152. 
93. Dong, Y., Xu, Y., Li, H. Feng, B. 2010. The OWA-based consensus operator under linguistic representation models using position indexes. European Journal of Operational Research 203(2): 455-463.

94. Dong, Y., Xu, Y., Yu, S. 2009. Linguistic multiperson decision making based on the use of multiple preference relations. Fuzzy Sets and Systems 160(5): 603-623.

95. Dursun, M., Karsak , E. E. 2010. A fuzzy MCDM approach for personnel selection. Expert Systems with Applications 37(6): 4324-4330.

96. Dursun, M., Karsak, E. E., Karadayi, M. A. 2011. A fuzzy multi-criteria group decision making framework for evaluating health-care waste disposal alternatives. Expert Systems with Applications 38(9): 11453-11462.

97. Eldrandaly, K. A. 2013. Exploring multi-criteria decision strategies in GIS with linguistic quantifiers: an extension of the analytical network process using ordered weighted averaging operators. International Journal of Geographical Information Science 271(2): 24552482.

98. Emrouznejad, A. 2008. MP-OWA: The most preferred OWA operator. Knowledge-Based Systems 21(8): 847-851.

99. Emrouznejad, A. 2010. SAS/OWA: ordered weighted averaging in SAS optimization. Soft Computing 14(4): 379-386.

100. Emrouznejad, A., Amin, G. R. 2010. Improving minimax disparity model to determine the OWA operator weights. Information Sciences 180(8): 1477-1485.

101. Engemann, K. J., Filev, D. P., Yager, R. R. 1996. Modelling decision making using immediate probabilities. International Journal of General Systems 24(3): 281-294.

102. Engemann, K. J., Miller, H. E., Yager, R. R. 1996. Decision making with belief structures: An application in risk management. International Journal of Uncertainty Fuzziness and Knowledge-Based Systems 4(1): 1-25.

103. Engemann, K. J., Yager, R. R. 2001. A general approach to decision making with interval probabilities. International Journal of General Systems 30(6): 623-647.

104. Fields, E. B., Okudan, G. E., Ashour, O. M. 2013. Rank aggregation methods comparison: A case for triage prioritization. Expert Systems with Applications 40(4): 1305-1311.

105. Filev, D., Yager, R. R. 1995. Analytic properties of maximum-entropy OWA operators. Information Sciences 851(3): 11-27.

106. Fodor, J. M. Roubens 1995. On meaningfulness of means. Journal of Computational and Applied Mathematics 641-2: 103-115.

107. Fodor, J., Marichal, J. L., Roubens, M. 1995. Characterization of the ordered weighted averaging operators. IEEE Transactions on Fuzzy Systems 32: 236-240.

108. Fonooni, B., I. C. Soc 2007. Rational-emotional agent decision making algorithm design with OWA. 19th IEEE International Conference on Tools with Artificial Intelligence, Vol Ii, Proceedings: 63-66.

109. Fonooni, B., Moghadam, S. J. M. 2008. Designing financial market intelligent monitoring system based on OWA. Proceedings of the WSEAS International Conference on Applied Computing Conference, 35-39. 
110. Fonooni, B., Moghadam, S. J. M. 2009. Applying Induced Aggregation Operator in Designing Intelligent Monitoring System for Financial Market.

111. Fonooni, B., Moghadam, S. J. M. 2009. Automated Trading Based On Uncertain OWA In Financial Markets. Proceedings of the WSEAS International Conference on Mathematics and computers in business and economics.

112. Fuller, R. 2007. On obtaining OWA operator weights: A sort survey of recent developments. International Conference on Computational Cybernetics.

113. Fuller, R. Majlender, P. 2003. On obtaining minimal variability OWA operator weights. Fuzzy Sets and Systems 136(2): 203-215.

114. Fuller, R., Majlender, P. 2001. An analytic approach for obtaining maximal entropy OWA operator weights. Fuzzy Sets and Systems 124(1): 53-57.

115. Gader, P. D., Lee, W. H., Zhang, X. 2004. Renyi entropy with respect to Choquet capacities. IEE International Conference on Fuzzy Systems

116. Gagolewski, M., Grzegorzewski, P. 2010. Arity-Monotonic Extended Aggregation Operators. Information Processing and Management of Uncertainty in Knowledge-Based Systems: Theory and Methods, Pt 1. E. Hullermeir, R. Kruse and F. Hoffmann. 80: 693-702.

117. Garcia-Lapresta, J. L., Llamazares, B. 2001. Majority decisions based on difference of votes. Journal of Mathematical Economics 35(3): 463-481.

118. Gbanie, S. P.,Tengbe, P. B., Momoh, J. S., Medo, J., Kabba, T. B. 2013. Modelling landfill location using Geographic Information Systems GIS and Multi-Criteria Decision Analysis MCDA: Case study Bo, Southern Sierra Leone. Applied Geography 36(1): 3-12.

119. Gheysari, K., Khoei, A., Hadidi, K., Mokarram, M. 2008. Analog CMOS Implementation of order weight Average operator for fuzzy logic controller chip. IEEE Conference on Intelligent Systems 1: 2-22.

120. Gheysari, K., Mashoufi, B. 2011. Implementation of CMOS flexible fuzzy logic controller chip in current mode. Fuzzy Sets and Systems 185(1): 125-137.

121. Gong, Y. 2011. A combination approach for obtaining the minimize disparity OWA operator weights. Fuzzy Optimization and Decision Making 10(4)ì: 311-321.

122. Gorsevski, P. V., Jankowski, P. Gessler, P. E. 2006. An heuristic approach for mapping landslide hazard by integrating fuzzy logic with analytic hierarchy process. Control and Cybernetics 35(1): 121-146.

123. Hao, J., Wang, J. H. 2008. On weighted p-quantile aggregation. International Journal of Intelligent Systems 23(3): 332-354.

124. Hermans, E., et al. 2008. Evaluation of road safety performance indicators using OWA operators.

125. Hermans, E., Ruan, D., Brijs, T., Wets, G., Vanhoof, K. 2010. Road safety risk evaluation by means of ordered weighted averaging operators and expert knowledge. Knowledge-Based Systems 23(1): 48-52.

126. Herrera, F., Herrera-Viedma, E., Chiclana, F. 2003. A study of the origin and uses of the ordered weighted geometric operator in multicriteria decision making. International Journal of Intelligent Systems 18(6): 689-707. 
127. Herrera, F., Herrera-Viedma, E., Verdegay, J. L. 1995. A sequential selection process in group decision making with a linguistic assessment approach. Information Sciences 85(4): 223-239.

128. Herrera, F., Herrera-Viedma, E., Verdegay, J. L. 1996. A linguistic decision process in group decision making. Group Decision and Negotiation 5(2): 165-176.

129. Herrera, F., Herrera-Viedma, E., Verdegay, J. L. 1996. Direct approach processes in group decision making using linguistic OWA operators. Fuzzy Sets and Systems 79(2): 175-190.

130. Herrera, F., Herrera-Viedma, E., Verdegay, J. L. 1998. Choice processes for nonhomogeneous group decision making in linguistic setting. Fuzzy Sets and Systems 94(3): 287308.

131. Herrera-Viedma, E. Peis, E. 2003. Evaluating the informative quality of documents in SGML format from judgements by means of fuzzy linguistic techniques based on computing with words. Information Processing \& Management 39(2): 233-249.

132. Herrera-Viedma, E., Alonso, S., Chiclana, F., Herrera, F., 2007. A consensus model for group decision making with incomplete fuzzy preference relations. IEEE Transactions on Fuzzy Systems 15(5): 863-877.

133. Herrera-Viedma, E., Pasi, G., Lopez-Herrera, A. G., 2006. Evaluating the information quality of Web sites: A methodology based on fuzzy computing with words. Journal of the American Society for Information Science and Technology 57(4): 538-549.

134. Herrera-Viedma, E.; Alonso, S., Chiclana, F., Herrera, F., 2007. Group decision-making model with incomplete fuzzy preference relations based on additive consistency. IEEE Transactions on Systems Man and Cybernetics Part B-Cybernetics 37(1): 176-189.

135. Herrera-Viedma, E.; Peis, E.; Morales-del-Castillo, J. M. 2007. A fuzzy linguistic model to evaluate the quality of Web sites that store XML documents. International Journal of Approximate Reasoning 46(1): 226-253.

136. Hong, D. H. 2006. A note on the minimal variability OWA operator weights. International Journal of Uncertainty Fuzziness and Knowledge-Based Systems 14(6): 747-752.

137. Hong, D. H. 2011. On proving the extended minimax disparity OWA problem. Fuzzy Sets and Systems 168(1): 35-46.

138. Hu, Y. C. 2007. Fusing fuzzy association rule-based classifiers using Sugeno integral with ordered weighted averaging operators. International Journal of Uncertainty Fuzziness and Knowledge-Based Systems 15(6): 717-735.

139. Huang, S. F., Cheng, C. H. 2008. Forecasting the air quality using OWA based time series model. Proceedings of the International Conference on Machine Learning and Cybernetics 17: 3254-3259

140. Hurkala, J., Sliwinski, T. 2012. Fair flow optimization with advanced aggregation operators in Wireless Mesh Networks. Federated Conference on Computer Science and Information Systems Fedcsis: 415-421.

141. Huynh, V. N., Yan, H., Nakamori, Y. 2010. A target-based decision-making approach to consumer-oriented evaluation model for Japanese traditional crafts. IEEE Transactions on Engineering Management 57(4): 575-588.

142. Isern, D., Marin, L., Vallas, A. 2010. The Unbalanced Linguistic Ordered Weighted Averaging Operator. Proceedingsof the IEEE International Conference on Fuzzy Systems. 
143. Jacas, J., Recasens, J. 2003. Aggregation of T-transitive relations. International Journal of Intelligent Systems 1812: 1193-1214.

144. Janev, M., Pekar, D., Jakovljevic, N. 2010. Eigenvalues Driven Gaussian Selection in continuous speech recognition using HMMs with full covariance matrices. Applied Intelligence 332: 107-116.

145. Jayaram, J., Malhotr, M. K. 2010. The differential and contingent impact of concurrency on new product development project performance: A holistic examination. Decision Sciences 41(1): 147-196.

146. Ji, Q., Liu, W., Qi, G., Bell, D.A. 2006. LCS: A linguistic combination system for ontology matching. In Knowledge Science, Engineering and Management (Eds) J. Lang, F. Lin and J. Wang, 176-189.

147. Jiang, G., Liu, Y. 2012. Research on Collaborative Forecasting Model Based on CPFR. Software Engineering and Knowledge Engineering: Theory and Practice, 11(4): 523-529.

148. Jiang, Y. P., Yu, Z. C.; Fan, Z. P. 2005. The evaluation of the customer service quality in a supply chain based on the LOWA aggregation operator. IEEE International Engineering Management Conference, 1(2): 415-418.

149. Jiang, Y., Li, B. 2006. A new ULOWA aggregation operator and its application in comprehensive evaluation. Conference proceedings International Conference on Industrial Engineering and Engineering Management Location, (Eds) Wang, XY; Shen, J. 1(5): 23162319.

150. Kacprzyk, J. 1996. Supporting consensus reaching under fuzziness via ordered weighted averaging OWA operators. Proceedings of Fuzzy Systems Symposium on Soft Computing in Intelligent Systems and Information processing, 453 - 458

151. Kacprzyk, J., Wilbik, A., Zadrozny, S. 2007. Linguistic summaries of time series via an OWA operator based aggregation of partial trends. 2007 IEEE International Conference on Fuzzy Systems, 1(4) 466-471.

152. Kacprzyk, J., Zadrozny, S. 2001. Computing with words in intelligent database querying: standalone and Internet-based applications. Information Sciences 134(1-4): 71-109.

153. Kacprzyk, J., Zadrozny, S. 2010. Supporting Consensus Reaching Processes under Fuzzy Preferences and a Fuzzy Majority via Linguistic Summaries. Preferences and Decisions: Models and Applications. S. Greco, R. A. M. Pereira, M. Squillante, R. R. Yager and J. Kacprzyk. 257: 261-279.

154. Karakosta, C., Askounis, D. 2010. Developing countries' energy needs and priorities under a sustainable development perspective: A linguistic decision support approach. Energy for Sustainable Development 144: 330-338.

155. Kasperski, A., Zielinski, P. 2013. Bottleneck combinatorial optimization problems with uncertain costs and the OWA criterion. Operations Research Letters 416: 639-643.

156. Kazai, G., et al. 2001. A model for the representation and focussed retrieval of structured documents based on fuzzy aggregation.

157. Kazemian, M., et al. 2005. Protein secondary structure classifiers fusion using OWA. Biological and Medical Data Analysis, Proceedings. J. L. Oliveira, V. Maojo, F. MartinSanchez and A. S. Pereira. 3745: 338-345. 
158. Keikha, M. F. Crestani 2009. Effectiveness of Aggregation Methods in Blog Distillation. Flexible Query Answering Systems: 8th International Conference, Fqas 2009. T. reasen, R. R. Yager, H. Bulskov, H. Christiansen and H. L. Larsen. 5822: 157-167.

159. Keikha, M. 2010. Investigation on Smoothing and Aggregation Methods in Blog Retrieval.

160. Keikha, M., Crestani, F. 2012. Linguistic aggregation methods in blog retrieval. Information Processing \& Management 483: 467-475.

161. Keikha, M., Crestani. F. 2009. Experimental results on the aggregation Methods in Blog Distillation.

162. Kentel, E., Aral, M. M. 2007. Fuzzy multiobjective decision-making approach for groundwater resources management. Journal of Hydrologic Engineering 122: 206-217.

163. Keyhanipour, A. H., Moshiri, B., Kazemian, M., Piroozman, M., Caro, L. 2007. Aggregation of web search engines based on users' preferences in WebFusion. Knowledge-Based Systems 20(4): 321-328.

164. Khan, J. A., Sait, S. M. 2002. Fuzzy aggregating functions for multiobjective VLSI placement. Proceedings of the 2002 IEEE International Conferences on Fuzzy Systems 1-2: 831-836

165. Khan, S. A. Engelbrecht, A. P. 2007. A new fuzzy operator and its application to topology design of distributed local area networks. Information Sciences 177(13): 2692-2711.

166. Khilwani, N., Shankar, R., Tiwari, M. K 2008. Facility layout problem: an approach based on a group decision-making system and psychoclonal algorithm. International Journal of Production Research 464: 895-927.

167. Kim, Z. V. P. Singh 2014. Assessment of Environmental Flow Requirements by EntropyBased Multi-Criteria Decision. Water Resources Management 282: 459-474.

168. Klement, E. P. R. Mesiar 2011. Integral-Based Modifications of OWA-Operators. Nonlinear Mathematics for Uncertainty and Its Applications. S. Li, X. Wang, Y. Okazaki et al. 100: 325331.

169. Koeppen, M., et al. 2011. Fuzzy Fusion Fairness Relations for the Evaluation of User Preference. IEEE International Conference on Fuzzy Systems Fuzz 2011: 2566-2574.

170. Koeppen, M., et al. 2012. Comparative Study on Meta-Heuristics for Achieving Parabolic Fairness in Wireless Channel Allocation.

171. Kojadinovic, I. J.-L. Marichal 2007. On the moments and the distribution of the Choquet integral.

172. Kojadinovic, I. J.-L. Marichal 2009. On the moments and distribution of discrete Choquet integrals from continuous distributions. Journal of Computational and Applied Mathematics 2301: 83-94.

173. Koppen, M. K. Franke 2000. Fuzzy morphologies revisited.

174. Kostreva, M. M., et al. 2004. Equitable aggregations and multiple criteria analysis. European Journal of Operational Research 1582: 362-377.

175. Kurowski, K., et al. 2010. Multicriteria, multi-user scheduling in grids with advance reservation. Journal of Scheduling 135: 493-508. 
176. Kusumadewi, et al. 2007. Sensitivity Analysis of Multi-Attribute Decision Making Methods in Clinical Group Decision Support System.

177. Lai, J., et al. 2010. Aggregating Multiple Ontology Similarity Based on IOWA Operator.

178. Lamata, M. T. 2004. Ranking of alternatives with ordered weighted averaging operators. International Journal of Intelligent Systems 195: 473-482.

179. Lan, J., et al. 2013. Group decision making based on induced uncertain linguistic OWA operators. Decision Support Systems 551: 296-303.

180. Larsen, H. L. 1999. Importance weighted OWA aggregation of multicriteria queries.

181. Larsen, H. L. 2009. Multiplicative and implicative importance weighted averaging aggregation operators with accurate andness direction.

182. Le, C. A., et al. 2007. Combining classifiers for word sense disambiguation based on Dempster-Shafer theory and OWA operators. Data \& Knowledge Engineering 632: 381-396.

183. Leski, J. M. N. Henzel 2012. Generalized ordered linear regression with regularization. Bulletin of the Polish Academy of Sciences-Technical Sciences 603: 481-489.

184. Li, C., et al. 2012. Safety Risk Assessment of Complex Socio-technical System Based on Fuzzy Cognitive Maps.

185. Li, D.-F. 2009. MULTIATTRIBUTE GROUP DECISION MAKING METHOD USING EXTENDED LINGUISTIC VARIABLES. International Journal of Uncertainty Fuzziness and Knowledge-Based Systems 176: 793-806.

186. Li, D.-F. 2010. Multiattribute decision making method based on generalized OWA operators with intuitionistic fuzzy sets. Expert Systems with Applications 3712: 8673-8678.

187. Li, D.-F. 2011. The GOWA operator based approach to multiattribute decision making using intuitionistic fuzzy sets. Mathematical and Computer Modelling 535-6: 1182-1196.

188. Li, D.-F., et al. 2010. GROUP DECISION MAKING METHODOLOGY BASED ON THE ATANASSOV'S INTUITIONISTIC FUZZY SET GENERALIZED OWA OPERATOR. International Journal of Uncertainty Fuzziness and Knowledge-Based Systems 186: 801-817.

189. Li, N. X. Huang 2012. A Combination of Inference Method for Rule Based Fuzzy Classification. Software Engineering and Knowledge Engineering: Theory and Practice, Vol 1. Y. W. Wu. 114: 411-416.

190. Li, Q. IEEE 2008. A Triangular Fuzzy Number-Based Approach to Group Decision Making with Linguistic Preference Information.

191. Li, Q. IEEE 2008. An approach to multi-criteria group decision making with linguistic preference information. Proceedings of 2008 IEEE International Conference on Networking, Sensing and Control, Vols 1 and 2: 494-497.

192. Li, Q. 2008. A Method for Multi-criteria Decision Making with Linguistic Preference Information on Criteria and Alternatives.

193. Li, Q. 2011. A Study on Evalution of HR Outsourcing Providers Based on Multi-criteria Decision Making with Linguistic Preference Information. Smart Materials and Intelligent Systems, Pts 1 and 2. H. Wang, B. J. Zhang, X. Z. Liu, D. Z. Luo and S. B. Zhong. 143-144: 499502. 
194. Li, X. J. Du 2013. Adaptive and attribute-based trust model for service-level agreement guarantee in cloud computing. Iet Information Security 71: 39-50.

195. Li, X., et al. 2008. Linguistic-valued aggregation operators applied to multiple attribute group decision making.

196. Li, X., et al. 2010. A METHOD FOR MULTIPLE ATTRIBUTE GROUP DECISION MAKING BASED ON LINGUISTIC-VALUED AGGREGATION OPERATORS.

197. Li, X., et al. 2011. A multi-dimensional trust evaluation model for large-scale P2P computing. Journal of Parallel and Distributed Computing 716: 837-847.

198. Li, X., et al. 2011. RESEARCH ON TRUST PREDICTION MODEL FOR SELECTING WEB SERVICES BASED ON MULTIPLE DECISION FACTORS. International Journal of Software Engineering and Knowledge Engineering 218: 1075-1096.

199. Li, X.-Y. X.-L. Gui 2009. A Comprehensive and Adaptive Trust Model for Large-Scale P2P Networks. Journal of Computer Science and Technology 245: 868-882.

200. Li, Z., et al. 2009. Identification of Web Information using Concept Hierarchies and On-line Updates of Concept Importance. Proceedings of the Joint 2009 International Fuzzy Systems Association World Congress and 2009 European Society of Fuzzy Logic and Technology Conference: 1583-1588.

201. Liaw, C.-S., et al. 2011. ME-OWA based DEMATEL reliability apportionment method. Expert Systems with Applications 388: 9713-9723.

202. Lin, R. G. Wei 2008. Dependent Linguistic OWGA Operator.

203. Liu, G.-h., et al. 2012. The Application of Multiple Attribute Decision Making on Radio Signal Searching. Measuring Technology and Mechatronics Automation Iv, Pts 1 and 2. Z. X. Hou. 128-129: 714-717.

204. Liu, H., et al. 2007. An approach to robot motion behaviour representation. 2007 IEEE International Conference on Fuzzy Systems, Vols 1-4: 961-966.

205. Liu, H., et al. 2013. The importance weighted continuous generalized ordered weighted averaging operator and its application to group decision making. Knowledge-Based Systems 48: 24-36.

206. Liu, H.-C., et al. 2013. Assessment of health-care waste disposal methods using a VIKORbased fuzzy multi-criteria decision making method. Waste Management 3312: 2744-2751.

207. Liu, H.-C., et al. 2013. Induced aggregation operators in the VIKOR method and its application in material selection. Applied Mathematical Modelling 379: 6325-6338.

208. Liu, J., et al. 2013. The Continuous Quasi-OWA Operator and its Application to Group Decision Making. Group Decision and Negotiation 224: 715-738.

209. Liu, J.-W., et al. 2010. OWA rough set model for forecasting the revenues growth rate of the electronic industry. Expert Systems with Applications 371: 610-617.

210. Liu, P. R. Hu 2007. Research on evaluation of e-commerce websites based on linguistic ordered weighted averaging operator.

211. Liu, P. X. Wu 2013. Multi-attribute group decision-making method based on generalized aggregation operators in trapezoidal fuzzy linguistic variables. Journal of Computational Analysis and Applications 155: 807-816. 
212. Liu, P. Y. Su 2010. The multiple-attribute decision making method based on the TFLHOWA operator. Computers \& Mathematics with Applications 609: 2609-2615.

213. Liu, W. Q. Li 2013. A Multi-criteria Decision Making Method Based on Linguistic Preference Information for IT Outsourcing Vendor Selection in Hospitals. Proceedings of the 2013 International Conference on Information, Business and Education Technology. L. Zhang, X. Li and J. Chen. 26: 341-344.

214. Liu, X. H. Lou 2008. On the equivalence of some approaches to the OWA operator and RIM quantifier determination. Fuzzy Sets and Systems 159(13): 1673-1688.

215. Liu, X. Q. Da 2008. On the properties of regular increasing monotone RIM quantifiers with maximum entropy. International Journal of General Systems 372: 167-179.

216. Liu, X. S. Yu 2012. On the Stress Function-Based OWA Determination Method With Optimization Criteria. IEEE Transactions on Systems Man and Cybernetics Part BCybernetics 421: 246-257.

217. Liu, X. 2008. A general model of parameterized OWA aggregation with given orness level. International Journal of Approximate Reasoning 482: 598-627.

218. Liu, X. 2010. The orness measures for two compound quasi-arithmetic mean aggregation operators. International Journal of Approximate Reasoning 513: 305-334.

219. Liu, X. 2010. THE RELATIONSHIPS BETWEEN TWO VARIABILITY AND ORNESS OPTIMIZATION PROBLEMS FOR OWA OPERATOR WITH RIM QUANTIFIER EXTENSIONS. International Journal of Uncertainty Fuzziness and Knowledge-Based Systems 185: 515-538.

220. Liu, X. 2012. Models to determine parameterized ordered weighted averaging operators using optimization criteria. Information Sciences 190: 27-55.

221. Liu, X. W. L. H. Chen 2004. On the properties of parametric geometric OWA operator. International Journal of Approximate Reasoning 352: 163-178.

222. Liu, X. W. 2005. On the properties of equidifferent RIM quantifier with generating function. International Journal of General Systems 345: 579-594.

223. Liu, X. W., et al. 2004. Generating function representation of RIM quantifiers.

224. Liu, Y., et al. 2013. IDENTIFYING PRIORITY AREAS FOR THE CONSERVATION OF ECOSYSTEM SERVICES USING GIS-BASED MULTICRITERIA EVALUATION. Polish Journal of Ecology 613: 415-430.

225. Llamazares, B. 2004. Simple and absolute special majorities generated by OWA operators. European Journal of Operational Research 1583: 707-720.

226. Llamazares, B. 2007. Choosing OWA operator weights in the field of Social Choice. Information Sciences 17721: 4745-4756.

227. Llamazares, B. 2013. An Analysis of Some Functions That Generalizes Weighted Means and OWA Operators. International Journal of Intelligent Systems 284: 380-393.

228. Loboda, T. V. 2009. Modeling fire danger in data-poor regions: a case study from the Russian Far East. International Journal of Wildland Fire 181: 19-35.

229. Lopez-de-los-Mozsa, M. C., et al. 2008. A generalized model of equality measures in network location problems. Computers \& Operations Research 353: 651-660. 
230. Luo, Y., et al. 2010. Fuzzy Evaluation of IP Network Running Quality Using WOWA. 2nd IEEE International Conference on Advanced Computer Control Icacc 2010, Vol. 4: 51-55.

231. Luukka, P. O. Kurama 2013. Similarity classifier with ordered weighted averaging operators. Expert Systems with Applications 404: 995-1002.

232. Luukka, P., et al. 2013. Fuzzy Scorecards, FHOWA, and a New Fuzzy Similarity Based Ranking Method for Selection of Human Resources. 2013 IEEE International Conference on Systems, Man, and Cybernetics: 601-606.

233. Ma, F.-M. Y.-J. Guo 2011. Density-Induced Ordered Weighted Averaging Operators. International Journal of Intelligent Systems 269: 866-886.

234. Ma, F.-M. Y.-J. Guo 2013. Determination of the Attitudinal Character by Self-Evaluation for the Maximum Entropy OWA Approach. International Journal of Intelligent Systems 2811: 1089-1098.

235. Ma, F.-M., et al. 2012. Analysis of the impact of attitudinal character on the multicriteria decision making with OWA operators. International Journal of Intelligent Systems 275: 502518.

236. Ma, F.-M., et al. 2012. Cluster-reliability-induced OWA operators. International Journal of Intelligent Systems 279: 823-836.

237. Majdan, M. W. Ogryczak 2012. Determining OWA Operator Weights by Mean Absolute Deviation Minimization. Artificial Intelligence and Soft Computing, Pt I. L. Rutkowski, M. Korytkowski, R. Scherer et al. 7267: 283-291.

238. Majlender, P. 2005. OWA operators with maximal Renyi entropy. Fuzzy Sets and Systems 1553: $340-360$.

239. Makropoulos, C. K. D. Butler 2006. Spatial ordered weighted averaging: incorporating spatially variable attitude towards risk in spatial multi-criteria decision-making. Environmental Modelling \& Software 211: 69-84.

240. Makropoulos, C. K., et al. 2003. Fuzzy logic spatial decision support system for urban water management. Journal of Water Resources Planning and Management-Asce 1291: 69-77.

241. Malczewski, J. 2006. Ordered weighted averaging with fuzzy quantifiers: GIS-based multicriteria evaluation for land-use suitability analysis. International Journal of Applied Earth Observation and Geoinformation 84: 270-277.

242. Malczewski, J., et al. 2003. GIS - multicriteria evaluation with ordered weighted averaging OWA: case study of developing watershed management strategies. Environment and Planning A 3510: 1769-1784.

243. Marichal, J. L. P. Mathonet 1999. A characterization of the ordered weighted averaging functions based on the ordered bisymmetry property. IEEE Transactions on Fuzzy Systems 71: 93-96.

244. Mees, W. R. Heremans 2012. Multisensor data fusion for IED threat detection. Optics and Photonics for Counterterrorism, Crime Fighting, and Defence Viii. C. Lewis and D. Burgess. 8546.

245. Meng, D. Z. Pei 2013. On weighted unbalanced linguistic aggregation operators in group decision making. Information Sciences 223: 31-41. 
246. Merigo, J. M. A. A. Gil-Lafuente 2008. THE LINGUISTIC GENERALIZED OWA OPERATOR AND ITS APPLICATION INSTRATEGIC DECISION MAKING.

247. Merigo, J. M. A. M. Gil-Lafuente 2009. The induced generalized OWA operator. Information Sciences 1796: 729-741.

248. Merigo, J. M. A. M. Gil-Lafuente 2010. DECISION MAKING TECHNIQUES IN A UNIFIED MODEL BETWEEN THE WEIGHTED AVERAGE AND THE OWA OPERATOR.

249. Merigo, J. M. A. M. Gil-Lafuente 2010. New decision-making techniques and their application in the selection of financial products. Information Sciences 18011: 2085-2094.

250. Merigo, J. M. A. M. Gil-Lafuente 2010. THE INDUCED GENERALIZED OWAWA DISTANCE OPERATOR.

251. Merigo, J. M. A. M. Gil-Lafuente 2011. Decision-making in sport management based on the OWA operator. Expert Systems with Applications 388: 10408-10413.

252. Merigo, J. M. A. M. Gil-Lafuente 2011. Fuzzy induced generalized aggregation operators and its application in multi-person decision making. Expert Systems with Applications 388: 9761-9772.

253. Merigo, J. M. A. M. Gil-Lafuente 2011. OWA OPERATORS IN HUMAN RESOURCE MANAGEMENT. Economic Computation and Economic Cybernetics Studies and Research 452: 153-168.

254. Merigo, J. M. A. M. Gil-Lafuente 2012. A Method for Decision Making with the OWA Operator. Computer Science and Information Systems 91: 357-380.

255. Merigo, J. M. A. M. Gil-Lafuente 2013. A Method for Decision Making Based on Generalized Aggregation Operators. International Journal of Intelligent Systems 285: 453-473.

256. Merigo, J. M. A. M. Gil-Lafuente 2013. Induced 2-tuple linguistic generalized aggregation operators and their application in decision-making. Information Sciences 236: 1-16.

257. Merigo, J. M. G. Wei 2011. PROBABILISTIC AGGREGATION OPERATORS AND THEIR APPLICATION IN UNCERTAIN MULTI-PERSON DECISION-MAKING. Technological and Economic Development of Economy 172: 335-351.

258. Merigo, J. M. IEEE 2010. Fuzzy Generalized Aggregation Operators in a Unified Model between the Probability, the Weighted Average and the OWA Operator. 2010 IEEE International Conference on Fuzzy Systems Fuzz-IEEE 2010.

259. Merigo, J. M. K. J. Engemann 2010. FUZZY DECISION MAKING WITH PROBABILITIES AND INDUCED AGGREGATION OPERATORS.

260. Merigo, J. M. M. Casanovas 2008. Decision making with Dempster-Shafer belief structure using the 2-tuple linguistic representation model.

261. Merigo, J. M. M. Casanovas 2008. Decision making with distance measures and induced aggregation operators.

262. Merigo, J. M. M. Casanovas 2008. FUZZY INDUCED AGGREGATION OPERATORS IN DECISION MAKING WITH DEMPSTER-SHAFER BELIEF STRUCTURE.

263. Merigo, J. M. M. Casanovas 2008. THE GENERALIZED HYBRID AVERAGING OPERATOR AND ITS APPLICATION INFINANCIAL DECISION MAKING. 
264. Merigo, J. M. M. Casanovas 2009. Induced Aggregation Operators in Decision Making with the Dempster-Shafer Belief Structure. International Journal of Intelligent Systems 248: 934954.

265. Merigo, J. M. M. Casanovas 2010. A NEW DECISION MAKING METHOD BASED ON DISTANCE MEASURES AND ITS APPLICATION IN EDUCATIONAL MANAGEMENT. 4th International Technology, Education and Development Conference Inted 2010: 987-998.

266. Merigo, J. M. M. Casanovas 2010. DEALING WITH UNCERTAIN INFORMATION IN THE INDUCED PROBABILISTIC OWA OPERATOR.

267. Merigo, J. M. M. Casanovas 2010. Decision Making with Distance Measures and Linguistic Aggregation Operators. International Journal of Fuzzy Systems 123: 190-198.

268. Merigo, J. M. M. Casanovas 2010. FUZZY AGGREGATION OPERATORS AND ITS APPLICATION IN THE SELECTION OF PROFESSORS. 4th International Technology, Education and Development Conference Inted 2010: 975-986.

269. Merigo, J. M. M. Casanovas 2010. Fuzzy Generalized Hybrid Aggregation Operators and its Application in Fuzzy Decision Making. International Journal of Fuzzy Systems 121: 15-24.

270. Merigo, J. M. M. Casanovas 2010. Induced and heavy aggregation operators with distance measures. Journal of Systems Engineering and Electronics 213: 431-439.

271. Merigo, J. M. M. Casanovas 2010. The Fuzzy Generalized OWA Operator and Its Application in Strategic Decision Making. Cybernetics and Systems 415: 359-370.

272. Merigo, J. M. M. Casanovas 2010. USING DISTANCE MEASURES IN HEAVY AGGREGATION OPERATORS.

273. Merigo, J. M. M. Casanovas 2011. A New Minkowski Distance Based on Induced Aggregation Operators. International Journal of Computational Intelligence Systems 42: 123133.

274. Merigo, J. M. M. Casanovas 2011. Decision-making with distance measures and induced aggregation operators. Computers \& Industrial Engineering 601: 66-76.

275. Merigo, J. M. M. Casanovas 2011. FUZZY GROUP DECISION MAKING IN RESEARCH MANAGEMENT. Edulearn11: 3rd International Conference on Education and New Learning Technologies. L. G. Chova, D. M. Belenguer and A. L. Martinez: 6057-6064.

276. Merigo, J. M. M. Casanovas 2011. Generalized Aggregation Operators in Decision Making with Dempster-Shafer Belief Structure. Information-an International Interdisciplinary Journal 148: 2711-2732.

277. Merigo, J. M. M. Casanovas 2011. Induced aggregation operators in the Euclidean distance and its application in financial decision making. Expert Systems with Applications 386: 76037608.

278. Merigo, J. M. M. Casanovas 2011. Induced and uncertain heavy OWA operators. Computers \& Industrial Engineering 601: 106-116.

279. Merigo, J. M. R. R. Yager 2013. GENERALIZED MOVING AVERAGES, DISTANCE MEASURES AND OWA OPERATORS. International Journal of Uncertainty Fuzziness and Knowledge-Based Systems 214: 533-559. 
280. Merigo, J. M. 2009. On the Use of the OWA Operator in the Weighted Average and its Application in Decision Making. World Congress on Engineering 2009, Vols I and Ii. S. I. Ao, L. Gelman, D. W. L. Hukins, A. Hunter and A. M. Korsunsky: 82-87.

281. Merigo, J. M. 2009. Probabilistic Decision Making with the OWA Operator and its Application in Investment Management. Proceedings of the Joint 2009 International Fuzzy Systems Association World Congress and 2009 European Society of Fuzzy Logic and Technology Conference: 1364-1369.

282. Merigo, J. M. 2010. A METHOD FOR DECISION MAKING BASED ON PROBABILISTIC INFORMATION AND DISTANCE MEASURES. Edulearn10: International Conference on Education and New Learning Technologies.

283. Merigo, J. M. 2010. Fuzzy decision making with immediate probabilities. Computers \& Industrial Engineering 584: 651-657.

284. Merigo, J. M. 2010. INDUCED GENERALIZED AGGREGATION OPERATORS IN THE WEIGHTED AVERAGE.

285. Merigo, J. M. 2010. INDUCED GENERALIZED PROBABILISTIC OWAWA OPERATOR.

286. Merigo, J. M. 2010. ON THE UNIFICATION BETWEEN THE PROBABILITY, THE WEIGHTED AVERAGE AND THE OWA OPERATOR.

287. Merigo, J. M. 2011. A unified model between the weighted average and the induced OWA operator. Expert Systems with Applications 389: 11560-11572.

288. Merigo, J. M. 2011. Fuzzy Multi-Person Decision Making with Fuzzy Probabilistic Aggregation Operators. International Journal of Fuzzy Systems 133: 163-174.

289. Merigo, J. M., et al. 2009. Induced Aggregation Operators in the Generalized Adequacy Coefficient. World Congress on Engineering 2009, Vols I and Ii. S. I. Ao, L. Gelman, D. W. L. Hukins, A. Hunter and A. M. Korsunsky: 7-11.

290. Merigo, J. M., et al. 2009. On the Use of the Uncertain Induced OWA Operator and the Uncertain Weighted Average and its Application in Tourism Management.

291. Merigo, J. M., et al. 2010. LINGUISTIC AGGREGATION OPERATORS FOR LINGUISTIC DECISION MAKING BASED ON THE DEMPSTER-SHAFER THEORY OF EVIDENCE. International Journal of Uncertainty Fuzziness and Knowledge-Based Systems 183: 287-304.

292. Merigo, J. M., et al. 2010. Probabilistic Aggregation Operators with the Induced Generalized OWA Operator. 2010 IEEE International Conference on Fuzzy Systems Fuzz-IEEE 2010.

293. Merigo, J. M., et al. 2011. DECISION MAKING WITH THE INDUCED GENERALIZED ADEQUACY COEFFICIENT. Applied and Computational Mathematics 102: 321-339.

294. Merigo, J. M., et al. 2011. Generalization of the linguistic aggregation operator and its application in decision making. Journal of Systems Engineering and Electronics 224: 593-603.

295. Merigo, J. M., et al. 2011. MAKING DECISIONS IN EDUCATIONAL MANAGEMENT WITH PROBABILISTIC AND IMPRECISE INFORMATION. Edulearn11: 3rd International Conference on Education and New Learning Technologies. L. G. Chova, D. M. Belenguer and A. L. Martinez: 6041-6051. 
296. Merigo, J. M., et al. 2011. Soft Computing Techniques for Decision Making with Induced Aggregation Operators. Information-an International Interdisciplinary Journal 146: 20192039.

297. Merigo, J. M., et al. 2012. Decision making in the European Union under risk and uncertainty. European Journal of International Management 65: 590-609.

298. Merigo, J. M., et al. 2012. GROUP DECISION-MAKING WITH GENERALIZED AND PROBABILISTIC AGGREGATION OPERATORS. International Journal of Innovative Computing Information and Control 87A: 4823-4835.

299. Merigo, J. M., et al. 2012. Induced and Linguistic Generalized Aggregation Operators and Their Application in Linguistic Group Decision Making. Group Decision and Negotiation 214: 531-549.

300. Merigo, J. M., et al. 2012. Uncertain induced aggregation operators and its application in tourism management. Expert Systems with Applications 391: 869-880.

301. Merigo, J. M., et al. 2013. DECISION MAKING WITH DEMPSTER-SHAFER BELIEF STRUCTURE AND THE OWAWA OPERATOR. Technological and Economic Development of Economy 19: S100-S118.

302. Merigo, J. M., et al. 2013. DECISION MAKING WITH INDUCED AGGREGATION OPERATORS AND THE ADEQUACY COEFFICIENT. Economic Computation and Economic Cybernetics Studies and Research 471: 185-202.

303. Merigo, J. M., et al. 2013. Group decision making with distance measures and probabilistic information. Knowledge-Based Systems 40: 81-87.

304. Mesiar, R. S. Saminger 2004. Domination of ordered weighted averaging operators over tnorms. Soft Computing 88: 562-570.

305. Min, Z., et al. 2008. Dynamic Evaluation of Supplier Performance Based on Product Strategy.

306. Mitchell, H. B. D. D. Estrakh 1997. A modified OWA operator and its use in lossless DPCM image compression. International Journal of Uncertainty Fuzziness and Knowledge-Based Systems 54: 429-436.

307. Mitchell, H. B. D. D. Estrakh 1998. An OWA operator with fuzzy ranks. International Journal of Intelligent Systems 131: 69-81.

308. Mitchell, H. B. P. A. Schaefer 2000. Multiple priorities in an induced ordered weighted averaging operator. International Journal of Intelligent Systems 154: 317-327.

309. Mokarram, M., et al. 2011. Land suitability evaluation using ordered weight averaging with fuzzy quantifier in Shavoor plain, Iran. Research on Crops 122: 593-599.

310. Moshiri, B., et al. 2006. Application of OWA based classifier fusion in diagnosis and treatment offering for female urinary incontinence. AI 2006: Advances in Artificial Intelligence, Proceedings. A. Sattar and B. H. Kang. 4304: 433-442.

311. Murata, T., et al. 1998. Formulation of multi-objective fuzzy scheduling problems using OWA operator.

312. Muzychuk, A. 2011. OWA Weight Updating in Repeated Decision Making under the Influence of Additional Information. International Journal of Intelligent Systems 267: 591602. 
313. Nadi, S. M. R. Delavar 2011. Multi-criteria, personalized route planning using quantifierguided ordered weighted averaging operators. International Journal of Applied Earth Observation and Geoinformation 133: 322-335.

314. Naether, W. K. Waelder 2007. Applying fuzzy measures for considering interaction effects in root dispersal models. Fuzzy Sets and Systems 1585: 572-582.

315. Nasibov, E. C. Kandemir-Cavas 2011. OWA-based linkage method in hierarchical clustering: Application on phylogenetic trees. Expert Systems with Applications 3810: 12684-12690.

316. Nawaz, A. A. Khanum 2011. Ranked Neuro Fuzzy Inference System RNFIS for Information Retrieval. Advances in Neural Networks - Isnn 2011, Pt I. D. Liu, H. G. Zhang, M. Polycarpou, C. Alippi and H. He. 6675: 578-586.

317. Nemmour, H. Y. Chibani 2005. Neural network combination by fuzzy integral for robust change detection in remotely sensed imagery. Eurasip Journal on Applied Signal Processing 200514: 2187-2195.

318. Nettleton, D. R. Baeza-Yates 2008. Web Retrieval: Techniques for the Aggregation and Selection of Queries and Answers. International Journal of Intelligent Systems 2312: 12231234.

319. Nusrat, E. K. Yamada 2013. A DESCRIPTIVE DECISION-MAKING MODEL UNDER UNCERTAINTY: COMBINATION OF DEMPSTER-SHAFER THEORY AND PROSPECT THEORY. International Journal of Uncertainty Fuzziness and Knowledge-Based Systems 211: 79-102.

320. Ogryczak, W. T. Sliwinski 2003. On solving linear programs with the ordered weighted averaging objective. European Journal of Operational Research 1481: 80-91.

321. Ogryczak, W. T. Sliwinski 2007. On decision support under risk by the WOWA optimization. Symbolic and Quantitative Approaches to Reasoning with Uncertainty, Proceedings. K. Mellouli. 4724: 779-790.

322. Ogryczak, W. T. Sliwinski 2007. On optimization of the importance weighted OWA aggregation of multiple criteria. Computational Science and Its Applications - ICCSA 2007, Pt 1, Proceedings. O. Gervasi and M. L. Gavrilova. 4705: 804-817.

323. Ogryczak, W. T. Sliwinski 2009. On efficient WOWA optimization for decision support under risk. International Journal of Approximate Reasoning 506: 915-928.

324. Ohagan, M. 1990. A FUZZY NEURON BASED ON MAXIMUM-ENTROPY ORDERED WEIGHTED AVERAGING. Twenty-Fourth Asilomar Conference on Signals, Systems \& Computers, Vols 1 and 2: 618-623.

325. Ohagan, M. 1991. A FUZZY NEURON BASED UPON MAXIMUM-ENTROPY ORDERED WEIGHTED AVERAGING. Lecture Notes in Computer Science 521: 598-609.

326. Ohagan, M. 1991. A FUZZY NEURON BASED UPON MAXIMUM-ENTROPY ORDERED WEIGHTED AVERAGING. Uncertainty in Knowledge Bases. B. Bouchonmeunier, R. R. Yager and L. A. Zadeh. 521: 598-609.

327. Okur, A., et al. 2009. Using OWA aggregation technique in QFD: a case study in education in a textile engineering department. Quality \& Quantity 436: 999-1009.

328. Pei, Z. L. Yi 2006. A new aggregation operator of linguistic information and its properties. 
329. Pei, Z., et al. 2005. Gathering linguistic information in distributed intelligent agent on the Internet.

330. Pei, Z., et al. 2007. Handling linguistic web information based on a multi-agent system. International Journal of Intelligent Systems 225: 435-453.

331. Pei, Z., et al. 2013. A LINGUISTIC AGGREGATION OPERATOR INCLUDING WEIGHTS FOR LINGUISTIC VALUES AND EXPERTS IN GROUP DECISION MAKING. International Journal of Uncertainty Fuzziness and Knowledge-Based Systems 216: 927-943.

332. Pelaez, J. I. 2001. AMA: An OWA operator based on the majority process. Computational Intelligence: Theory and Applications, Proceedings. B. Reusch. 2206: 937-949.

333. Peng, D.-H., et al. 2013. A Direct Approach Based on C-2-IULOWA Operator for Group Decision Making with Uncertain Additive Linguistic Preference Relations. Journal of Applied Mathematics.

334. Preethi, G. A. C. Chandrasekar 2013. A Network Selection Algorithm Based on AHP-OWA Methods.

335. Qi, X.-w., et al. 2013. Some Generalized Dependent Aggregation Operators with IntervalValued Intuitionistic Fuzzy Information and Their Application to Exploitation Investment Evaluation. Journal of Applied Mathematics.

336. Qian, G., et al. 2006. Extended IOWA operator and its application to group decision making with linguistic preference information.

337. Qu, Z. B. Ge 2008. Implementation of mail filtering based on multi-attribute group decision making.

338. Rahman, M. A., et al. 2012. A new spatial multi-criteria decision support tool for site selection for implementation of managed aquifer recharge. Journal of Environmental Management 99: 61-75.

339. Rahman, M. A., et al. 2013. An integrated study of spatial multicriteria analysis and mathematical modelling for managed aquifer recharge site suitability mapping and site ranking at Northern Gaza coastal aquifer. Journal of Environmental Management 124: 25-39.

340. Rahmani, M. A. M. Zarghami 2013. A new approach to combine climate change projections by ordered weighting averaging operator; applications to northwestern provinces of Iran. Global and Planetary Change 102: 41-50.

341. Rahmanimanesh, M. S. Jalili 2013. ADAPTIVE ORDERED WEIGHTED AVERAGING FOR ANOMALY DETECTION IN CLUSTER-BASED MOBILE AD HOC NETWORKS. Iranian Journal of Fuzzy Systems 102: 83-109.

342. Rajabi, M., et al. 2012. Susceptibility mapping of visceral leishmaniasis based on fuzzy modelling and group decision-making methods. Geospatial Health 71: 37-50.

343. Reformat, M. R. R. Yager 2008. Building ensemble classifiers using belief functions and OWA operators. Soft Computing 126: 543-558.

344. Reformat, M. Z. S. K. Golmohammadi 2010. Rule- and OWA-based Semantic Similarity for User Profiling. International Journal of Fuzzy Systems 122: 87-102. 
345. Reformat, M. Z., et al. 2011. Human-inspired Identification of High-level Concepts using OWA and Linguistic Quantifiers. International Journal of Computers Communications \& Control 63: 473-502.

346. Renaud, J., et al. 2008. Weights determination of OWA operators by parametric identification. Mathematics and Computers in Simulation 775-6: 499-511.

347. Ribeiro, R. A. R. A. M. Pereira 2003. Generalized mixture operators using weighting functions: A comparative study with WA and OWA. European Journal of Operational Research 1452: 329-342.

348. Rinner, C., et al. 2010. The Role of Maps in Neighborhood-level Heat Vulnerability Assessment for the City of Toronto. Cartography and Geographic Information Science 371: 31-44.

349. Robinson, J. P. H. E. C. Amirtharaj 2012. A Search for the Correlation Coefficient of Triangular and Trapezoidal Intuitionistic Fuzzy Sets for Multiple Attribute Group Decision Making. Mathematical Modelling and Scientific Computation. P. Balasubramaniam and R. Uthayakumar. 283: 333-342.

350. Robinson, T. P., et al. 2010. Comparison of alternative strategies for invasive species distribution modeling. Ecological Modelling 22119: 2261-2269.

351. Rocco S, C. M., et al. 2010. Composite indicators for security of energy supply in Europe using ordered weighted averaging.

352. Rodger, J. A., et al. 2014. Decision making using a fuzzy induced linguistic ordered weighted averaging approach for evaluating risk in a supply chain. International Journal of Advanced Manufacturing Technology 701-4: 711-723.

353. Ryoke, M., et al. 2008. Personalized recommendation for traditional crafts using fuzzy correspondence analysis with kansei data and OWA operator. Interval / Probabilistic Uncertainty and Non-Classical Logics. V. N. Huynh, Y. Nakamori, H. Ono et al. 46: 311-325.

354. Sadiq, R. S. Tesfamariam 2007. Probability density functions based weights for ordered weighted averaging OWA operators: An example of water quality indices. European Journal of Operational Research 1823: 1350-1368.

355. Sadiq, R. S. Tesfamariam 2008. Developing environmental indices using fuzzy numbers ordered weighted averaging FN-OWA operators. Stochastic Environmental Research and Risk Assessment 224: 495-505.

356. Sadiq, R., et al. 2007. Water quality failures in distribution networks - Risk analysis using fuzzy logic and evidential reasoning. Risk Analysis 275: 1381-1394.

357. Sadiq, R., et al. 2010. Integrating indicators for performance assessment of small water utilities using ordered weighted averaging OWA operators. Expert Systems with Applications 377: 4881-4891.

358. Sait, S. M., et al. 2001. Fuzzy simulated evolution for power and performance optimization of VLSI placement. Ijcnn'01: International Joint Conference on Neural Networks, Vols 1-4, Proceedings: 738-743.

359. Salahshoor, K., et al. 2010. Fault detection and diagnosis of an industrial steam turbine using fusion of SVM support vector machine and ANFIS adaptive neuro-fuzzy inference system classifiers. Energy 3512: 5472-5482. 
360. Salguero, A. F. Araque 2010. Integration of Similar Evolving Data Sources for Supporting Decision Making Tasks. Journal of Universal Computer Science 161: 22-36.

361. Sanchez-Hernandez, G., et al. 2013. Ranking and selection of unsupervised learning marketing segmentation. Knowledge-Based Systems 44: 20-33.

362. Sang, X., et al. 2014. Parametric Weighting Function for WOWA Operator and Its Application in Decision Making. International Journal of Intelligent Systems 292: 119-136.

363. Sener, Z. E. E. Karsak 2012. A decision model for setting target levels in software quality function deployment to respond to rapidly changing customer needs. Concurrent Engineering-Research and Applications 201: 19-29.

364. Sharifnasab, H., et al. 2009. DECISION SUPPORT SYSTEM BY ORDERED WEIGHT AVERAGING OWA METHOD. Computer and Computing Technologies in Agriculture Ii, Vol 1. D. Li and C. Zhao. 293: 613-623.

365. Sharma, S. K., et al. 2012. Choosing the best Twenty20 cricket batsmen using ordered weighted averaging. International Journal of Performance Analysis in Sport 123: 614-628.

366. Shen, W.-J., et al. 2013. An effective and effecient peptide binding prediction approach for a broad set of HLA-DR molecules based on ordered weighted averaging of binding pocket profiles. Proteome Science 11.

367. Sliwinski, T. 2013. Fair Resource Allocation in Multi-commodity Networks. New Trends in Databases and Information Systems. M. Pechenizkiy and M. Wojciechowski. 185: 261-269.

368. Smith, P. N. 2006. Flexible aggregation in multiple attribute decision making: Application to the Kuranda Range Road upgrade. Cybernetics and Systems 371: 1-22.

369. Smolikova, R. M. P. Wachowiak 2002. Aggregation operators for selection problems. Fuzzy Sets and Systems 1311: 23-34.

370. Snasel, V., et al. 2007. Fusing data and optimizing queries for intelligent search.

371. Squillante, M. V. Ventre 2010. Assessing False Consensus Effect in a Consensus Enhancing Procedure. International Journal of Intelligent Systems 253: 274-285.

372. Su, W., et al. 2013. A method for fuzzy group decision making based on induced aggregation operators and Euclidean distance. International Transactions in Operational Research 204: 579-594.

373. $\mathrm{Su}, \mathrm{W}$., et al. 2013. UNCERTAIN GROUP DECISION-MAKING WITH INDUCED AGGREGATION OPERATORS AND EUCLIDEAN DISTANCE. Technological and Economic Development of Economy 193: 431-447.

374. Su, W., et al. 2014. Atanassov's intuitionistic linguistic ordered weighted averaging distance operator and its application to decision making. Journal of Intelligent \& Fuzzy Systems 263: 1491-1502.

375. Su, Z.-x., et al. 2011. Some induced intuitionistic fuzzy aggregation operators applied to multi-attribute group decision making. International Journal of General Systems 408: 805835.

376. Su, Z.-X., et al. 2012. Induced generalized intuitionistic fuzzy OWA operator for multiattribute group decision making. Expert Systems with Applications 392: 1902-1910. 
377. Suo, M. Q., et al. 2012. Multicriteria decision making under uncertainty: An advanced ordered weighted averaging operator for planning electric power systems. Engineering Applications of Artificial Intelligence 251: 72-81.

378. Szidarovszky, F. M. Zarghami 2009. COMBINING FUZZY QUANTIFIERS AND NEAT OPEPRATORS FOR SOFT COMPUTING. Iranian Journal of Fuzzy Systems 61: 15-25.

379. Taber, R., et al. 2001. Small-sample quantization effects on the equilibrium behavior of combined fuzzy cognitive maps.

380. Taber, R., et al. 2007. Quantization effects on the equilibrium behavior of combined fuzzy cognitive maps. International Journal of Intelligent Systems 222: 181-202.

381. Tan, C. X. Chen 2010. Induced Choquet Ordered Averaging Operator and Its Application to Group Decision Making. International Journal of Intelligent Systems 251: 59-82.

382. Teresa Lamata, M. E. Cables Perez 2012. Obtaining OWA operators starting from a linear order and preference quantifiers. International Journal of Intelligent Systems 273: 242-258.

383. Tesfamariam, S. R. Sadiq 2008. Probabilistic risk analysis using ordered weighted averaging OWA operators. Stochastic Environmental Research and Risk Assessment 221: 1-15.

384. Tokhmechi, B., et al. 2009. A novel approach proposed for fractured zone detection using petrophysical logs. Journal of Geophysics and Engineering 64: 365-373.

385. Torra, V. Z. Lv 2009. On the WOWA Operator and Its Interpolation Function. International Journal of Intelligent Systems 2410: 1039-1056.

386. Triantakonstantis, D. P., et al. 2013. Autologistic regression and multicriteria evaluation models for the prediction of forest expansion. New Forests 442: 163-181.

387. Victor, P., et al. 2011. Practical aggregation operators for gradual trust and distrust. Fuzzy Sets and Systems 1841: 126-147.

388. Wang, C., et al. 2009. Fuzzy Group Decision Making Method and Its Application. Advances in Neural Networks - Isnn 2009, Pt 1, Proceedings. W. Yu, H. He and N. Zhang. 5551: 10901097.

389. Wang, C.-H. H. Luh 2006. Network dimensioning problems of applying achievement functions.

390. Wang, H., et al. 2014. PRIORITIZED AGGREGATION FOR NON-HOMOGENEOUS GROUP DECISION MAKING IN WATER RESOURCE MANAGEMENT. Economic Computation and Economic Cybernetics Studies and Research 481: 247-257.

391. Wang, J.-H. J. Hao 2009. An approach to aggregation of ordinal information in multi-criteria multi-person decision making using Choquet integral of Fubini type. Fuzzy Optimization and Decision Making 84: 365-380.

392. Wang, J.-Q., et al. 2012. MULTI-CRITERIA DECISION-MAKING METHOD BASED ON INDUCED INTUITIONISTIC NORMAL FUZZY RELATED AGGREGATION OPERATORS. International Journal of Uncertainty Fuzziness and Knowledge-Based Systems 204: 559-578.

393. Wang, Q., et al. 2010. A Numerical Method of Evaluating Brownfields using Fuzzy Boundaries and Fuzzy Real Options. IEEE International Conference on Systems, Man and Cybernetics. 
394. Wang, S., et al. 2009. Generalized ordered weighted averaging operators based methods for MADM in intuitionistic fuzzy set setting. Journal of Systems Engineering and Electronics 206: $1247-1254$.

395. Wang, S.-Y. 2008. Applying 2-tuple multigranularity linguistic variables to determine the supply performance in dynamic environment based on product-oriented strategy. IEEE Transactions on Fuzzy Systems 161: 29-39.

396. Wang, W. X. Liu 2012. Intuitionistic Fuzzy Information Aggregation Using Einstein Operations. IEEE Transactions on Fuzzy Systems 205: 923-938.

397. Wang, W. X. Liu 2013. Interval-valued intuitionistic fuzzy hybrid weighted averaging operator based on Einstein operation and its application to decision making. Journal of Intelligent \& Fuzzy Systems 252: 279-290.

398. Wang, W. 2014. Comment on Some hybrid weighted averaging operators and their application to decision making. Information Fusion 16: 84-85.

399. Wang, W., et al. 2012. Interval-valued intuitionistic fuzzy aggregation operators. Journal of Systems Engineering and Electronics 234: 574-580.

400. Wang, X. 2008. Fuzzy number intuitionistic fuzzy arithmetic aggregation operators. International Journal of Fuzzy Systems 102: 104-111.

401. Wang, X.-F., et al. 2012. General fuzzy number intuitionistic fuzzy arithmetic aggregation operators based on fuzzy structured element. Proceedings of the 2012 24th Chinese Control and Decision Conference: 2640-2645.

402. Wang, X.-F., et al. 2014. Multi-criteria group decision making method based on intuitionistic linguistic aggregation operators. Journal of Intelligent \& Fuzzy Systems 261: 115-125.

403. Wang, X.-q., et al. 2008. Some New Aggregation Operators and Their Application in Group Decision-making Based on Fuzzy Preference Relations.

404. Wang, Y. M. C. Parkan 2005. A minimax disparity approach for obtaining OWA operator weights. Information Sciences 1751-2: 20-29.

405. Wang, Y.-M. K.-S. Chin 2011. The use of OWA operator weights for cross-efficiency aggregation. Omega-International Journal of Management Science 395: 493-503.

406. Wang, Y.-M., et al. 2007. Aggregating preference rankings using OWA operator weights. Information Sciences 17716: 3356-3363.

407. Wang, Y.-M., et al. 2007. Two new models for determining OWA operator weights. Computers \& Industrial Engineering 522: 203-209.

408. Wang, Z., et al. 2011. An Information Fusion Based Multi-Agent Control System for Indoor Energy and Comfort Management in Smart and Green Buildings. 2011 IEEE Power and Energy Society General Meeting.

409. Wang, Z., et al. 2012. Multi-agent control system with information fusion based comfort model for smart buildings. Applied Energy 99: 247-254.

410. Wei, C. X. Tang 2012. Generalized prioritized aggregation operators. International Journal of Intelligent Systems 276: 578-589.

411. Wei, G. H. Yao 2006. Extended IOWA operator and its application to group decision making with linguistic information. 
412. Wei, G. U. Alfred 2007. Dependent OWGA operator.

413. Wei, G. U. Alfred 2007. Induced uncertain pure linguistic OWA operator and its application.

414. Wei, G. X. Zhao 2012. Some dependent aggregation operators with 2-tuple linguistic information and their application to multiple attribute group decision making. Expert Systems with Applications 395: 5881-5886.

415. Wei, G. X. Zhao 2013. Induced hesitant interval-valued fuzzy Einstein aggregation operators and their application to multiple attribute decision making. Journal of Intelligent \& Fuzzy Systems 244: 789-803.

416. Wei, G., et al. 2013. Some hesitant interval-valued fuzzy aggregation operators and their applications to multiple attribute decision making. Knowledge-Based Systems 46: 43-53.

417. Wei, G., et al. 2014. Hesitant triangular fuzzy information aggregation in multiple attribute decision making. Journal of Intelligent \& Fuzzy Systems 263: 1201-1209.

418. Wei, H., et al. 2010. Inoperability Input-Output Modeling IIM of Disruptions to Supply Chain Networks. Systems Engineering 134: 324-339.

419. Wong, W. K., et al. 2009. A fashion mix-and-match expert system for fashion retailers using fuzzy screening approach. Expert Systems with Applications 362: 1750-1764.

420. $\mathrm{Wu}$, J., et al. 2009. A linear programming model for determining ordered weighted averaging operator weights with maximal Yager's entropy. Computers \& Industrial Engineering 573: 742-747.

421. Wu, J., et al. 2009. The induced continuous ordered weighted geometric operators and their application in group decision making. Computers \& Industrial Engineering 564: 1545-1552.

422. Wu, Y.-h., et al. 2009. A Learning Evaluation System Based on Classifier fusion for Elearning.

423. Wu, Y.-h., et al. 2009. A New Method for Fish disease Diagnosis System Based on Rough Set and Classifier Fusion.

424. $\mathrm{Wu}, \mathrm{Z}$. Y. Chen 2007. The maximizing deviation method for group multiple attribute decision making under linguistic environment. Fuzzy Sets and Systems 15814: 1608-1617.

425. Xia, M. Z. Xu 2010. Generalized Point Operators for Aggregating Intuitionistic Fuzzy Information. International Journal of Intelligent Systems 2511: 1061-1080.

426. Xia, Y.-q. R.-p. Zhu 2009. Research on Gift Design and Decision-making Approach Based on Value Engineering Theory.

427. Xian, S. 2012. Fuzzy Linguistic Induced Ordered Weighted Averaging Operator and Its Application. Journal of Applied Mathematics.

428. Xu, J., et al. 2004. TOPSIS for group decision making under linguistic information and its application to CS evaluation. Proceedings of the Third International Conference on Information and Management Sciences. L. Liu, X. Zhao, M. Gen, L. Li and Y. Li. 3: 467-472.

429. Xu, W. X., et al. 2008. A new approach to decision-making with key constraint and its application in enterprise information systems. Enterprise Information Systems 23: 287-308.

430. Xu, Y. H. Wang 2012. The induced generalized aggregation operators for intuitionistic fuzzy sets and their application in group decision making. Applied Soft Computing 123: 1168-1179. 
431. Xu, Y., et al. 2010. Linear goal programming approach to obtaining the weights of intuitionistic fuzzy ordered weighted averaging operator. Journal of Systems Engineering and Electronics 216: 990-994.

432. Xu, Y., et al. 2010. Some properties of linguistic preference relation and its ranking in group decision making. Journal of Systems Engineering and Electronics 212: 244-249.

433. Xu, Y.-j., et al. 2007. A Priority Method Based on Induced Trapezoidal Fuzzy Ordered Weighted Averaging ITFOWA Operator for Fuzzy Linguistic Decision-Making Problems.

434. Xu, Z. J. Chen 2008. ORDERED WEIGHTED DISTANCE MEASURE. Journal of Systems Science and Systems Engineering 174: 432-445.

435. Xu, Z. 2006. A C-OWA operator-based approach to decision making with interval fuzzy preference relation. International Journal of Intelligent Systems 2112: 1289-1298.

436. Xu, Z. 2006. A note on linguistic hybrid arithmetic averaging operator in multiple attribute group decision making with linguistic information. Group Decision and Negotiation 156: 593-604.

437. Xu, Z. 2006. Induced uncertain linguistic OWA operators applied to group decision making. Information Fusion 72: 231-238.

438. Xu, Z. 2007. Group decision making with triangular fuzzy linguistic variables. Intelligent Data Engineering and Automated Learning - Ideal 2007. H. Yin, P. Tino, E. Corchado, W. Byrne and X. Yao. 4881: 17-26.

439. Xu, Z. 2007. Intuitionistic fuzzy aggregation operators. IEEE Transactions on Fuzzy Systems 156: 1179-1187.

440. Xu, Z. 2008. Dependent uncertain ordered weighted aggregation operators. Information Fusion 92: 310-316.

441. Xu, Z. 2008. Hybrid Weighted Distance Measures and Their Application to Pattern Recognition. Intelligent Data Engineering and Automated Learning - Ideal 2008. C. Fyfe, D. Kim, S. Y. Lee and H. Yin. 5326: 17-23.

442. Xu, Z. 2010. A Deviation-Based Approach to Intuitionistic Fuzzy Multiple Attribute Group Decision Making. Group Decision and Negotiation 191: 57-76.

443. Xu, Z. 2010. Uncertain Bonferroni Mean Operators. International Journal of Computational Intelligence Systems 36: 761-769.

444. Xu, Z. 2012. A Survey and Prospects of OWA Aggregation with Intuitionistic Fuzzy Information. Information-an International Interdisciplinary Journal 1511B: 4763-4776.

445. Xu, Z. S. Q. L. Da 2002. The uncertain OWA operator. International Journal of Intelligent Systems 176: 569-575.

446. Xu, Z. S. Q. L. Da 2003. An overview of operators for aggregating information. International Journal of Intelligent Systems 189: 953-969.

447. Xu, Z. S. W. L. Da 2002. The ordered weighted geometric averaging operators. International Journal of Intelligent Systems 177: 709-716.

448. Xu, Z. S. 2004. EOWA and EOWG operators for aggregating linguistic labels based on linguistic preference relations. International Journal of Uncertainty Fuzziness and Knowledge-Based Systems 126: 791-810. 
449. Xu, Z. S. 2004. Uncertain linguistic aggregation operators based approach to multiple attribute group decision making under uncertain linguistic environment. Information Sciences 1681-4: 171-184.

450. Xu, Z. S. 2006. Dependent OWA operators. Modeling Decisions for Artificial Intelligence. V. Torra, Y. Narukawa, A. Valls and J. DomingoFerrer. 3885: 172-178.

451. Xu, Z. S. 2006. On generalized induced linguistic aggregation operators. International Journal of General Systems 351: 17-28.

452. Xu, Z.-S. J. Chen 2007. An interactive method for fuzzy multiple attribute group decision making. Information Sciences 1771: 248-263.

453. Yager, R. R. D. P. Filev 1994. Parameterized and-like and or-like OWA operators. International Journal of General Systems 223: 297-316.

454. Yager, R. R. D. P. Filev 1999. Induced ordered weighted averaging operators. IEEE Transactions on Systems Man and Cybernetics Part B-Cybernetics 292: 141-150.

455. Yager, R. R. G. Beliakov 2010. OWA Operators in Regression Problems. IEEE Transactions on Fuzzy Systems 181: 106-113.

456. Yager, R. R. IEEE 2006. A human directed approach for data summarization. 2006 IEEE International Conference on Fuzzy Systems, Vols 1-5: 707-712.

457. Yager, R. R. N. Alajlan 2014. Probabilistically Weighted OWA Aggregation. IEEE Transactions on Fuzzy Systems 221: 46-56.

458. Yager, R. R. V. Kreinovich 2002. Main ideas behind OWA lead to a universal and optimal approximation scheme. Proceedings of Fuzzy Information Processing Society, 428-433.

459. Yager, R. R. 1988. ON ORDERED WEIGHTED AVERAGING AGGREGATION OPERATORS IN MULTICRITERIA DECISION-MAKING. IEEE Transactions on Systems Man and Cybernetics 181: 183-190.

460. Yager, R. R. 1993. FAMILIES OF OWA OPERATORS. Fuzzy Sets and Systems 592: 125-148.

461. Yager, R. R. 1995. MEASURES OF ENTROPY AND FUZZINESS RELATED TO AGGREGATION OPERATORS. Information Sciences 823-4: 147-166.

462. Yager, R. R. 1996. Constrained OWA aggregation. Fuzzy Sets and Systems 811: 89-101.

463. Yager, R. R. 1996. Fuzzy set methods in multi-media storage and retrieval.

464. Yager, R. R. 1997. On the analytic representation of the Leximin ordering and its application to flexible constraint propagation. European Journal of Operational Research 1021: 176-192.

465. Yager, R. R. 1998. Fusion of ordinal information using weighted median aggregation. International Journal of Approximate Reasoning 181-2: 35-52.

466. Yager, R. R. 1998. Including importances in OWA aggregations using fuzzy systems modeling. IEEE Transactions on Fuzzy Systems 62: 286-294.

467. Yager, R. R. 2000. A hierarchical document retrieval language. Information Retrieval 34: 357377.

468. Yager, R. R. 2002. Using fuzzy methods to model nearest neighbor rules. IEEE Transactions on Systems Man and Cybernetics Part B-Cybernetics 324: 512-525.

469. Yager, R. R. 2003. Induced aggregation operators. Fuzzy Sets and Systems 1371: 59-69. 
470. Yager, R. R. 2003. Toward a language for specifying summarizing statistics. IEEE Transactions on Systems Man and Cybernetics Part B-Cybernetics 332: 177-187.

471. Yager, R. R. 2004. Modeling prioritized multicriteria decision making. IEEE Transactions on Systems Man and Cybernetics Part B-Cybernetics 346: 2396-2404.

472. Yager, R. R. 2004. Soft aggregation methods in case based reasoning. Applied Intelligence 21(3): 277-288.

473. Yager, R. R. 2006. An extension of the naive Bayesian classifier. Information Sciences 176(5): 577-588.

474. Yager, R. R. 2007. Using stress functions to obtain OWA operators. IEEE Transactions on Fuzzy Systems 156: 1122-1129.

475. Yager, R. R. 2008. Time Series Smoothing and OWA Aggregation. IEEE Transactions on Fuzzy Systems 164: 994-1007.

476. Yager, R. R. 2009. OWA aggregation of intuitionistic fuzzy sets. International Journal of General Systems 386: 617-641.

477. Yager, R. R. 2009. Weighted Maximum Entropy OWA Aggregation With Applications to Decision Making Under Risk. IEEE Transactions on Systems Man and Cybernetics Part aSystems and Humans 393: 555-564.

478. Yager, R. R., Kelman, A. 1999. An extension of the analytical hierarchy process using OWA operators. Journal of Intelligent \& Fuzzy Systems 7(4): 401-417.

479. Yager, R. R., Xu, Z. S. 2006. The continuous ordered weighted geometric operator and its application to decision making. Fuzzy Sets and Systems 157(10): 1393-1402.

480. Yan, B., et al. 2013. A Combination Forecasting Model Based on IOWA Operator for Dam Safety Monitoring. 2013 Fifth International Conference on Measuring Technology and Mechatronics Automation: 5-8.

481. Yan, H. B., Huynh, V. N., Nakamori, Y., Murai, T. 2011. On prioritized weighted aggregation in multi-criteria decision making. Expert Systems with Applications 38(1): 812-823.

482. Yang, J., et al. 2006. Filtering e-mail based on fuzzy support vector machines and aggregation operator. Neural Information Processing, Pt 1, Proceedings. I. King, J. Wang, L. Chan and D. L. Wang. 4232: 882-891.

483. Yang, J., Qian, W. 2013. Fuzzification of lower and upper approximations in fuzzy information systems. Proceedings of the Fuzzy Systems, Knowledge Discovery, and Natural Computation Symposium, 91-100.

484. Yang, W. Y. Pang 2014. The quasi-arithmetic triangular fuzzy OWA operator based on Dempster-Shafer theory. Journal of Intelligent \& Fuzzy Systems 263: 1123-1135.

485. Yang, W. Z. Chen 2012. The quasi-arithmetic intuitionistic fuzzy OWA operators. Knowledge-Based Systems 27: 219-233.

486. Yari, G. A. Chaji 2012. Determination of Ordered Weighted Averaging Operator Weights Based on the M-Entropy Measures. International Journal of Intelligent Systems 2712: 10201033.

487. Yari, G. A. R. Chaji 2012. Maximum Bayesian entropy method for determining ordered weighted averaging operator weights. Computers \& Industrial Engineering 631: 338-342. 
488. Yeh, D.-Y., et al. 2007. Empirical research of the principal component analysis and ordered weighted averaging integrated evaluation model on software projects. Cybernetics and Systems 383: 289-303.

489. Yu, H. Q., et al. 2008. A Method for Automated Web Service Selection.

490. Yu, X. Z. Xu 2013. Prioritized intuitionistic fuzzy aggregation operators. Information Fusion 141: 108-116.

491. Yu, X., et al. 2006. Research on association rules based group ranking model with fuzzy preference relation structure.

492. Yu, X., et al. 2012. Multicriteria decision making with 2-dimension linguistic aggregation techniques. International Journal of Intelligent Systems 276: 539-562.

493. Zadrozny, S. J. Kacprzyk 2009. Issues in the practical use of the OWA operators in fuzzy querying. Journal of Intelligent Information Systems 333: 307-325.

494. Zakeri, P., et al. 2011. Prediction of protein submitochondria locations based on data fusion of various features of sequences. Journal of Theoretical Biology 2691: 208-216.

495. Zarghaami, M., et al. 2007. Obtaining robust decisions under uncertainty by sensitivity analysis on OWA operator.

496. Zarghaami, M., et al. 2007. Sensitivity analysis of an information fusion tool: OWA operator art. no. 65710P. Multisensor, Multisource Information Fusion: Architectures, Algorithms, and Applications 2007. B. V. Dasarathy. 6571: P5710-P5710.

497. Zarghami, M. F. Szidarovszky 2008. Fuzzy quantifiers in sensitivity analysis of OWA operator. Computers \& Industrial Engineering 544: 1006-1018.

498. Zarghami, M. F. Szidarovszky 2008. New approach in obtaining OWA weights for multi criteria decision making.

499. Zarghami, M. F. Szidarovszky 2009. Revising the OWA operator for multi criteria decision making problems under uncertainty. European Journal of Operational Research 1981: 259265.

500. Zarghami, M. F. Szidarovszky 2009. Stochastic-fuzzy multi criteria decision making for robust water resources management. Stochastic Environmental Research and Risk Assessment 233: 329-339.

501. Zarghami, M. F. Szidarovszky 2010. On the relation between Compromise Programming and Ordered Weighted Averaging operator. Information Sciences 18011: 2239-2248.

502. Zarghami, M. 2011. Soft computing of the Borda count by fuzzy linguistic quantifiers. Applied Soft Computing 111: 1067-1073.

503. Zarghami, M., et al. 2008. A fuzzy-stochastic OWA model for robust Multi-Criteria Decision Making. Fuzzy Optimization and Decision Making 71: 1-15.

504. Zarghami, M., et al. 2008. Extended OWA operator for group decision making on water resources projects. Journal of Water Resources Planning and Management-Asce 1343: 266275.

505. Zarghami, M., et al. 2008. Sensitivity analysis of the OWA operator. IEEE Transactions on Systems Man and Cybernetics Part B-Cybernetics 382: 547-552. 
506. Zarghami, M., et al. 2009. Multi-Attribute Decision Making on Inter-Basin Water Transfer Projects. Scientia Iranica Transaction E-Industrial Engineering 161: 73-80.

507. Zeng, S. J. Chen 2012. Intuitionistic Fuzzy Decision Making Based on OWA and Distance Measures. Information Computing and Applications, Pt 2. C. F. Liu, L. Z. Wang and A. M. Yang. 308: 243-248.

508. Zeng, S. W. Su 2012. LINGUISTIC INDUCED GENERALIZED AGGREGATION DISTANCE OPERATORS AND THEIR APPLICATION TO DECISION MAKING. Economic Computation and Economic Cybernetics Studies and Research 462: 155-172.

509. Zeng, S., et al. 2012. A Method Based on OWA Operator and Distance Measures for Multiple Attribute Decision Making with 2-Tuple Linguistic Information. Informatica 234: 665-681.

510. Zeng, S., et al. 2012. Fuzzy Generalized Ordered Weighted Averaging Distance Operator and Its Application to Decision Making. International Journal of Fuzzy Systems 143: 402-412.

511. Zeng, S., et al. 2013. EXTENDED INDUCED ORDERED WEIGHTED AVERAGING DISTANCE OPERATORS AND THEIR APPLICATION TO GROUP DECISION-MAKING. International Journal of Information Technology \& Decision Making 124: 789-811.

512. Zeng, S., et al. 2013. The uncertain probabilistic OWA distance operator and its application in group decision making. Applied Mathematical Modelling 379: 6266-6275.

513. Zeng, S., et al. 2014. Fuzzy decision making with induced heavy aggregation operators and distance measures. Journal of Intelligent \& Fuzzy Systems 261: 127-135.

514. Zhang, G., et al. 2011. Minimum-Cost Consensus Models Under Aggregation Operators. IEEE Transactions on Systems Man and Cybernetics Part a-Systems and Humans 416: 12531261.

515. Zhang, X., et al. 2008. Multi-Attribute Group Decision Making Model Based on Fuzzy Triangle Number.

516. Zhang, Z. P. Liu 2007. Research on evaluation of E-commerce websites based on linguistic ordered weighted averaging operator.

517. Zhang, Z. Z. Xu 2013. On Continuity of Ordered Aggregation Operators. International Journal of Intelligent Systems 284: 307-318.

518. Zhang, Z. L. C. Q. Zhang 2000. Decision aggregation in multi-agent systems. Advances in Intelligent Systems: Theory and Applications. M. Mohammadian. 59: 185-190.

519. Zhang, Z. L. 2006. Decision aggregation in an agent-based financial investment planning system. Modeling Decisions for Artificial Intelligence. V. Torra, Y. Narukawa, A. Valls and J. DomingoFerrer. 3885: 179-190.

520. Zhang, Z., et al. 2014. Induced generalized hesitant fuzzy operators and their application to multiple attribute group decision making. Computers \& Industrial Engineering 67: 116-138.

521. Zhao, H., et al. 2010. Generalized Aggregation Operators for Intuitionistic Fuzzy Sets. International Journal of Intelligent Systems 251: 1-30.

522. Zhao, N., et al. 2013. Sensitivity Analysis of Multiple Criteria Decision Making Method Based on the OWA Operator. International Journal of Intelligent Systems 2811: 1124-1139. 
523. Zhao, X., et al. 2014. Hesitant triangular fuzzy information aggregation based on Einstein operations and their application to multiple attribute decision making. Expert Systems with Applications 414: 1086-1094.

524. Zhou, H. a., et al. 2007. Method for uncertain multi-attribute decision-making with preference information in the form of interval numbers complementary judgment matrix. Journal of Systems Engineering and Electronics 182: 265-269.

525. Zhou, L. H. Chen 2013. On compatibility of uncertain additive linguistic preference relations based on the linguistic COWA operator. Applied Soft Computing 138: 3668-3682.

526. Zhou, L., et al. 2012. Generalized power aggregation operators and their applications in group decision making. Computers \& Industrial Engineering 624: 989-999.

527. Zhou, L., et al. 2013. Continuous Ordered Weighted Distance Measure and Its Application to Multiple Attribute Group Decision Making. Group Decision and Negotiation 224: 739-758.

528. Zhou, L., et al. 2013. Generalized Multiple Averaging Operators and their Applications to Group Decision Making. Group Decision and Negotiation 222: 331-358.

529. Zhou, L., et al. 2013. SOME ICOWA OPERATORS AND THEIR APPLICATIONS TO GROUP DECISION MAKING WITH INTERVAL FUZZY PREFERENCE RELATIONS. International Journal of Uncertainty Fuzziness and Knowledge-Based Systems 214: 579-601.

530. Zhou, L.-G. H.-Y. Chen 2011. Continuous generalized OWA operator and its application to decision making. Fuzzy Sets and Systems 1681: 18-34.

531. Zhou, L.-G., et al. 2012. Uncertain generalized aggregation operators. Expert Systems with Applications 391: 1105-1117.

532. Zhou, R., et al. 2008. A method for obtaining the maximum entropy OWA operator weights with uncertain orness measure.

533. Zhou, S.-M., et al. 2008. Type-2 OWA Operators - Aggregating Type-2 Fuzzy Sets in Soft Decision Making. 2008 IEEE International Conference on Fuzzy Systems, Vols 1-5: 625-630.

534. Zhou, S.-M., et al. 2010. On Aggregating Uncertain Information by Type-2 OWA Operators for Soft Decision Making. International Journal of Intelligent Systems 256: 540-558.

535. Zhou, S.-M., et al. 2011. Alpha-Level Aggregation: A Practical Approach to Type-1 OWA Operation for Aggregating Uncertain Information with Applications to Breast Cancer Treatments. IEEE Transactions on Knowledge and Data Engineering 2310: 1455-1468.

536. Zhu, Q. J. Chen 2011. Multi-Objective Decision Making in GIS-based Multi-Criteria Evaluation for Land Use. 2011 International Conference on Energy and Environmental Science-Icees 2011. X. Zhou. 11: 3634-3640.

537. Zhu, Q., et al. 2010. Risk assessment of land-use suitability and application to Tangshan City. International Journal of Environment and Pollution 424: 330-343. 